\title{
Local and regional controls of brook trout (Salvelinus fontinalis) metapopulation dynamics within a complex Appalachian riverscape
}

\author{
Brock Miles Huntsman \\ West Virginia University
}

Follow this and additional works at: https://researchrepository.wvu.edu/etd

\section{Recommended Citation}

Huntsman, Brock Miles, "Local and regional controls of brook trout (Salvelinus fontinalis) metapopulation dynamics within a complex Appalachian riverscape" (2014). Graduate Theses, Dissertations, and Problem Reports. 602.

https://researchrepository.wvu.edu/etd/602

This Dissertation is protected by copyright and/or related rights. It has been brought to you by the The Research Repository @ WVU with permission from the rights-holder(s). You are free to use this Dissertation in any way that is permitted by the copyright and related rights legislation that applies to your use. For other uses you must obtain permission from the rights-holder(s) directly, unless additional rights are indicated by a Creative Commons license in the record and/ or on the work itself. This Dissertation has been accepted for inclusion in WVU Graduate Theses, Dissertations, and Problem Reports collection by an authorized administrator of The Research Repository @ WVU.

For more information, please contact researchrepository@mail.wvu.edu. 


\title{
Local and regional controls of brook trout (Salvelinus fontinalis) metapopulation dynamics within a complex Appalachian riverscape
}

\author{
Brock Miles Huntsman
}

\author{
Dissertation submitted to the \\ Davis College of Agriculture, Natural Resources and Design \\ at West Virginia University \\ in partial fulfillment of the requirements \\ for the degree of \\ Doctor of Philosophy \\ in \\ Forest Resources Science
}
J. Todd Petty, Ph.D., Committee Chair
Kyle. J. Hartman, Ph.D.
Roy W. Martin, Ph.D.
Patricia M. Mazik, Ph.D.
Shikha Sharma, Ph.D.

Wildlife and Fisheries Resources Program

\section{Morgantown, West Virginia}

2014

Keywords: source-sink dynamics, mass effects, density-dependence, density-independence, regulating factors, limiting factors, pre-emptive habitat selection, thermal refugia, bioenergetics capture-mark-recapture, information-theoretic, climate change 


\begin{abstract}
Local and regional controls of brook trout (Salvelinus fontinalis) metapopulation dynamics within a complex Appalachian riverscape
\end{abstract}

Brock Miles Huntsman

Brook trout have recently become a species of conservation focus due to their unique spatial structure and restricted thermal requirements. These life history characteristics make brook trout particularly vulnerable to major biodiversity threats, such as climate change and habitat loss. For appropriate conservation actions to be taken, it is imperative to identify the scale that limits brook trout productivity. The popular view of brook trout ecology indicates that populations exist as isolated fragments within watersheds, where productivity is concentrated in small, cold tributaries. This has led to management resources being allocated towards small tributaries with a goal to enhance local habitat characteristics. However, recent evidence suggests broader spatial scales are equally important for appropriate management planning. Application of landscape ecology theory has indicated that some brook trout populations may demonstrate linked metapopulation structure, where productivity and population dynamics operate at the watershed scale. Contrasting views on the appropriate spatial scale limiting brook trout productivity must be resolved for effective conservation planning: are brook trout fragmented isolates within watersheds, limited by local resources, or are they linked metapopulations that rely on dispersal and population dynamics operating at regional scales? 
Applying landscape ecology to the aquatic environment has led to the development of an important concept towards aquatic ecology, known as the riverscape. The riverscape emphasizes the study of aquatic populations at multiple spatial scales. This is important because populations rarely experience habitats at one spatial scale (e.g. microhabitat), and ecological processes rarely affect only the local habitat patch (e.g. organic matter transport). For aquatic populations that demonstrate relatively mobile life-histories, like brook trout (Salvelinus fontinalis), incorporating a riverscape approach towards understanding factors limiting their productivity is critical to better develop conservation strategies for such populations.

The upper Shavers Fork watershed in West Virginia supports a historically productive brook trout fishery. However, numerous anthropogenic factors within this watershed have led to a drastic decline in the brook trout population. Loss of riparian vegetation and increasing temperatures due to climate change has reduced the amount of larger, more productive mainstem habitats available to supplement brook trout productivity. Additional isolation by impassible barriers (e.g. culverts perched above the stream bottom) limits the number of brook trout spawning tributaries that are well connected to high quality foraging mainstem locations. Lastly, poor buffering geology increases the susceptibility of many tributary spawning areas to acid precipitation. For my dissertation, I adopted a riverscape approach to better understand which factors limit brook trout productivity within this historically productive watershed. In particular, my dissertation is strongly focused on factors that limit brook trout use of the supplementary mainstem.

My first chapter applies multiple spatial population hypotheses to a longterm brook trout monitoring data set collected along a continuum of stream sizes. In particular, these hypotheses are based within a concept known as the abundant center hypothesis. This hypothesis predicts 
stronger density-dependent regulation at the core of a species distribution, while densityindependent factors become the limiting mechanism with distance from the core. We applied this hypothesis to the Shavers Fork brook trout population, where we defined core habitat as small headwater tributaries where reproduction is focused, and peripheral sites as large mainstem locations where no reproduction occurs and densities are relatively low. We used an information theoretic approach to rank a suite of candidate models that considered both density-dependent and density-independent mechanisms at different monitoring sites along this continuum to test whether brook trout within this watershed adhere to predictions of the abundant center hypothesis.

Our results did not show a shift from density-dependent regulation at the core to densityindependent limitation towards the periphery. Interestingly, density-dependence was observed at nearly all sites, suggesting that competition for limiting resources was the driving mechanism limiting brook trout productivity within the watershed. However, there was likely a shift in competition for different limiting factors along this continuum. At the core tributary site, competition was likely for limited foraging position as has been shown in many brook trout systems. In the periphery, competition likely shifted towards limited thermal refugia. However, another potential explanation for brook trout regulation in the periphery could have been a strongly regulated source of mobile brook trout from the core to the periphery through sourcesink mass effects. Although this hypothesis was not tested in this chapter, it led to the development of our second chapter which purpose was to test this mechanism of limitation in the periphery.

The second chapter of this dissertation also used the same data set as analyzed in chapter one, but incorporated a regional analysis component to partition out the actual mechanism 
limiting brook trout productivity in the mainstem. Both source-sink dynamics (i.e. mass effects) and habitat limitation (i.e. thermal refugia) are equally likely factors controlling brook trout distributions within the mainstem. Therefore a series of models were ranked using information theoretic to explain brook trout densities and sizes along the core to periphery, with particular focus on the periphery. We used this approach to not only determine whether mainstem use was controlled by local (e.g. temperature) or regional mechanisms (e.g. mass effects for tributaries), but to also explore size distributions within the riverscape.

Our results showed that both mass effects and local thermal refugia were limiting brook trout distributions at different peripheral sites. The presence of larger brook trout in the mainstem, especially during warmer years suggested that the larger dominant brook trout were controlling areas of thermal refugia in the mainstem. Evidence for this was provided by the positive relationship between brook trout standard length and stream temperature, while stream temperature negatively correlated with brook trout densities in the mainstem. The prevalence of mass effects from the tributary to the mainstem and domination of large adults in the mainstem during especially warm years suggest that a pre-emptive habitat selection mechanism may be controlling brook trout distributions on the riverscape. Specifically, large adult brook trout are likely those leaving the tributaries during high density years due to an ability to monopolize limited thermal refugia in the mainstem, especially during warm years.

The third chapter of this dissertation took advantage of a robust capture-mark-recapture data set within this watershed to identify the relative strength of different sources and sinks as contributors to the brook trout metapopulation. Often defining sources and sinks within a landscape is limited to a discrete categorical classification. However, identifying the habitats that provide the greatest contribution to the entire metapopulation would provide substantially greater 
benefit towards development of management strategies. Therefore, we used capture-markrecapture analysis of reverse-time capture histories in combination with forward time approaches (contribution metric) to apply a more continuous source-sink classification scheme to different habitats within the Shavers Fork watershed. The strongest sources were expected to show stronger local contributions (i.e. survival and recruitment) to population growth as well as provide a greater number of emigrants to the entire metapopulation.

We found that not all small tributaries demonstrated source characteristics, where a few small tributaries ranked below the large tributary in terms of source strength. We also observed three small tributaries to be considered among the strongest sources in the watershed. Therefore, being able to rank different patches based on their potential to support the metapopulation provides invaluable information for informed conservation strategies to be developed. Our findings also emphasize the importance of connectivity among habitat patches, especially for locations that required substantial support in population growth from regional (immigration) sources.

The fourth chapter of this dissertation was designed to model growth potential and habitat selection by brook trout within this watershed as a function of current and anticipated temperature regimes along a stream continuum. Habitat quality based on energetic potential has often been used to describe fish distributions at multiple spatial scales (i.e. microhabitat to the reach). We used bioenergetics software along with previously published diet analysis and capture-mark-recapture data from within the Shavers Fork watershed to identify the impacts of thermal regime on brook trout growth potentials from core headwater sites to peripheral mainstem sites. We also employed a pre-emptive habitat selection framework for explaining a unique watershed scale expansion and contraction of brook trout during cold and hot years. 
Habitat selection was based on access to high quality habitat, where habitat quality was defined by a brook trout's growth potential within a habitat patch relative to other available patches.

Our results showed that brook trout expansion into mainstem habitats during cold years and contraction into the tributaries during hot years could be explained through habitat selection of the best growing locations on the riverscape. Additionally, modest increases in temperature were shown to drastically reduce the number of profitable habitat patches available to brook trout in the mainstem. These results suggested that the increased temperatures predicted by climate change in this region could result in the complete removal of mainstem foraging habitat from brook trout exploitation. This would result in converting the mainstem into more of an uninhabitable matrix used solely for brook trout movement, as opposed to a supplementary foraging habitat used to enhance productivity at the watershed scale. Therefore, it would be imperative for management in this watershed to focus on conserving and creating important microhabitat thermal refugia that not only promotes movement into the mainstem but to also exploit the high quality forage that is available in these habitats. 


\section{ACKNOWLEDGEMENTS}

I would like to thank numerous people for their help and guidance over the years. First I would like to thank my committee for their guidance throughout my time as a graduate student, Dr. Todd Petty, Dr. Kyle Hartman, Dr. Patricia Mazik, Dr. Roy Martin, and Dr. Shikha Sharma. I would also like to thank the numerous members of the Petty lab that have helped maintain the longterm data sets made available for my dissertation work. I would like to especially thank the members of the Petty lab that I have had the opportunity to work with over the past few years, Michael Tincher, Eric Merriam, Eric Miller, Alison “A-Train” Anderson, Andrew "New Guy” Watson, Brian Carlson, Cat Artis, Jenni Franks, and Donna Hartman as well as all the technicians that were hired to help each summer. In addition, I would like to thank people outside of the Petty lab who have also helped me collect and process data, Nate "Beefneck" Taylor, Ross Andrew, Christina Slover, Gabe Strain, Mike Porto, Andy Hafs, Daniel Hanks, Bethany Meier, Andrea Sack, Dr. Ajaya Warrier, and Darren Wood. In addition to my committee, I would also like to thank Dr. George Merovich and Dr. Phil Turk for their expertise with many statistical questions I have had over the years. I would also like to thank my Masters advisor Dr. Jon Benstead and fellow lab mate at the University of Alabama Mike Venarsky for much of their advice and mentoring during my graduate career. Lastly, I would like to thank my friends and family for their continued support during my time as a graduate student. 


\section{TABLE OF CONTENTS}

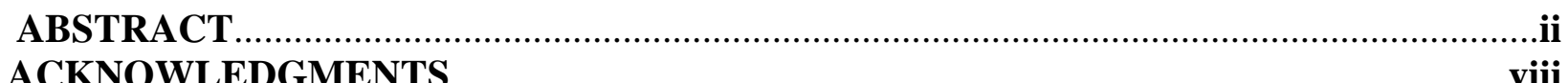

CHAPTER 1: Density-dependent regulation of brook trout population dynamics along a coredistribution gradient in a central Appalachian watershed.................................. 1

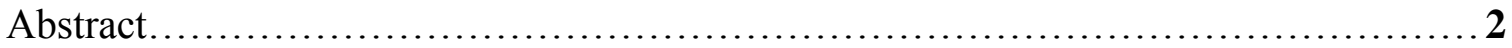

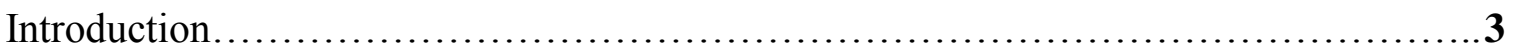

Study Area and Expectations................................................. 5

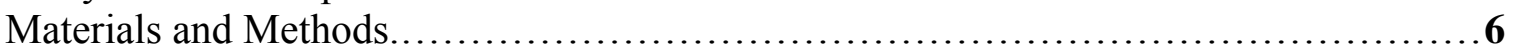

Study Sites........................................................... 6

Trout Population Sampling.............................................. 7

Ethics Statement........................................................8

Water Temperature and Flow ........................................... 8

Statistical Analyses.................................................... 8

Results.................................................................. 1

Total per capita growth rate ........................................... 12

Adult per capita growth rate .............................................12

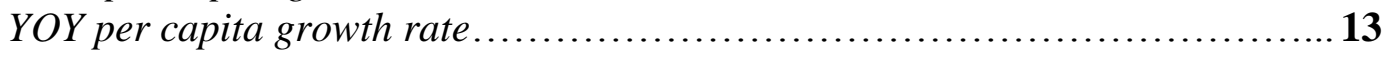

Correlation between brook trout and competitors..........................13

Pairwise correlation among sites...................................... 13

Discussion................................................................ 14

Management Implications .........................................21

Acknowledgments...................................................... 22

Works Cited............................................................ 23

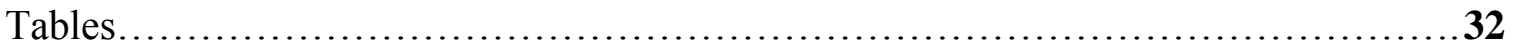

Figure Legends..............................................................

Figures............................................................40

CHAPTER 2: Brook trout distribution within sink habitat of an Appalachian watershed mediated by complex stream temperature dynamics and mass effects.................... 49

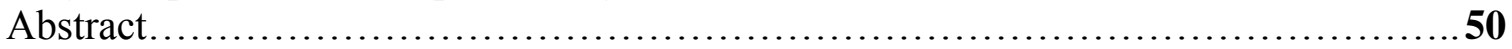

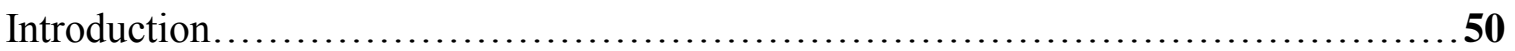

Study Site and Predictions ...........................................53

Methods................................................................ 54

Trout Population Sampling ............................................55

Water Temperature and Flow..........................................55

Statistical Analyses.................................................... 55

Results......................................................................56

Adult Brook Trout Densities........................................... 57

Adult Brook Trout SL..................................................... 57

Discussion................................................................... 57

Source-Sink Structure ..................................................58

Habitat Selection and Microhabitat ...........................................59

Acknowledgments........................................................ 63

Works Cited................................................................... 63

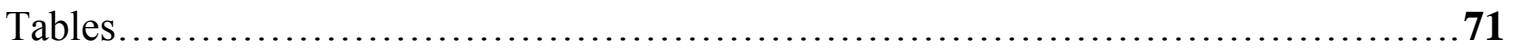




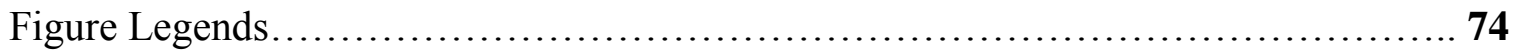

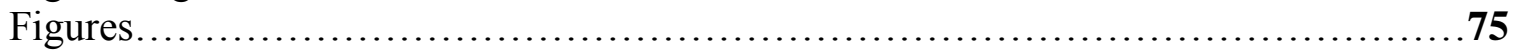

CHAPTER 3: Brook trout population dynamics within a complex riverscape: Identifying the

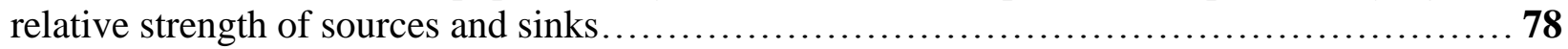

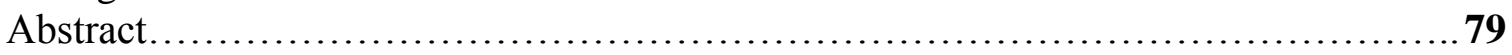

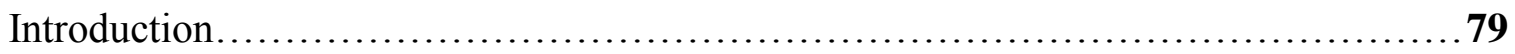

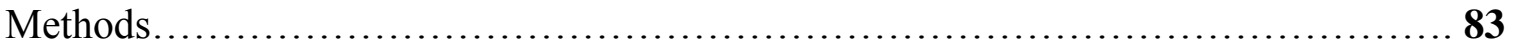

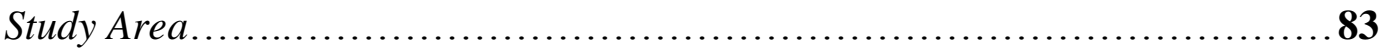

Brook Trout Sampling ................................................884

Local vs. Regional Contributions to Population Growth.........................85

Contribution Metric ........................................................ 87

Source Ranking ..........................................................

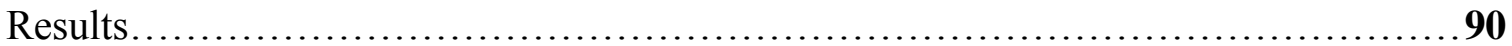

Local vs. Regional Contributions to Population Growth........................90

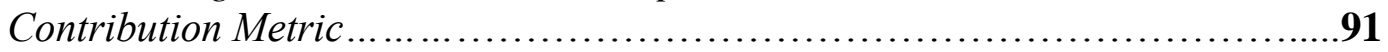

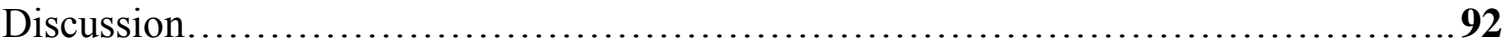

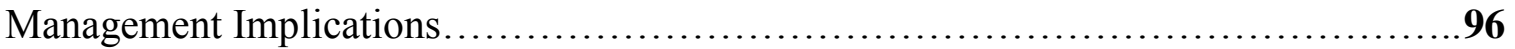

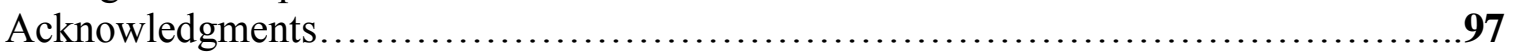

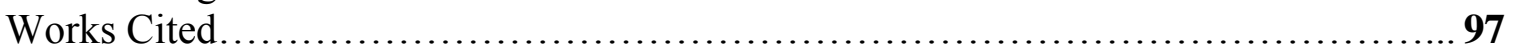

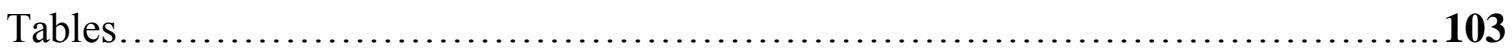

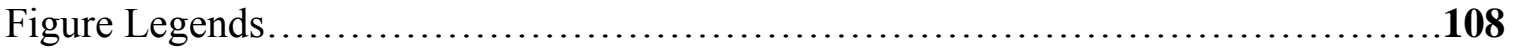

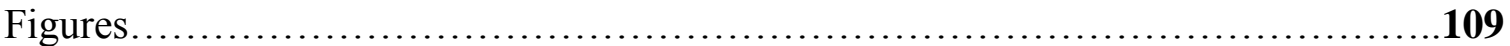

CHAPTER 4: Brook trout habitat selection along a complex stream continuum: energetically regulated riverscape expansion and contraction......................................... 112

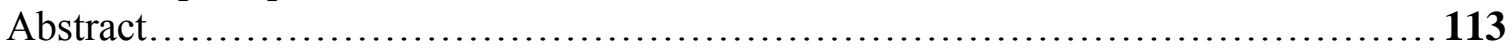

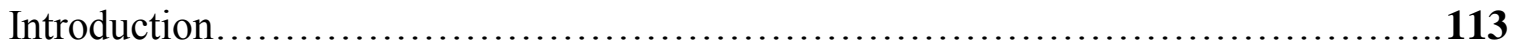

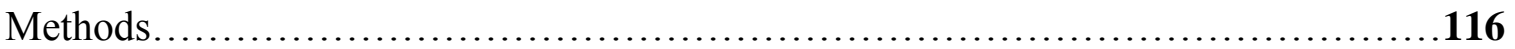

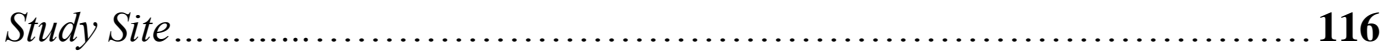

Temperature Data ................................................116

Consumption Estimates................................................117

Growth Simulations ......................................................119

Watershed Expansion/Contraction...................................120

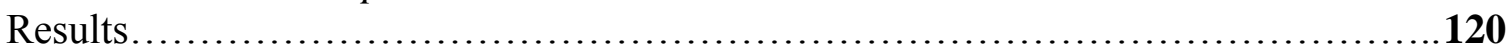

Temperature Models................................................120

CMR Growth and Consumption Estimates...............................121

Growth Simulations ..................................................121

Growth Under Increasing Temperatures...............................122

Watershed Expansion/Contraction..................................... 123

Discussion................................................................... 124

Riverscape Growth Potential across Temperature Regimes..................... 124

Profitable Habitat Loss with Increasing Temperatures........................ 126

Energetic Habitat Selection on the Riverscape ............................... 127

Management Implications.............................................129

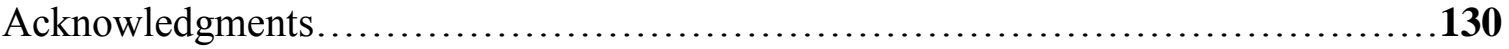

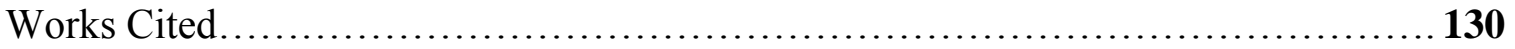

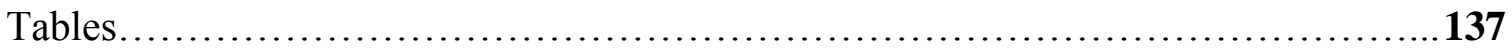


Figure Legends..........................................................

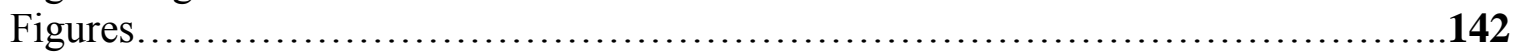

Appendices...........................................................................

Appendix A: A priori models explaining response variables of brook trout time series data at

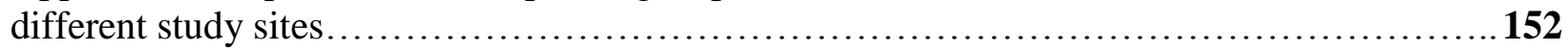

Appendix B: All results from candidate models using $\mathrm{AIC}_{\mathrm{c}}$ for 7 sites................... 155

Appendix C: Seasonal parameter estimates from the best fitted model in forward-time mark

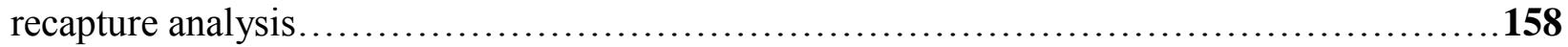

Appendix D: Seasonal parameter estimates from the best fitted model in reverse-time mark

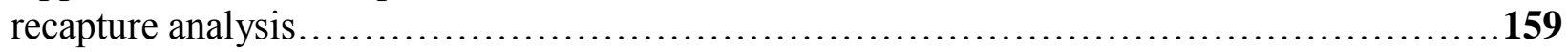

Appendix E: Parameters used for bioenergetic simulations..............................161

Appendix F: Results from bioenergetic simulations of growth across site types and consumption

estimates for each temperature regime and associated forcasted temperatures................162 
Chapter 1: Density-dependent regulation of brook trout population dynamics along a coreperiphery distribution gradient in a central Appalachian watershed

Brock M. Huntsman* and J. Todd Petty

Division of Forestry and Natural Resources, West Virginia University, Morgantown, WV 26506, U.S.A.

*Corresponding author: brockhunts@ gmail.com

THIS CHAPTER HAS BEEN ACCEPTED FOR PUBLICATION IN THE JOURNAL PloS One, AND THE FORMAT FOLLOWS THAT REQUIRED FOR THE JOURNAL. 


\begin{abstract}
Spatial population models predict strong density-dependence and relatively stable population dynamics near the core of a species' distribution with increasing variance and importance of density-independent processes operating towards the population periphery. Using a 10-year data set and an information-theoretic approach, we tested a series of candidate models considering density-dependent and density-independent controls on brook trout population dynamics across a core-periphery distribution gradient within a central Appalachian watershed. We sampled seven sub-populations with study sites ranging in drainage area from $1.3-60 \mathrm{~km}^{2}$ and long-term average densities ranging from $0.335-0.006$ trout $/ \mathrm{m}$. Modeled response variables included per capita population growth rate of young-of-the-year, adult, and total brook trout. We also quantified a stock-recruitment relationship for the headwater population and coefficients of variability in mean trout density for all sub-populations over time. Density-dependent regulation was prevalent throughout the study area regardless of stream size. However, density-independent temperature models carried substantial weight and likely reflect the effect of year-to-year variability in water temperature on trout dispersal between cold tributaries and warm mainstems. Estimated adult carrying capacities decreased exponentially with increasing stream size from $0.24 \mathrm{trout} / \mathrm{m}$ in headwaters to $0.005 \mathrm{trout} / \mathrm{m}$ in the mainstem. Finally, temporal variance in brook trout population size was lowest in the high-density headwater population, tended to peak in mid-sized streams and declined slightly in the largest streams with the lowest densities. Our results provide support for the hypothesis that local density-dependent processes have a strong control on brook trout dynamics across the entire distribution gradient. However, the mechanisms of regulation likely shift from competition for limited food and space in headwater streams to competition for thermal refugia in larger mainstems. It also is likely that source-sink
\end{abstract}


dynamics and dispersal from small headwater habitats may partially influence brook trout population dynamics in the mainstem.

\section{Introduction}

Historical debate over population regulation focused on the relative occurrence of density-dependent (DD) vs. density-independent (DI) mechanisms (see reviews by Murdoch [1], Krebs [2], and Hixon et al. [3]). Currently it is accepted that both DD and DI processes interact to affect the dynamics of most natural populations [4-6]. For example, Prevateli et al. [7] showed that measures of both density and precipitation best explained the dynamics of two rodent species. Both DD and DI mechanisms have been shown to influence population dynamics of mammals [7,8], birds [9,10], amphibians [11,12], and fishes [6,13-15], providing evidence for the prevalence of both mechanisms in influencing population dynamics. Consequently, ecologists recognize that it is not only important to consider how DD and DI forces interact, but also how the prevalence of these factors may vary across the landscape [16,17].

A promising approach to understanding complex population dynamics across heterogeneous landscapes is to apply a core-periphery perspective $[9,17,18-20]$. A population living within its core distribution is considered to be at a location where it is least susceptible to environmental variability due to habitat specific adaptation. A population at its periphery is more susceptible to those environmental characteristics and therefore less adapted to the local habitat [17]. As a consequence, it is expected that a population should be at its highest densities at the core and decrease with distance from the core [16]. Populations within the core of their distribution are then expected to be strongly regulated by local DD mechanisms, such as competition [17]. This occurs not only because densities are high near the core, but also because 
variability in important environmental factors should be low. At the periphery of the population distribution, highly variable environmental conditions and relatively low population densities are expected to result in weak DD regulation and increasing importance of local DI factors on population dynamics [17]. Successful applications of core-periphery concepts to explain landscape scale variability in population dynamics have been made in terrestrial, terrestrial/aquatic [9,18,21-24], and aquatic environments (see Nicola et al. [6], Haak et al. [20], Kim \& Lapointe [25]).

River networks, or riverscapes [26], provide a unique opportunity to study the complexities of population dynamics at a scale relevant to aquatic metapopulations [25,27-29]. Watersheds often show strong environmental gradients over relatively small spatial scales. For example, tributary-mainstem confluences can support highly diverse habitat due to transitioning between large and small stream dynamics over short flow distances [30,31]. Gradients in environmental conditions such as temperature are particularly important for cold-water specialists like salmonids that require specific thermal ranges for optimal performance within a habitat [32-34]. Petty et al. [28] observed high mobility in brook trout exposed to elevated thermal conditions within a large mainstem habitat, while tributary residents showed less mobility, likely due to relatively lower thermal stress. Additionally, demographic rates of fish species (e.g., survival and birth rates) have been shown to differ based on whether fish were present in their core or peripheral distribution within the same watershed [27]. Therefore, applying a core-periphery approach within a riverscape can potentially give an important perspective of population dynamics that could not be obtained by focusing on one location. Understanding the strength of DD vs. DI mechanisms limiting fishes across population distribution gradients is crucial given current climate change scenarios. Numerous studies 
recognize that alterations to climatic variables could have substantial affects on fish species distributions [20,35-37]. However, impacts may also be observed affecting fish productivity [38]. This could be especially detrimental to populations supplementing their productivity through exploiting peripheral habitat patches. For example, substantial gains in productivity have been shown for stream fishes able to access highly productive floodplain habitat [29,39]. However, higher temperatures and more sporadic flooding events could substantially reduce access to these supplementary feeding habitats or increase mortality through fish stranding. For cold-water species with distinct core-periphery distributions (i.e. brook trout, Salvelinus fontinalis, [27]), the strength of climatic variables in limiting population productivity may be strongly linked to location within their spatial distribution. In order to properly assess how such populations would respond to climate change predictions, we must understand the relative importance of DD vs. DI factors along a species distribution gradient. Therefore, our objectives for this study were to: 1- quantify the relative importance of DD and DI controls on brook trout population dynamics, 2- quantify a stock-recruitment relationship for brook trout populations within a known source headwater stream; and 3- quantify temporal variation in brook trout densities and spatial variation in brook trout carrying capacities across a core-periphery distribution gradient.

\section{Study Area and Expectations}

The upper Shavers Fork is a large (i.e., $>150 \mathrm{~km}^{2}$ basin area), high elevation (originates at $1500 \mathrm{~m}$ ) watershed located in the central Appalachian Mountains of eastern West Virginia (Pocahontas and Randolph Counties, Figure 1). The Shavers Fork is part of the Cheat River 
drainage flowing north to its confluence with the Monongahela River. A detailed description of the Shavers Fork can be found in Petty et al. [27].

Brook trout inhabit a broad range of stream sizes in the Shavers Fork watershed, ranging from extremely small headwater seeps $\left(<1 \mathrm{~km}^{2}\right)$ to large mainstem reaches $\left(>100 \mathrm{~km}^{2}\right)$. The mainstem is relatively wide and shallow, has a low gradient and an open canopy, is warmer and more productive, and possesses a more diverse brook trout prey assemblage than smaller tributaries [28]. Greater than $80 \%$ of brook trout reproduction occurs in headwater streams with drainage areas less than $3 \mathrm{~km}^{2}$, and brook trout reproduction has rarely been observed in streams with drainage areas greater than $15 \mathrm{~km}^{2}$ [27]. As a consequence, brook trout density is highest in small headwater streams (core habitat) and decreases with increasing stream size down to only a few individuals in larger mainstem sites (periphery habitat) (Table 1).

Based on what we know about brook trout populations in this watershed, we expected the following results: 1- local DD mechanisms should be the dominant control on brook trout dynamics within headwater (i.e., core) habitats and decline in importance with movement towards larger mainstem (i.e., periphery) habitats; 2- local DI mechanisms should be the strongest factor limiting brook trout population dynamics within larger, periphery habitats; and 3- temporal variation in population densities should be highest at the periphery and lowest in the core.

\section{Materials and Methods}

Study Sites

Seven sites within the upper Shavers Fork watershed were chosen for this study (Figure 1, Table 1). These sites were selected to fully represent potential habitat available for brook trout 
within this watershed. Headwater site 1 has a drainage area less than $3 \mathrm{~km}^{2}$. Large tributary 1 and 2 have drainage areas greater than $3 \mathrm{~km}^{2}$, but have been shown to support low levels of brook trout spawning (Table 1, [27]). The final four mainstem sites (1, 2, 3, and 4) all have drainage areas outside of what has been shown to support spawning activity (> $16 \mathrm{~km}^{2}$, [27]). All stream lengths were established in 2001, and the same length of stream was monitored on subsequent sampling events. Stream lengths were standardized by stream width, where a site's length was 40 times mean stream width and at least $150 \mathrm{~m}$ long.

\section{Trout Population Sampling}

Every spring from 2002 until 2011 (end of May-Early June), brook trout, brown trout (Salmo trutta), and rainbow trout (Oncorhynchus mykiss) were sampled from the 7 study sites. Each fish was measured for standard length (SL) and mass (g). Trout abundances were converted to densities by dividing abundance by reach specific lengths (\#/m stream length). Trout were collected with backpack electrofishing units (Smith-Root, DC, $60 \mathrm{~Hz} .400-600 \mathrm{~V}$ ) in an upstream direction using a single pass procedure [40].

Single pass electrofishing makes it possible to sample large areas over time, which was a priority for us. However, this approach can produce biased abundance estimates if there is significant spatial or temporal variation in first pass capture efficiencies [40]. In order to quantify site-to-site and year-to-year variation in capture probabilities among study sites, threepass depletion methods were used at all sites in 2002 and 2006 and at the headwater 1 and mainstem 2 sampling sites in 2011. During this sampling, block nets were placed at the beginning and end of each reach, all trout were captured and removed on each pass, and we used the analytical methods of Hense et al. [40] to quantify brook trout capture probabilities at each 
site and each sampling event. Capture probabilities ranged from $0.75-0.78$ in the first pass, which was consistent with previous studies in the region $[27,40]$. There were no consistent patterns of sample bias at any given site, nor in any given year. Instead, spatio-temporal variation of $\pm 3 \%$ appeared to represent a range of random variation associated with sampling error. Given these findings, we assumed a temporally and spatially constant sampling efficiency and did not apply correction factors across study sites or years.

\section{Ethics Statement}

After measurements were taken, fish were placed in a live-well until they recovered from electrofishing. All sampling was approved by the committee of animal use and care (IACUC) of West Virginia University (most recent protocol number 11-0507).

\section{Water Temperature and Flow}

Stream temperature was collected from all study sites using HOBO Water Temp Pro V2 data loggers from 2002-2011. Average maximum stream temperature for July and average maximum daily stream temperature from April-June (growing period for brook trout, [41]) were temperature indices used for DI models. Discharge data were downloaded from a local U.S. Geological Survey stream gaging station at the Cheat bridge (USGS 03067510). Estimates of mean discharge $(Q)$ from March-June were used as a DI mechanism. This is approximately when brook trout emerge from eggs [42], and has been shown to be a time during a salmonid's life cycle when they are highly susceptible to discharge events [43].

\section{Statistical Analyses}


We constructed general linear models within the R statistical program (R Development Core Team 2011) to test for density-dependent (DD) and density-independent (DI) controls on brook trout population dynamics $[14,44,45]$. Specific response variables analyzed were brook trout per capita rate of change for young-of-the-year (YOY), adult, and total brook trout ( $r=$ $\left.\ln \left(n_{t} / n_{t-1}\right)\right)$. Length-frequency histograms from Petty et al. [27] were used to differentiate small adult, large adult, and YOY brook trout size-classes. Based on this criterion, YOY were defined as individuals smaller than or equal to $60 \mathrm{~mm}$ SL, small adults were anything between 60 and 100 $\mathrm{mm}$ SL, and large adults were anything greater than or equal to $100 \mathrm{~mm} \mathrm{SL}$ at the time of sampling. Although the YOY size-class represents a true representation of age and denotes trout known to have been produced the previous fall, the small and large adult size-classes likely do not represent a true distinction of age [27]. As such, all analyses for adult size-classes represent the combination of both small and large adult size-classes, but does not represent true age class or sexual maturity.

The candidate set of models for each response variable was evaluated using an information-theoretic approach and Akaike Information Criterion corrected for small sample size $\left(\mathrm{AIC}_{\mathrm{c}},[46]\right)$. This approach ranks a suite of candidate models by maximum parsimony. Within this approach, $\mathrm{AIC}_{\mathrm{c}}$ weights $\left(w_{i}\right)$ were constructed for each candidate model to evaluate the strength of the best model compared to the rest of the candidate set. Criteria for model interpretation were similar to that utilized by Grossman et al. $[14,44]$. The model with the highest $w_{i}$ was compared to each model in the candidate set by dividing the best model by each candidate model. This percentage then gave an estimate of the relative strength of the best model over the remaining models in the candidate set. Only models with $w_{i}$ values greater than $10 \%$ of the best 
model's $w_{i}$ were considered interpretable models (see Appendix A for all constructed models) $[14,44,46]$.

Candidate sets of models were constructed to be similar among sites, in order to compare the strength of DD vs DI, and to identify local temporal brook trout dynamics. Due to extremely low competitor densities in tributary sites (especially headwater 1 and large tributary 1 , see Table 1), competitor densities were not included in candidate sets of models. Therefore, post-hoc analyses were conducted on mainstem sites to explore the potential effects of competitors on brook trout population dynamics. We used correlation analysis (pearson's correlation) between total competitor densities (i.e. rainbow and brown trout) and brook trout densities to test for temporal autocorrelation between the time-series at each periphery site.

Additionally, pearson's correlation coefficient was used to test for spatial correlation in the time series of brook trout densities among all sites. Regression analysis was then used to test for relationships between differences in stream sizes and brook trout densities between sites. We also used regression analysis to test for relationships between swim distance and brook trout densities as a means of exploring the potential effects of dispersal among sites on local population dynamics.

Since adult brook trout were consistently found throughout the watershed, but only a few YOY were found in larger mainstem habitat (Table 1), adult brook trout carrying capacities were estimated for each site. To estimate carrying capacity, adult brook trout per capita rate of change was plotted as a function of adult brook trout densities. The $\mathrm{x}$-intercept then represents the stable equilibrium point for the adult brook trout population at each site and the theoretical adult brook trout carrying capacity [47]. 
Stock recruitment assessment was addressed in the headwater 1 site using multiple stepwise linear regression analysis. YOY densities were modeled as a function of similar predictor variables outlined for YOY per capita rate of change, with a few exceptions. No YOY density predictor variables were included in the analysis, and adult brook trout densities at time $t$ 1 and time $t$ were included.

To test whether variability in brook trout densities increased with distance from the core on the riverscape, coefficients of variation (C.V.) were estimated from brook trout time series for each site. These values were then plotted against site drainage area, to determine if variability in density increased with drainage area.

\section{Results}

A total of 1737 brook trout was captured over the course of this study with a maximum observed in $2005(n=344)$ and a minimum in $2010(n=80)$. No rainbow trout were captured in headwater 1 , and no brown trout were captured in headwater 1 or large tributary 1 (Table 1 ). The highest brown trout densities were observed at mainstem 2, and rainbow trout were most dense at mainstem 1 (Table 1). Mean brook trout density was greatest at headwater 1 and decreased with an increase in drainage area (Table 1). In the core (headwater 1), small adult densities were highest, followed by large adult and YOY density (Table 1). For all other sites, large adult densities were highest, followed by small adults and YOY (large tributary and mainstem, Table $1)$.

Brook trout densities as well as environmental characteristics (temperature and flow) varied considerably over time (Figures 2 and 3). Temporal variance in brook trout density demonstrated a hump-shaped relationship with drainage area (Figure 3). Coefficient of variation 
(C.V.) in brook trout density was highest in streams with drainage areas ranging from $10-30 \mathrm{~km}^{2}$ (Figure 3). C.V. of brook trout density was considerably lower in the smallest headwater habitat and also declined in the two largest sites (Figure 3). The observed increase in population variance from small to intermediate sized streams was consistent with expectations. However, the decline in C.V. in the two largest sites was unexpected.

Total per capita growth rate- A total of 13 candidate models was constructed for total brook trout per capita growth (Appendix B). In five of the seven sites analyzed, DD models (trout density $\mathrm{t}_{\mathrm{t}-1}$ ) were the most parsimonious for total per capita growth, whereas a complex model (both DD and DI) best explained variability in the headwater 1 site (Figure 4, Table 2). The only site with a DI model as the highest ranked in the candidate set was in the mainstem 2 site, where per capita growth was positively correlated with April-June temperature. In 4 of 7 sites, a substantial amount of variability was explained by multi-mechanism models, involving combined effects of spring or summer water temperature and trout density the previous year $\left(R^{2}\right.$ in Table 2).

Adult per capita growth rate - A total of 13 models was also constructed for adult brook trout per capita growth (Appendix B). Adult brook trout per capita growth was best explained by a DD model in six of the seven sites (adult density), with adult population growth rates in mainstem 2 being positively correlated to April-June stream temperature (Table 2, Figure 5). As expected, a large amount of variability in adult $r$ was explained by the best model in the headwater site $\left(R^{2}=0.64\right.$, Table 2$)$, although the best models in the large tributaries explained less variability than most other sites $\left(R^{2}=0.31\right.$ and 0.32 , Table 2$)$. Surprisingly, a large amount of variability ( $R^{2}=0.46-0.52$, Table 2$)$ was explained by the best models (DD) in the peripheral sites (mainstem 1, 3, and 4). Multi-mechanism models that included water temperature and 
density effects were interpretable in 2 of 3 smaller sites (headwater 1 and large tributary 1), whereas only one of four sites in the periphery had an interpretable multi-mechanism model (Table 2, Figure 5).

YOY per capita growth rate - YOY per capita growth was analyzed for headwater 1 and the two large tributary sites only due to few YOY being found in peripheral sites over the course of the study. All three sites analyzed showed DD being the most parsimonious model, where per capita growth of YOY was negatively correlated with YOY densities the previous year (Table 2). The same multi-mechanism model was interpretable for both headwater 1 and large tributary 2 sites and included a positive effect of July temperature and a negative effect of YOY density on YOY per capita growth (Table 2, Figure 6). Multiple stepwise regression revealed that July temperature, adult densities, and March-June discharge all were important variables influencing YOY brook trout densities within the core headwater 1 site (Table $3, R^{2}=0.96, p<0.001$ ). The positive relationship between adult densities and YOY densities the following year indicates a significant stock-recruitment relationship within the core site (Figure 7A) that is also significantly modified by July water temperatures (Table 3, Figure 7B).

Correlation between brook trout and competitors - Total brook trout densities showed strong positive temporal correlation with densities of potential competitors within three of four peripheral sites (Pearson's r; 0.81, 0.72, 0.80 for mainstem 1, 2, and 3 respectively). Brook trout and competitor densities were not significantly correlated in the largest mainstem site $(r=0.06)$.

Pairwise correlation among sites - We observed high temporal correlation in the brook trout time series for most pairwise site comparisons (Figure 8). There was a significant decrease in pairwise correlation between sites as the difference in drainage area between the sites increased (Figure $8 \mathrm{a}, R^{2}=0.27, p=0.01$ ). However, the mainstem 4 site appeared to be out of 
phase with other similar sized mainstem sites (Figure 8). Similar analyses relating correlations in brook trout densities between sites close in proximity (swim distance) did not show a significant relationship (Figure 8b, $R^{2}<0.01, p=0.93$ ) between the strength of correlation and swim distance between the sites. For example, high positive year-to-year correlations in brook trout density was observed between sites separated by as much as $5-10 \mathrm{~km}$ swim distance (Figure $8 \mathrm{~b}$ ). Again, many of the lowest pairwise correlations involved comparisons with the mainstem 4 site.

\section{Discussion}

Density-dependent regulation was prominent throughout the watershed. The finding that population dynamics within the core headwater habitat was strongly regulated by densitydependent mechanisms was expected and consistent with previous studies $[9,44,45,48,49]$. High population densities along with species adaptation to environmental conditions characteristic of the core habitat are expected to result in strong density-dependent regulating mechanisms around a relatively stable carrying capacity [17]. The high brook trout density relative to variability (C.V., Table 1) and prevalence of density-dependence suggests the core headwater habitat conforms to these expectations.

Surprisingly, brook trout dynamics within more peripheral habitats downstream also were strongly regulated by density-dependent mechanisms. We expected brook trout populations to become increasingly influenced by density-independent factors, such as water temperature and flow, with distance away from core habitats. Previous studies outside of a species core distribution have found density-independent mechanisms to be the dominant factor limiting populations [6,50-52]. However, we found that density-dependence was a dominant regulating force on brook trout, regardless of spatial distribution within the watershed. Density-dependence 
has also been shown to regulate brook trout at broader spatial scales, from Michigan streams $[45,53]$ to streams in North Carolina [44]. To our knowledge, however, our study is the first to document density-dependent regulation of brook trout populations both within small headwater streams and within larger streams that represent the periphery of their distribution. Consequently, our results coupled with previous studies provide evidence for how extensive density-dependent regulation is for brook trout populations in the Appalachians.

When plotting adult brook trout carrying capacities against stream drainage area, a significant exponential decline in carrying capacity was observed $(p<0.01$, Figure 9). This suggests that brook trout population size amongst habitats is limited by various mechanisms along this stream continuum. Results from this system and other systems suggest that competition for food and / or foraging habitat may be the dominant density-dependent mechanism regulating brook trout populations in small headwater streams that demonstrate ideal growth temperatures for brook trout $[45,54,55,56]$. Interestingly this is also consistent with processes known to affect mottled sculpin populations within their core distribution $[14,57,58]$.

Extremely high prey productivity [28] and greater growth potential of brook trout residing in the mainstem $[59,60]$ suggest that mechanisms other than competition for food may regulate brook trout populations in more peripheral habitats. One explanation for strong regulation of peripheral populations is based on source-sink theory [61]. Dispersal of brook trout from strongly regulated core / source populations in the headwaters may produce strong densitydependence in the peripheral / sink populations in larger mainstems. Evidence of densitydependence in the periphery, consequently, may not be the result of local negative feedback, but rather is the result of a density-regulated source of immigrants. Under such a mechanism, when population size in the core habitat is low, population growth rates the following year are high. 
This results in an increased number of potential immigrants to the periphery and an increase in peripheral growth rates. High densities in the core then result in elevated growth rates in and dispersal to the periphery. Dispersal between patches potentially synchronize population dynamics among different habitat patches $[62,63]$. The result is the appearance of densitydependent regulation in the periphery. However the actual mechanism would be densitydependence in the core/source habitat and a linkage to the periphery/sink habitat via dispersal. This mechanism can be used to explain the pattern of decreasing correlation with drainage area difference, but lack of relationship with swim distance (Figure 8). If brook trout movement is from a core/source (tributary) to a sink (mainstem) during years of elevated densities, then we would expect to see a stronger relationship in correlation with drainage area as opposed to swim distance. Our current analysis is insufficient to unequivocally conclude a source-sink mechanism of regulation in the periphery, but it does suggest an important avenue of further investigation within this watershed.

An alternative explanation is that larger streams may possess local carrying capacities defined by local resources. Previous research in this system suggests that brook trout inhabiting larger mainstem sites may compete for thermal refugia during prolonged periods of warm and dry conditions [28]. During the spring, brook trout in the mainstem may also compete for optimal growing habitat [64]. The spring is known to be an important growing period for brook trout in Shavers Fork and surrounding watersheds [41,59]. Competition for ideal foraging microhabitats in the mainstem could then act as a potential regulating factor, where microhabitats with the greatest prey density and temperatures within optimal growth ranges would be an important resource for habitat selection. Consequently, even though environmental conditions may represent a strong density-independent force in peripheral habitats, the overall dynamics of 
brook trout in these habitats may be predominantly influenced by density-dependent mechanisms, such as competition for suitable microhabitat.

An important factor to consider when estimating carrying capacity with this approach is harvest pressure. Unfortunately very little data exists on harvest pressure within this watershed. Neither the actual intrinsic rate of increase nor the carrying capacity should be directly affected by harvest pressure, however mortality rates and in turn densities would be. Since we observed a strong negative relationship between densities and adult intrinsic rate of increase at most sites, harvest pressure likely does not strongly influence our estimates of carrying capacity. However, if harvest pressure showed a strong direct relationship to brook trout densities, then harvest could be a strong regulating factor within this watershed. Hixon and Carr [65] found that in the absence of a resident and transient predator, the reef fish Chromis cyanea demonstrated densityindependence. However, in the presence of both predators, the reef fish showed strong densitydependent mortality. Therefore, our estimates of carrying capacity in the mainstem of this watershed could potentially be influenced by the presence of strong harvest pressure, however, lack of data on harvest pressure limits our ability to further investigate this mechanism.

Although density-independent factors were rarely the most parsimonious models in candidate sets, most density-independent models were interpretable and accounted for a substantial amount of variability when in combination with density-dependent models (Table 2). For the majority of interpretable temperature models, we observed a positive relationship between population growth rates and temperature (Table 2). In all four mainstem sites, per capita growth of total and adult brook trout tended to be greatest in years with intermediate spring-time temperatures $\left(\sim 12.5^{\circ} \mathrm{C}\right.$, Figures 4 and 5$)$. This pattern is consistent with population dynamics of other salmonid species when modeled as a function of DI mechanisms. For example, Isaak \& 
Hubert [66] observed the greatest total trout abundances (Oncorhynchus clarki, Salmo trutta, and Salvelinus fontinalis) at streams with temperatures of approximately $12^{\circ} \mathrm{C}$, regardless of the stream size and distribution. Additionally, mortality and recruitment rates for brown trout populations in northwestern Spain have been observed to be best suited for intermediate discharge rates [5].

Within core headwater habitats, YOY recruitment was positively correlated with both spring and summer water temperature. Spawning and YOY dynamics are predominantly controlled by density-independent mechanisms, such as stream temperature and discharge $[5,38,43,53,67]$. However, the positive relationship between temperature and brook trout per capita growth rates that we observed across size-classes suggest that elevated mortality rates in response to warmer temperatures is less likely to influence population dynamics within this watershed than temperature effects on trout dispersal [28].

Our current results, combined with previous studies, provide a good picture of the density-dependent and density-independent forces influencing brook trout populations across stream size gradients $[44,45,53,55,66-68]$. In particular, density-independent effects on YOY may actually reflect an indirect stock-recruitment relationship. Higher summer temperatures likely reduce the number of adult brook trout that emigrate from cooler headwater sites [59]. The higher number of spawning adults within headwaters would then increase the number of YOY the following year as a result of a strong positive relationship between YOY densities and adult densities the previous year (Table 3, Figure 7). Year to year variation in juvenile recruitment, coupled with strong density-dependent feedback then sets adult population sizes in subsequent years. Consequently, our evidence suggests that the density-independent variables, such as water temperature, may be less important for controlling survival rates and more important for 
behavioral demographic rates (e.g. emigration and immigration). Numerous studies have shown that salmonids will relocate within streams to select microhabitats within thermal tolerance ranges $[28,69,70]$. Therefore, density-independent mechanisms within this system may be influencing brook trout distributions within the watershed, more so than affecting mortality rates. Consequently, connectivity between small cold and larger warm streams along with behavioral decisions by adult trout may control the relationship between population dynamics and water temperature.

We predicted that C.V. of brook trout density would increase with drainage area, indicating an increase in population variability with distance from the core [17]. In the headwater 1 site, variability in population density was lowest among all sites. The expected increasing variability with drainage area was also observed, until stream size exceeded approximately 35 $\mathrm{km}^{2}$ (Figure 3). We believe that the low C.V. in the headwater site is likely due to high trout densities and strong DD regulation. The increasing variability in the larger streams is likely due to DI effects of temperature on dispersal behavior of larger brook trout size-classes. It is unclear, however, why we observed the hump-shaped pattern in population variability when considering the full extent of stream sizes sampled. The low temporal variability in density at the largest sites along this continuum was not expected. In these sites, population sizes were always low, suggesting potentially poorer brook trout habitat. There may be substantial discrepancies in the amount of "preferred" microhabitat within these mainstem sites. Hansbarger et al. [71] and Petty et al. [28] showed that brook trout within both mainstem and tributary reaches select for specific microhabitats (e.g. stream velocities, depths, temperature). Therefore, differences in preferred microhabitat in this watershed could then explain the discrepancies in density variability observed here. This may be further complicated at sites such as mainstem 4 , where potential 
refugia is in close proximity to the Second Fork tributary (Figure 1, large tributary 1 and 2, and headwater 1). Correlation analysis revealed that brook trout densities from mainstem 4 were out of phase with all other similar sized sites (Figure 8a), although it seemed to be more in phase with the smaller sites in the adjacent tributary. This then suggests that not only the presence of lower quality habitat, but also the proximity to higher quality habitat may drastically reduce the potential for the lower quality habitat to be occupied, even under optimal seasonal conditions.

Furthermore, brown and rainbow trout densities are much higher in these larger mainstem habitats (Tables 1). Competition with non-native trout could potentially be excluding brook trout from important microhabitats. Brown trout in particular have been shown to reduce the probability of brook trout occupying some streams [72], and almost completely replace brook trout from others [73]. Consequently, peripheral sites for brook trout within this watershed may be defined by streams with drainage areas of $10-30 \mathrm{~km}^{2}$, and larger streams may then fit into more of an "extra-periphery" classification. The strong positive correlation between total competitor densities and brook trout densities for the peripheral sites suggests that the same factors that influence brook trout may also affect rainbow and brown trout in these streams. Furthermore, this suggests that rainbow and brown trout may add to the density-dependent regulatory effect on brook trout populations. However, competition is likely occurring at the microhabitat scale as opposed to the reach scale, which could explain why correlation analysis did not demonstrate negative relationships between brook trout and exotic species. Limited brook trout productivity as a response to local temperatures exceeding optimal growth ranges $\left(10-19^{\circ} \mathrm{C},[56]\right)$ and competition with exotic salmonids for important microhabitats within the "extra-periphery" may then explain the consistently lowered brook trout densities and variability over the study period $[33,37]$. 
It is important to acknowledge that our results are limited to only one watershed within the state of West Virginia, and only one core site within this watershed. Data collection within this site was originally designed to investigate population dynamics along a continuum of drainage area rather than discrete core-periphery categories. Continued investigation within this watershed has allowed us to better understand the spatial arrangement of the brook trout population within this watershed $[27,28,71,74-76]$. Although this 1 core site may not represent the typical core within this watershed, investigation of other tributaries within this watershed has led us to believe that this is a typical core tributary. Previous studies within different tributaries of the Shavers Fork watershed have shown that most productivity occurs in these small tributaries, and that the majority of brook trout within these small tributaries possess relatively sedentary life styles [27,28]. Additionally, others have found strong synchrony in brook trout populations at the state scale [53]. Short term analyses of different headwater tributary sites in this watershed have also revealed strong synchrony among different core sites (B. M. Huntsman unpublished manuscript). Because of these factors, we feel confident that the small tributary used in this study represents a typical core site within the Shavers Fork watershed.

Management implications - The prevalence of DD within this watershed suggests that any efforts to supplement brook trout productivity would require increasing the carrying capacity within the entire watershed. This would involve identifying the limiting factors setting carrying capacities in both tributaries and mainstem sites. We believe that the tributaries within this watershed are strongly limited by food availability, as has been suggested for many other headwater brook trout populations $[28,54,55,59]$. This means that increasing the amount of food as well as increasing the number of available spawning habitats (e.g. treating acidity, [74,77]) would be important at the core. In more peripheral sites however, the abundance of food suggests 
that brook trout in the mainstem are more limited in available microhabitat rather than food [28]. Consequently, maintenance of riparian cover and creation of deep coldwater refugia are essential to supplement brook trout productivity in larger mainstem habitats of this watershed [75].

Additionally, reducing competition with exotic salmonids (i.e. rainbow and brown trout) for these limited microhabitats would also be important to enhance productivity.

Under current climate change scenarios, there are at least 2 major concerns about the response of brook trout population dynamics to increasing temperatures. First, there may be fewer "cool" years where trout will be able to disperse from headwater tributaries into mainstem habitat [59]. Although this would likely have limited impact on headwater carrying capacities, it could potentially affect the total productivity within the entire watershed. With fewer brook trout moving into the mainstem, there would be fewer fish supplementing their growth with mainstem forage. Second, increasing temperatures would likely reduce the number of thermal refugia available in the mainstem. This would then directly reduce the carrying capacity of mainstem habitat, possibly to a point where it is no longer functionally available to brook trout within the watershed. This affect may be particularly acute when exotic competitors are present. Understanding how changing climate may affect the watershed scale dynamics of brook trout in this region is a priority for future research.

\section{Acknowledgments:}

We would like to acknowledge numerous contributors to field sampling over the years, including Jesse Bopp, Pete Lamothe, David Thorne, Zach Liller, Jeff Hansbarger, Roy Martin, Eric Merriam, Eric Miller, Allison Anderson, and Michael Tincher. 


\section{Works Cited:}

1. Murdoch WW (1994) Population regulation in theory and practice. Ecology 75:271-287.

2. Krebs CJ (2002) Beyond population regulation and limitation. Wildlife Research 29:1-10.

3. Hixon MA, Pacala SW, Sandin SA (2002) Population regulation: Historical context and contemporary challenges of open vs. closed systems. Ecology 83:1490-1508.

4. Turchin P (1999) Population regulation: a synthetic view. Oikos 84:153-159.

5. Lobón-Cerviá J (2007) Numerical changes in stream-resident brown trout (Salmo trutta): uncovering the roles of density-dependent and density-independent factors across space and time. Canadian Journal of Fisheries and Aquatic Sciences 64:1429-1447.

6. Nicola GG, Almodóvar A, Jonsson B, Elvira B (2008) Recruitment variability of resident brown trout in peripheral populations from southern Europe. Freshwater Biology $53: 2364-2374$.

7. Previtali MA, Lima M, Meserve PL, Kelt DA, Gutierrez JR (2009) Population dynamics of two sympatric rodents in a variable environment: rainfall, resource availability, and predation. Ecology 90:1996-2006.

8. Goswami VR, Getz LL, Hostetler JA, Ozgul A, Oli MK (2011) Synergistic influences of phase, density, and climatic variation on the dynamics of fluctuating populations. Ecology 92:1680-1690.

9. Williams CK, Ives AR, Applegate RD (2003) Population dynamics across geographical ranges: time-series analyses of three small game species. Ecology 84:2654-2667.

10. Breininger DR, Oddy DM (2004) Do habitat potential, population density, and fires influence scrub-jay source-sink dynamics? Ecological Applications 14:1079-1089. 
11. Petranka JW, Sih A. (1986) Environmental instability, competition, and density-dependent growth and survivorship of a stream-dwelling salamander. Ecology 67:729-736.

12. Semlitsch RD (1987) Density-dependent growth and fecundity in the paedomorphic salamander Ambystoma talpoideum. Ecology 68:1003-1008.

13. Dunham JB, Vinyard GL (1997) Relationships between body mass, population density, and the self-thinning rule in stream-living salmonids. Canadian Journal of Fisheries and Aquatic Sciences 54:1025-1030.

14. Grossman GD, Ratajczak RE, Petty JT, Hunter MD, Peterson JT, et al. (2006) Population dynamics of mottled suclpin (Pisces) in a variable environment: information theoretic approaches. Ecological Monographs 76:217-234.

15. Johnston FD, Post JR, Mushens CJ, Stelfox JD, Paul AJ, et al. (2007) The demography of recovery of an overexploited bull trout, Salvelinus confluentus, population. Canadian Journal of Fisheries and Aquatic Sciences 64:113-126.

16. Sagarin RD, Gaines SD (2002) The 'abundant centre' distribution: to what extent is it a biogeographical rule? Ecology Letters 5:137-147.

17. Guo Q, Taper M, Schoenberger M, Brandle J (2005) Spatial-temporal population dynamics across species range: from centre to margin. Oikos 108:47-57.

18. Kanda LL, Fuller TK, Sievert PR, Kellogg RL (2009) Seasonal source-sink dynamics at the edge of a species' range. Ecology 90:1574-1585.

19. Kunin WE, Vergeer P, Kenta T, Davey MP, Burke T, et al. (2009) Variation at range margins across multiple spatial scales: environmental temperature, population genetics and metabolomic phenotype. Proceedings of the Royal Society B 276:1495-1506.

20. Haak AL, Williams JE, Neville HM, Dauwalter DC, Colyer WT (2010) Conserving 
peripheral trout populations: the values and risks of life on the edge. Fisheries 35:530549.

21. Pope SE, Fahrig L, Merriam HG (2000) Landscape complementation and metapopulation effects on leopard frog populations. Ecology 81:2498-2508.

22. Van Buskirk J (2005) Local and landscape influence on amphibian occurrence and abundance. Ecology 86:1936-1947.

23. Werner EE, Yurewicz KL, Skelly DK, Relyea RA (2007) Turnover in an amphibian metacommunity: the role of local and regional factors. Oikos 116:1713-1725.

24. Cornell KL, Donovan TM (2010) Effects of spatial habitat heterogeneity on habitat selection and annual fecundity for a migratory forest songbird. Landscape Ecology 25:109-122.

25. Kim M, Lapointe M (2011) Regional variability in Atlantic salmon (Salmo salar) riverscapes: a simple landscape ecology model explaining the large variability in size of salmon runs across Gaspe watersheds, Canada. Ecology of Freshwater Fish 20:144-156.

26. Fausch KD, Torgersen CE, Baxter CV, Li HW (2002) Landscapes to riverscapes: Bridging the gap between research and conservation of stream fishes. BioScience 52:483-498.

27. Petty JT, Lamothe PJ, Mazik PM (2005) Spatial and seasonal dynamics of brook trout populations inhabiting a central Appalachian watershed. Transactions of the American Fisheries Society 134:572-587.

28. Petty JT, Hansbarger JL, Huntsman BM, Mazik PM (2012) Brook trout movement in response to temperature, flow, and thermal refugia within a complex Appalachian riverscape. Transactions of the American Fisheries Society 141:1060-1073.

29. Rypel AL, Pounds KM, Findlay RH (2012) Spatial and temporal trade-offs by bluegills in floodplain river ecosystems. Ecosystems 15:555-563. 
30. Benda L, Poff NL, Miller D, Dunne T, Reeves G, et al. (2004) The network dynamics hypothesis: How channel networks structure riverine habitats. BioScience 54:413-427.

31. Kiffney PM, Greene CM, Hall JE, Davies JR (2006) Tributary streams create spatial discontinuities in habitat, biological productivity, and diversity in mainstem rivers. Canadian Journal of Fisheries and Aquatic Sciences 63:2518-2530.

32. Hughes NF (1998) A model of habitat selection by drift-feeding stream salmonids at different scales. Ecology 79:281-294.

33. Taniguchi Y, Rahel FJ, Novinger DC, Gerow KG (1998) Temperature mediation of competitive interactions among three fish species that replace each other along longitudinal stream gradients. Canadian Journal of Fisheries and Aquatic Sciences 55:1894-1901.

34. McMahon TE, Zale AV, Barrows FT, Selong JH, Danehy RJ (2007) Temperature and competition between bull trout and brook trout: a test of the elevation refuge hypothesis. Transactions of the American Fisheries Society 136:1313-1326.

35. Flebbe PA, Roghair LD, Bruggink JL (2006) Spatial modeling to project Southern Appalachian trout distribution in a warmer climate. Transactions of the American Fisheries Society 135:1371-1382.

36. Rieman BE, Isaak D, Adams S, Horan D, Nagel D, et al. (2007) Anticipated climate warming effects on bull trout habitats and populations across the interior Columbia River basin. Transactions of the American Fisheries Society 136:1552-1565.

37. Wenger SJ, Isaak DJ, Luce CH, Neville HM, Fausch KD, et al. (2011a) Flow regime, temperature, and biotic interactions drive differential declines of trout species under climate change. PNAS 108:14175-14180. 
38. Warren DR, Robinson JM, Josephson DC, Sheldon DR, Kraft CE (2012) Elevated summer temperatures delay spawning reduce redd construction for resident brook trout (Salvelinus fontinalis). Global Change Biology 18:1804-1811.

39. Limm MP, Marchetti MP (2009) Juvenile Chinook salmon (Oncorhynchus tshawytscha) growth in off-channel and main-channel habitats on the Scaramento River, CA using otolith increment widths. Environmental Biology of Fish 85:141-151.

40. Hense Z, Martin RW, Petty JT (2010) Electrofishing capture efficiencies for common stream fish species to support watershed-scale studies in the central Appalachians. North American Journal of Fisheries Management 30:1041-1050.

41. Utz RM, Hartman KJ (2006) Temporal and spatial variation in the energy intake of a brook trout (Salvelinus fontinalis) population in an Appalachian watershed. Canadian Journal of Fisheries and Aquatic Sciences 63:2675-2686.

42. Wenger SJ, Isaak DJ, Dunham JB, Fausch KD, Luce CH, et al. (2011b) Role of climate and invasive species in structuring trout distributions in the interior Columbia River Basin, USA. Canadian Journal of Fisheries and Aquatic Sciences 68:988-1008.

43. Lobón-Cerviá J (2009) Why, when and how do fish populations decline, collapse and recover? The example of brown trout (Salmo trutta) in Rio Chaballos (northwestern Spain). Freshwater Biology 54:1149-1162.

44. Grossman GD, Ratajczak RE, Wagner CM, Petty JT (2010) Dynamics and regulation of the southern brook trout (Salvelinus fontinalis) population in an Appalachian stream. Freshwater Biology 55:1494-1508.

45. Grossman GD, Nuhfer A, Zorn T, Sundin G, Alexander G (2012) Population regulation of brook trout (Salvelinus fontinalis) in Hunt Creek, Michigan: a 50-year study. Freshwater 
Biology 57:1434-1448.

46. Burnham KP, Anderson DR (2002) Model selection and inference: a practical information theoretic approach. $2^{\text {nd }}$ ed. Springer, New York.

47. Stevens MH (2009) A primer of ecology with R. Springer, New York.

48. Johnston FD, Post JR (2009) Density-dependent life-history compensation of an iteroparous salmonid. Ecological Applications 19:449-467.

49. Lobón-Cerviá J (2012) Density-dependent mortality in adults, but not juveniles, of streamresident brown trout (Salmo trutta). Freshwater Biology 57:2181-2189.

50. Dunham J, Rieman B, Chandler G (2003) Influences of temperature and environmental variables on the distribution of bull trout within streams at the southern margin of its range. North American Journal of Fisheries Management 23:894-904.

51. Martin RW, Petty JT (2009) Local stream temperature and drainage network topology interact to influence the distribution of smallmouth bass and brook trout in a central Appalachian watershed. Journal of Freshwater Ecology 24:497-508.

52. Nicola GG, Almodóvar A, Elvira B (2009) Influence of hydrologic attributes on brown trout recruitment in low-latitude range margins. Oecologia 160:515-524.

53. Zorn TG, Nuhfer AJ (2007a) Regional synchrony of brown trout and brook trout population dynamics among Michigan rivers. Transactions of the American Fisheries Society 136:706-717.

54. Nislow KH, Lowe WH (2006) Influences of logging history and riparian forest characteristics on macroinvertebrates and brook trout (Salvelinus fontinalis) in headwater streams (New Hampshire, U.S.A). Freshwater Biology 51:388-397.

55. Utz RM, Hartman KJ (2009) Density-dependent individual growth and size dynamics of 
central Appalachian brook trout (Salvelinus fontinalis). Canadian Journal of Fisheries and Aquatic Sciences 66:1072-1080.

56.Hartman KJ, Sweka JA (2001) Development of a bioenergetics model for Appalachian brook trout. Proceedings of the Southeastern Association of Fish and Wildlife Agencies 55:3851.

57. Petty JT, Grossman GD (2007) Size-dependent territoriality of mottled sculpin in a southern Appalachian stream. Transactions of the American Fisheries Society 136:1750-1761.

58. Petty JT, Grossman GD (2010) Giving-up densities and ideal pre-emptive patch use in a predatory benthic stream fish. Freshwater Biology 55:780-793.

59. Petty JT, Thorne D, Huntsman BM, Mazik PM (2014) The temperature - productivity squeeze: constraints on brook trout growth along an Appalachian river continuum. Hydrobiologia 727:151-166.

60. Tincher M (2013) Modeling water temperatures and brook trout (Salvelinus fontinalis) growth potential within a complex Appalachian riverscape. Thesis. West Virginia University, Morgantown, West Virginia, U.S.A.

61. Pulliam HR (1988) Sources, sinks, and population regulation. The American Naturalist 132:652-661.

62. Kendall BE, Bjørnstad N, Bascompte J, Keitt TH, Fagan FF (2000) Dispersal, environmental correlation, and spatial synchrony in population dynamics. The American Naturalist 155:628-636.

63. Steiner CF, Stockwell RD, Kalaimani V, Aqel Z (2013) Population synchrony and stability in environmentally forced metacommunities. Oikos 122:1195-1206.

64. Fausch KD, White RJ (1981) Competition between brook trout (Salvelinus fontinalis) and 
brown trout (Salmo trutta) for positions in a Michigan stream. Canadian Journal of Fisheries and Aquatic Sciences 38:1220-1227.

65. Hixon MA, Carr MH (1997) Synergistic predation, density dependence, and population regulation in marine fish. Science 277:946-949.

66. Isaak DJ, Hubert WA (2004) Nonlinear response of trout abundance to summer stream temperatures across a thermally diverse montane landscape. Transactions of the American Fisheries Society 133:1254-1259.

67. Zorn TG, Nuhfer AJ (2007b) Influences on brown trout and brook trout population dynamics in a Michigan river. Transactions of the American Fisheries Society 136:691-705.

68. Kratzer JF, Warren DR (2013) Factors Limiting Brook Trout Biomass in Northeastern Vermont Streams. North American Journal of Fisheries Management 33:130-139.

69. Goniea TM, Keefer ML, Bjornn TC, Peery CA, Bennett DH, et al. (2006) Behavioral thermoregulation and slowed migration by adult fall Chinook salmon in response to high Columbia River water temperatures. Transactions of the American Fisheries Society $135: 408-419$.

70. Young RG, Wilkinson J, Hay J, Hayes JW (2010) Movement and mortality of adult brown trout in the Motupiko River, New Zealand: effects of water temperature, flow, and flooding. Transactions of the American Fisheries Society 139:137-146.

71. Hansbarger JL, Petty JT, Mazik PM (2008) Microhabitat use by brook trout inhabiting small tributaries and a large river mainstem: implications for stream habitat restoration in the Central Appalachians. Proceedings of the Annual Conference of the Southeastern Association of Fish and Wildlife Agencies 62:142-148.

72. Wagner T, Deweber JT, Detar J, Sweka JA (2013) Landscape-Scale Evaluation of 
Asymmetric Interactions between Brown Trout and Brook Trout Using Two-Species

Occupancy Models. Transactions of the American Fisheries Society 142:353-361.

73. Waters TF (1983) Replacement of brook trout by brown trout over 15 years in a Minnesota stream: Production and Abundance. Transactions of the American Fisheries Society 112:137-146.

74. Petty JT, Thorne D (2005) An ecologically based approach to identifying restoration priorities in an acid-impacted watershed. Restoration Ecology 13:348-357.

75. Petty JT, Merriam EP (2012) Brook trout restoration. Nature Education Knowledge 3:17.

76. Poplar-Jeffers IO, Petty JT, Anderson JT, Kite SJ, Strager MP, et al. (2009) Culvert replacement and stream habitat restoration: Implications from brook trout management in an Appalachian watershed, U.S.A. Restoration Ecology 17:404-413.

77. McClurg SE, Petty JT, Mazik PM, Clayton JL (2007) Stream ecosystem response to limestone treatment in acid impacted watersheds of the Allegheny Plateau. Ecological Applications 17:1087-1104. 


\section{Tables:}

Table 1: Site description for each stream selected for this study.

\begin{tabular}{|c|c|c|c|c|c|c|c|}
\hline & Headwater & Larg & utary & & Mai & & \\
\hline & 1 & 1 & 2 & 1 & 2 & 3 & 4 \\
\hline $\mathrm{DA}\left(\mathrm{km}^{2}\right)$ & 1.3 & 10.4 & 15.4 & 27.9 & 30.3 & 41.1 & 59.8 \\
\hline Elevation (m) & 1255 & 1184 & 1149 & 1177 & 1170 & 1157 & 1137 \\
\hline Stream length $(\mathrm{m})$ & 150 & 306 & 315 & 944 & 863 & 919 & 1007 \\
\hline Max July temp $\left({ }^{\circ} \mathrm{C}\right)$ & $14.8(0.2)$ & $14.1(0.2)$ & $15.9(0.2)$ & $19.7(0.4)$ & $19.7(0.3)$ & $20.0(0.3)$ & $19.5(0.5)$ \\
\hline Prey density $\left(\# / \mathrm{m}^{2}\right)$ & 1834 & 1019 & 721 & NA & 3917 & 2363 & 1580 \\
\hline Total brook trout density $(\# / m)$ & $0.335(0.040)$ & $0.132(0.036)$ & $0.081(0.012)$ & $0.023(0.006)$ & $0.014(0.004)$ & $0.022(0.004)$ & $0.006(0.001)$ \\
\hline Brook trout density C.V. & 36.28 & 81.86 & 44.53 & 83.81 & 91.69 & 59.14 & 61.44 \\
\hline Brook trout L.A. density $(\# / m)$ & $0.103(0.010)$ & $0.063(0.014)$ & $0.039(0.005)$ & $0.013(0.003)$ & $0.007(0.002)$ & $0.017(0.003)$ & $0.004(0.001)$ \\
\hline Brook trout S.A. density $(\# / m)$ & $0.154(0.029)$ & $0.039(0.011)$ & $0.034(0.008)$ & $0.007(0.003)$ & $0.004(0.002)$ & $0.004(0.001)$ & $0.001(0.001)$ \\
\hline Brook trout YOY density $(\# / m)$ & $0.077(0.023)$ & $0.030(0.023)$ & $0.008(0.004)$ & $0.003(0.002)$ & $0.003(0.002)$ & $0.001(0.001)$ & $0.001(0.000)$ \\
\hline Mean brook trout SL (mm) & $96.5(1.7)$ & $114.3(2.5)$ & $117.4(2.5)$ & $133.2(7.1)$ & $133.3(10.3)$ & $148.3(7.0)$ & $128.3(16.1)$ \\
\hline Brown trout density $(\# / m)$ & 0 & 0 & $0.001(0.001)$ & $0.011(0.003)$ & $0.014(0.002)$ & $0.007(0.001)$ & $0.007(0.002)$ \\
\hline Rainbow trout density $(\# / m)$ & 0 & $0.001(0.001)$ & $0.013(0.005)$ & $0.018(0.005)$ & $0.011(0.003)$ & $0.015(0.003)$ & $0.002(0.001)$ \\
\hline Fish richness & 1 & 5 & 13 & NA & 17 & 17 & NA \\
\hline Spawning intensity & 22 & 3 & 2 & 0 & 0 & 0 & 0 \\
\hline
\end{tabular}

Mean density (s.e.) of total brook trout (SAFO), as well as large adult (L.A.), small adult (S.A.), and young-of-the-year (YOY). Similarly, brown trout, and rainbow trout densities are reported as means captured from 2002-2011 by site. Mean brook trout standard length (SL) is reported for just adults. Coefficient of variation (C.V.) was also estimated for total brook trout densities. Max July temp is the mean daily maximum temperature for the month of July averaged over 
the 10 year study period. Prey density values are estimates from unpublished data of benthic kick-net samples for the 2011 spring sampling season. Fish richness values represent the number of different fish species captured from each location (J.T. Petty unpublished data). Spawning intensity is the total number of redd counts observed during the Fall spawning season [27]. Drainage area is represented by DA. 
Table 2: Results from candidate models using $\mathrm{AIC}_{\mathrm{c}}$ for the 7 study sites.

\begin{tabular}{|c|c|c|c|c|c|c|c|c|c|c|c|c|c|c|c|c|c|c|c|c|c|c|}
\hline \multirow{3}{*}{$\begin{array}{l}\text { Res. } \\
\text { Var. }\end{array}$} & \multirow{3}{*}{$\begin{array}{l}\text { Predictor } \\
\text { Variable }\end{array}$} & \multicolumn{3}{|c|}{ Headwater } & \multicolumn{6}{|c|}{ Large Tributary } & \multicolumn{12}{|c|}{ Mainstem } \\
\hline & & & 1 & & & 1 & & & 2 & & & 1 & & & 2 & & & 3 & & & 4 & \\
\hline & & $w_{i}$ & $\mathrm{R}^{2}$ & dir. & $w_{i}$ & $\mathrm{R}^{2}$ & dir. & $w_{i}$ & $\mathrm{R}^{2}$ & dir. & $w_{i}$ & $\mathrm{R}^{2}$ & dir. & $w_{i}$ & $\mathrm{R}^{2}$ & dir. & $w_{i}$ & $\mathrm{R}^{2}$ & dir. & $w_{i}$ & $\mathrm{R}^{2}$ & dir. \\
\hline \multirow[t]{7}{*}{ rpop } & dtrout $_{\mathrm{t}-1}$ & $0.227 *$ & 0.28 & - & $0.491 *$ & 0.29 & - & $0.357 *$ & 0.22 & - & $0.709 *$ & 0.46 & - & $0.253^{*}$ & 0.16 & - & $0.591 *$ & 0.38 & - & $0.710 *$ & 0.50 & - \\
\hline & $\operatorname{dyoy}_{t-1}$ & $0.073^{*}$ & 0.08 & - & & & & $0.147 *$ & 0.05 & - & & & & & & & $0.073 *$ & 0.01 & - & & & \\
\hline & $\mathrm{su}_{\mathrm{t}-1} \mathrm{~T}$ & $0.076^{*}$ & 0.09 & + & $0.139 *$ & 0.06 & + & $0.126^{*}$ & 0.01 & + & 0.068 & 0.09 & - & $0.122 *$ & 0.01 & - & & & & 0.031 & 0.00 & + \\
\hline & $\mathrm{sp}_{\mathrm{t}} \mathrm{T}$ & $0.051 *$ & 0.00 & + & $0.109 *$ & 0.01 & + & $0.132 *$ & 0.02 & - & $0.077 *$ & 0.12 & + & $0.464 *$ & 0.27 & + & $0.211 *$ & 0.22 & + & 0.041 & 0.07 & - \\
\hline & $\mathrm{sp}_{\mathrm{t}} \mathrm{Q}$ & $0.113^{*}$ & 0.16 & + & $0.108^{*}$ & 0.01 & + & $0.177^{*}$ & 0.09 & + & 0.054 & 0.04 & - & $0.118^{*}$ & 0.01 & + & $0.073^{*}$ & 0.01 & - & 0.049 & 0.10 & + \\
\hline & $\mathrm{su}_{\mathrm{t}-1} \mathrm{~T}+\mathrm{dtrout}_{\mathrm{t}-1}$ & $0.429 *$ & 0.72 & $+/-$ & $0.123^{*}$ & 0.57 & $+/-$ & 0.010 & 0.22 & $+/-$ & 0.025 & 0.49 & $+/-$ & 0.007 & 0.17 & $+/-$ & & & & 0.042 & 0.58 & $+/-$ \\
\hline & $\mathrm{sp}_{\mathrm{t}} \mathrm{T}+\mathrm{dtrout}_{\mathrm{t}-1}$ & 0.006 & 0.29 & $-/-$ & 0.013 & 0.29 & $-/-$ & 0.014 & 0.28 & $-1-$ & 0.035 & 0.53 & $+/-$ & 0.017 & 0.31 & $+/-$ & 0.021 & 0.42 & $+/-$ & $0.106^{*}$ & 0.66 & $-/-$ \\
\hline \multirow[t]{4}{*}{ radult } & dadult $_{\mathrm{t}-1}$ & $0.589 *$ & 0.64 & - & $0.420 *$ & 0.31 & - & 0.488* & 0.32 & - & $0.697 *$ & 0.46 & - & $0.246^{*}$ & 0.14 & - & $0.622 *$ & 0.40 & - & $0.682 *$ & 0.52 & - \\
\hline & dyoy $_{t-1}$ & 0.008 & 0.05 & - & & & & $0.094 *$ & 0.01 & - & & & & & & & $0.064 *$ & 0.00 & - & 0.036 & 0.08 & - \\
\hline & $\mathrm{su}_{\mathrm{t}-1} \mathrm{~T}$ & 0.006 & 0.00 & + & $0.318^{*}$ & 0.26 & + & $0.129^{*}$ & 0.08 & + & 0.066 & 0.09 & - & $0.125^{*}$ & 0.00 & - & & & & 0.026 & 0.01 & + \\
\hline & $\mathrm{sp}_{\mathrm{t}} \mathrm{T}$ & 0.007 & 0.02 & + & $0.091^{*}$ & 0.28 & + & $0.093 *$ & 0.01 & - & $0.085^{*}$ & 0.14 & + & $0.460 *$ & 0.25 & + & $0.192 *$ & 0.22 & + & 0.035 & 0.07 & - \\
\hline
\end{tabular}




\begin{tabular}{|c|c|c|c|c|c|c|c|c|c|c|c|c|c|c|c|c|c|c|c|c|c|}
\hline $\mathrm{sp}_{\mathrm{t}} \mathrm{Q}$ & 0.010 & 0.09 & + & $0.082^{*}$ & 0.01 & + & $0.127 *$ & 0.08 & + & 0.003 & 0.05 & - & $0.127^{*}$ & 0.00 & + & $0.070 *$ & 0.02 & - & 0.040 & 0.10 & + \\
\hline $\mathrm{su}_{\mathrm{t}-1} \mathrm{~T}+$ dadult $_{\mathrm{t}-1}$ & $0.343 *$ & 0.82 & $+/-$ & $0.062 *$ & 0.52 & $+/-$ & 0.014 & 0.33 & $+/-$ & 0.022 & 0.48 & $+/-$ & 0.008 & 0.16 & $+-/$ & & & & 0.042 & 0.60 & $+/-$ \\
\hline $\mathrm{sp}_{\mathrm{t}} \mathrm{T}+$ dadult $_{\mathrm{t}-1}$ & 0.017 & 0.64 & $-/-$ & 0.013 & 0.33 & $+/-$ & 0.014 & 0.33 & $-/-$ & 0.050 & 0.57 & $+/-$ & 0.015 & 0.28 & $+-/$ & 0.021 & 0.43 & $+/-$ & $0.114^{*}$ & 0.68 & $-/-$ \\
\hline dadult $_{t-1}$ & $0.088 *$ & 0.11 & + & $0.209^{*}$ & 0.07 & - & 0.023 & 0.20 & + & & & & & & & & & & & & \\
\hline $\mathrm{su}_{\mathrm{t}-1} \mathrm{~T}$ & $0.235^{*}$ & 0.28 & + & & & & 0.013 & 0.09 & + & & & & & & & & & & & & \\
\hline $\mathrm{sp}_{\mathrm{t}} \mathrm{T}$ & $0.055^{*}$ & 0.01 & - & $0.155^{*}$ & 0.00 & + & 0.030 & 0.25 & - & & & & & & & & & & & & \\
\hline $\mathrm{sp}_{\mathrm{t}} \mathrm{Q}$ & $0.145^{*}$ & 0.20 & + & $0.164 *$ & 0.02 & + & 0.008 & 0.00 & - & & & & & & & & & & & & \\
\hline
\end{tabular}

Only interpretable predictor variables in at least one site are provided (see Table S2 for all models analyzed). The first value represents the Akaike's weight ( $w_{i}$ ) given to each model in the candidate set followed by the $R^{2}$ statistic and the direction of the relationship. Bold values represent the best model in each candidate set. Abbreviations are as follows: rpop = per capita growth rate $\left(r=\ln \left(n_{t} / n_{t-1}\right)\right.$ for the total brook trout population, radult $=r$ for adults, ryoy $=r$ for young-of-theyear, dtrout $=$ density of all brook trout, dadult $=$ density of adult brook trout, dyoy $=$ density of young-of-the-year brook trout, $\mathrm{sp}_{\mathrm{t}} \mathrm{T}=$ mean $\mathrm{April}-\mathrm{June}$ maximum temperature, $\mathrm{su}_{\mathrm{t}-1} \mathrm{~T}=$ mean July maximum temperature, and $\mathrm{sp}_{\mathrm{t}} \mathrm{Q}=$ mean March-June discharge. Missing values represent predictor variables that were correlated 
with another predictor variable in the candidate set and therefore removed. No models were constructed for ryoy at mainstem sites because few YOY were found in those sites. Models with an * were considered interpretable models using criteria from Grossman et al. [14]. 
Table 3. Multiple stepwise regression predicting density of YOY at Headwater 1.

$\begin{array}{llllll}\text { Variable } & \text { Estimate } & \text { P-value } & {\text { Partial } \mathbf{R}^{2}} & \text { Final model } \mathbf{R}^{2} & \text { Final model p-value } \\ \text { intercept } & -0.9751 & 0.001 & & 0.96 & 0.0006 \\ \text { dadult }_{\mathrm{t}-1} & 0.2956 & 0.005 & 0.38 & & \\ \mathrm{su}_{\mathrm{t}-1} \mathrm{~T} & 0.0561 & 0.002 & 0.44 & & \\ \mathrm{sp}_{\mathrm{t}} \mathrm{Q} & 0.0005 & 0.002 & 0.14 & \end{array}$

The final regression equation is $y=0.2956 d_{a d u l t} t_{t-1}+0.0561 s u_{t-1} T+0.0005 \operatorname{sp}_{t} Q-0.9751$. 


\section{Figure Legends}

Figure 1. Seven study sites within the upper Shavers Fork watershed in Pocahontas and Randolph counties, WV.

Figure 2. Time series plot of mean temperature and discharge across site types. Time series plots are of year versus mean April $\mathrm{t}_{\mathrm{t}}-\mathrm{June}_{\mathrm{t}}$ maximum water temperature and mean $\mathrm{March}_{\mathrm{t}}-\mathrm{June}_{\mathrm{t}}$ discharge (Q). Means were for the 2 large tributary sites and the 4 mainstem sites.

Figure 3. Total brook trout density coefficient of variation (C.V.) as a function of stream drainage area.

Figure 4. Time series, best model, and residual plots for total brook trout analyses. Plots of total brook trout density time series, the highest Akaike weighted $\left(w_{i}\right)$ model, and the residuals of the best model as a function of the best DI predictor variable for per capita rate of change in the total brook trout population (rpop). The residual plot was selected based on the highest $R^{2}$ model in the multi-mechanism set that also contained the highest weighted predictor variable. Horizontal dotted lines represent the local carrying capacity for each site.

Figure 5. Time series, best model, and residual plots for adult brook trout analyses. Plots of adult brook trout density time series, the highest Akaike weighted $\left(w_{i}\right)$ model, and the residuals of the best model as a function of the best DI predictor variable for per capita rate of change in the adult brook trout population (radult). The residual plot was selected based on the highest $R^{2}$ model in the multi-mechanism set that also contained the highest weighted predictor variable. Horizontal dotted lines represent the local carrying capacity for each site.

Figure 6. Time series, best model, and residual plots for young-of-the-year brook trout analyses. Plots of YOY brook trout density time series, the highest Akaike weighted $\left(w_{i}\right)$ model, and the residuals of the best model as a function of the best DI predictor variable for per capita rate of 
change in the YOY brook trout population (ryoy). The residual plot was selected based on the highest $R^{2}$ model in the multi-mechanism set that also contained the highest weighted predictor variable. Horizontal dotted lines represent the local carrying capacity for each site.

Figure 7. Predictors of young-of-the-year recruitment in the core. Stock-recruitment curve for YOY brook trout density as a function of (A) adult brook trout density the previous year and (B) mean July maximum temperature at the headwater 1 site.

Figure 8. Brook trout pairwise correlation analysis among sites. a) Correlation of brook trout densities regressed against drainage area differences between sites $\left(p=0.01, \mathrm{R}^{2}=0.27\right)$ and $\left.\mathrm{b}\right)$ correlation of brook trout densities regressed against swim distances between sites $\left(p=0.93, \mathrm{R}^{2}\right.$ $=0.00)$.

Figure 9. Brook trout carrying capacity along the stream continuum. Plot of the local adult carrying capacity as a function of stream drainage area $\left(\right.$ kilometers $\left.^{2}\right)$. Carrying capacity was estimated as the point where radult $=0$ when plotted as a function of local adult density (see Figure 5). 


\section{Figures}

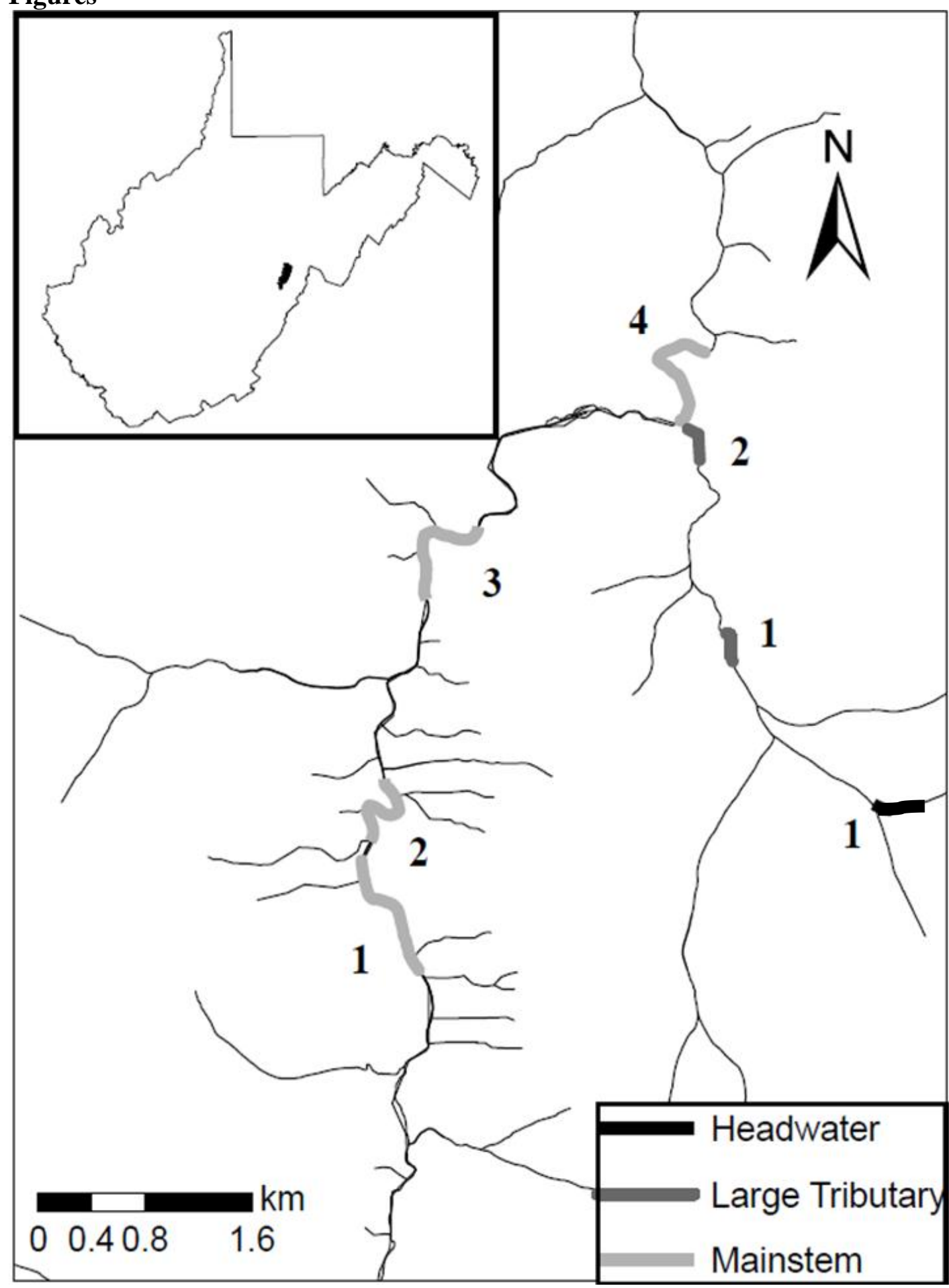

Figure 1 


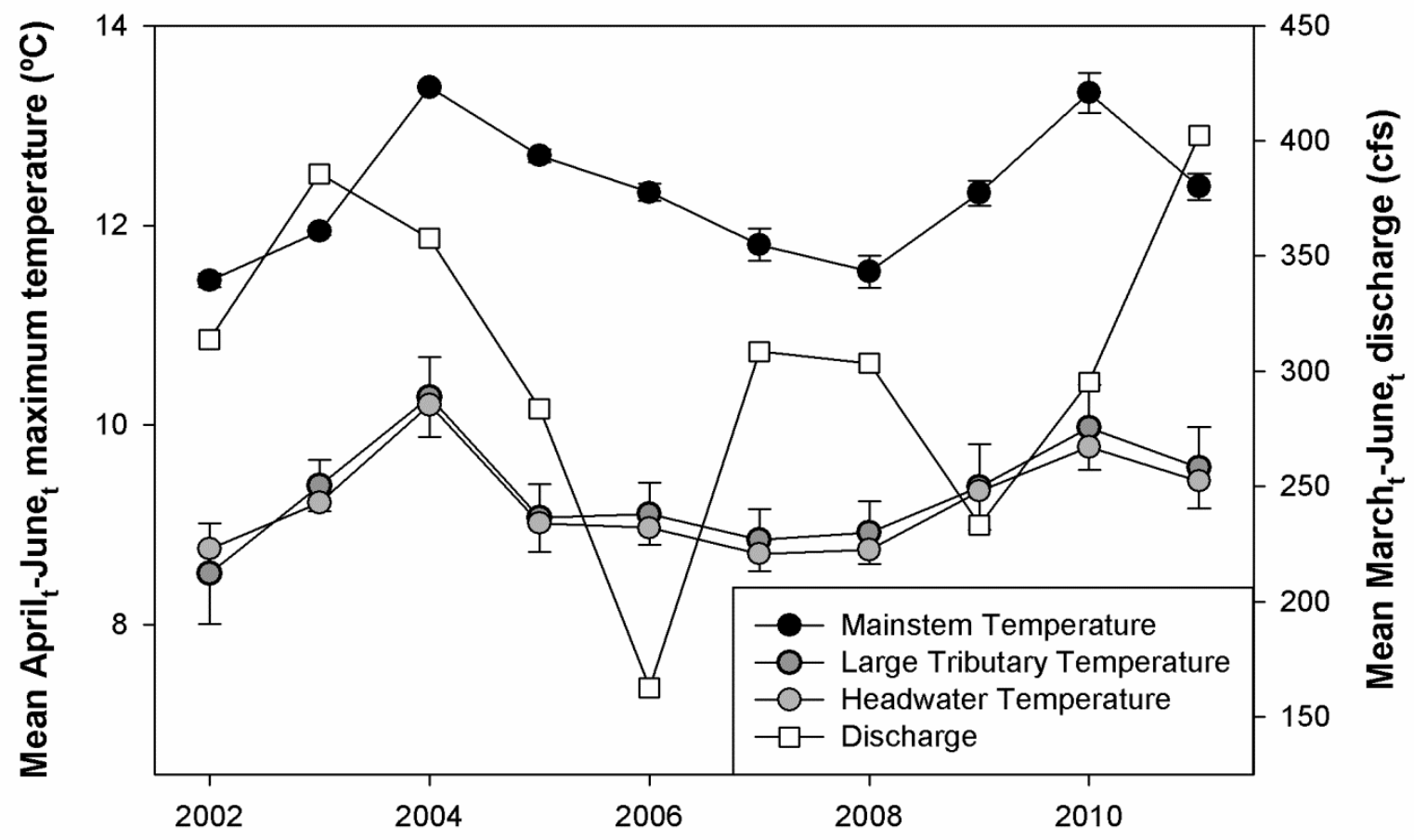

Figure 2 


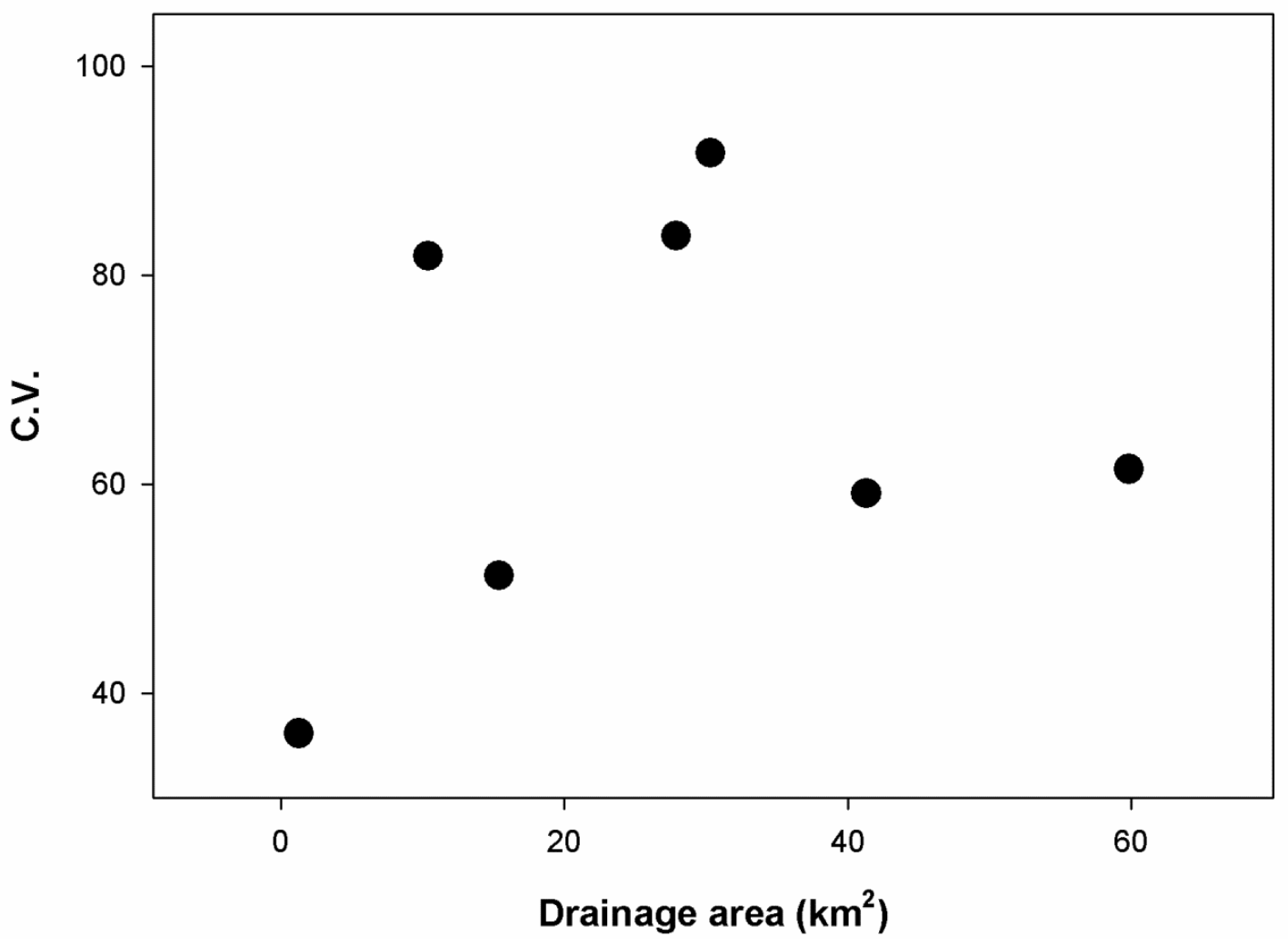

Figure 3 

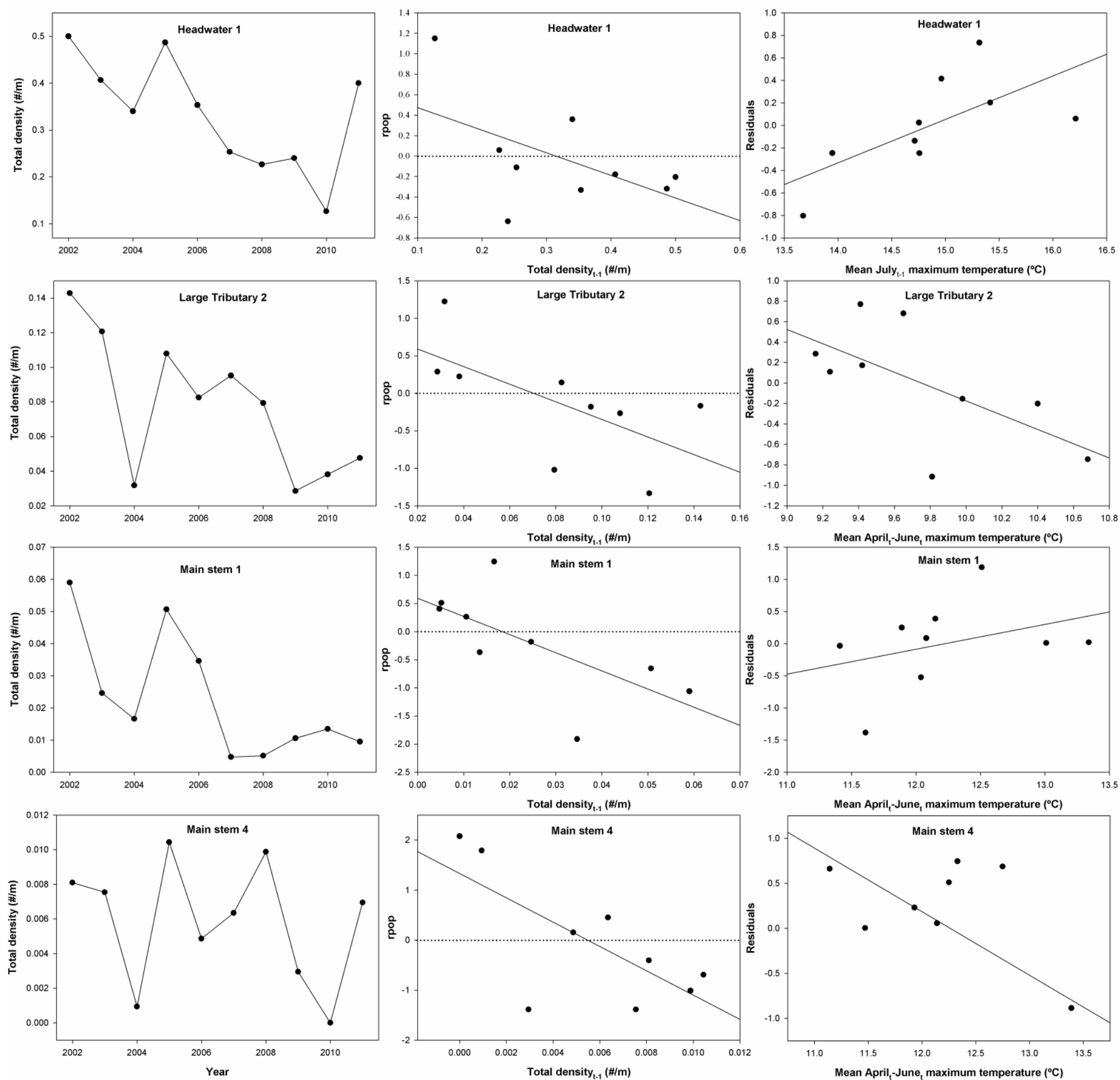

Figure 4 

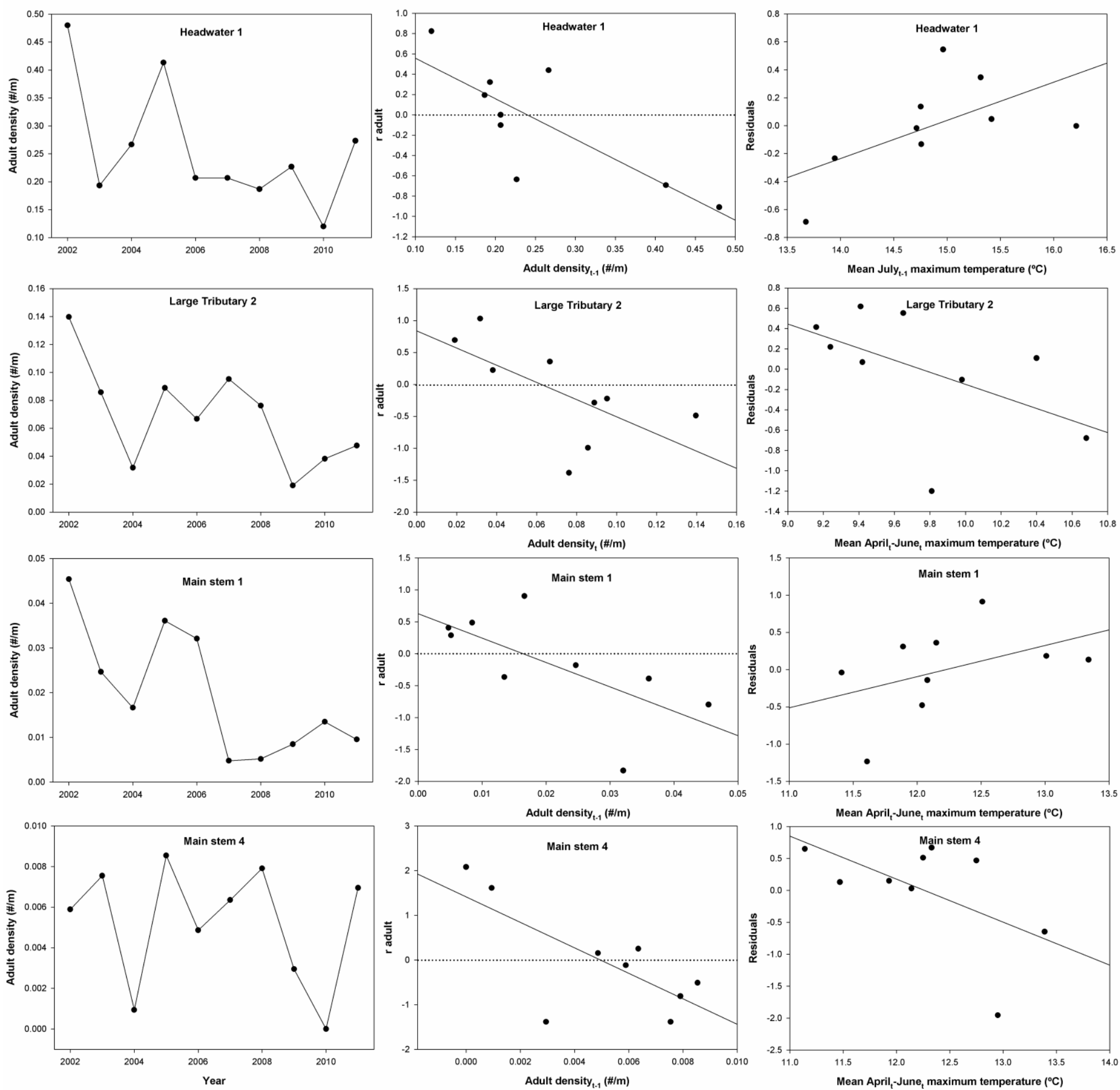

Figure 5 

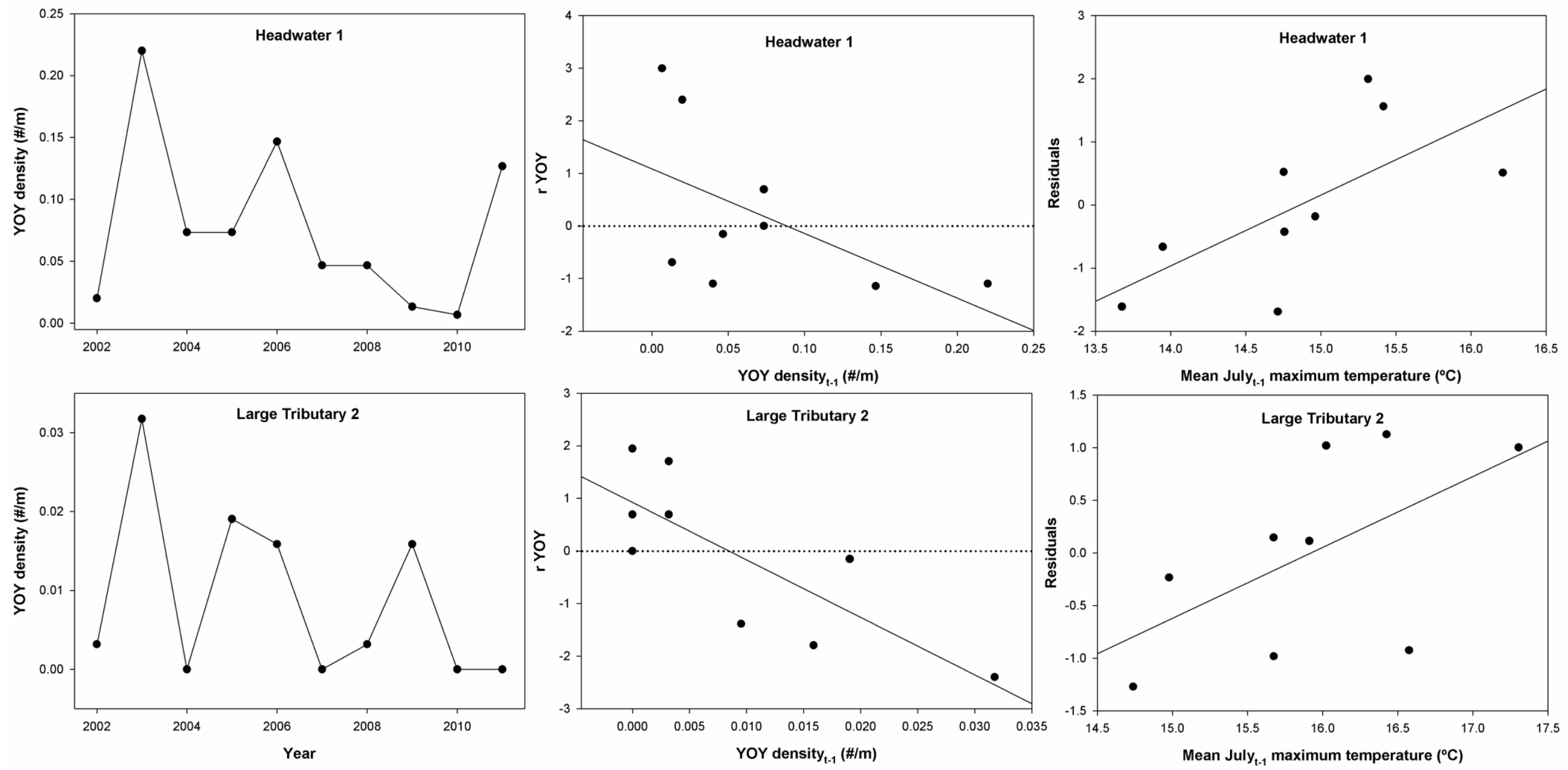

Figure 6 

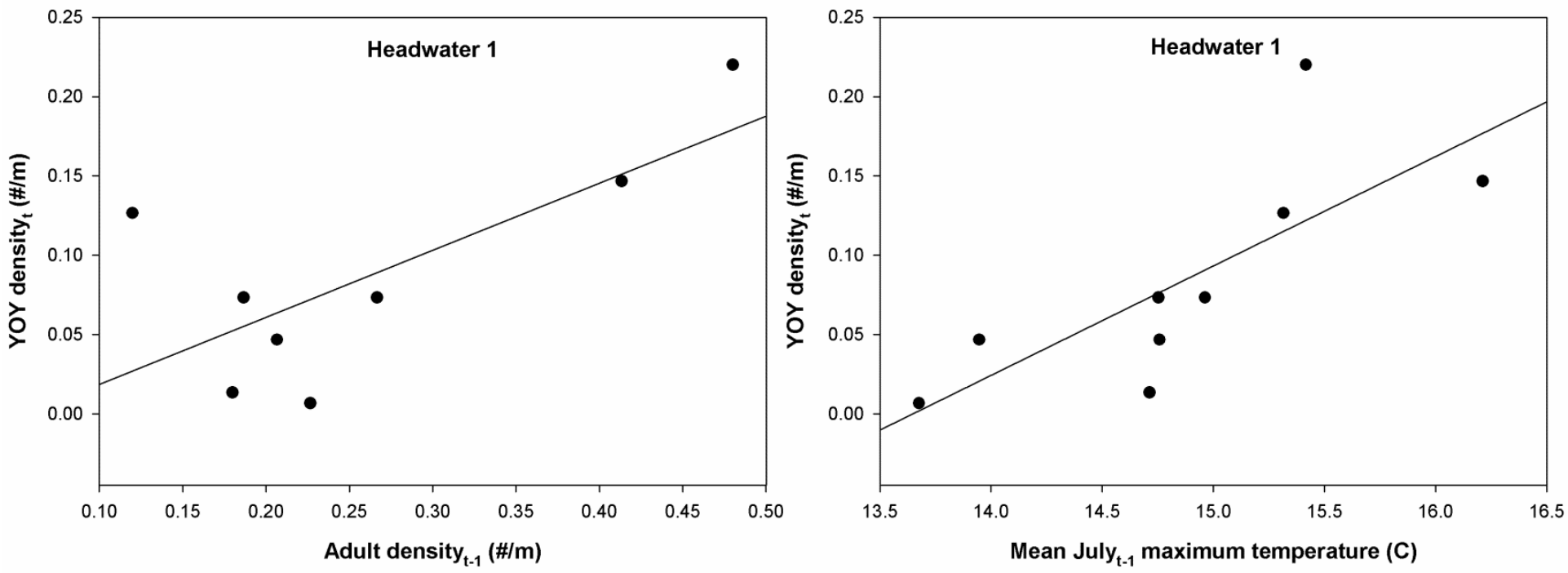

Figure 7 

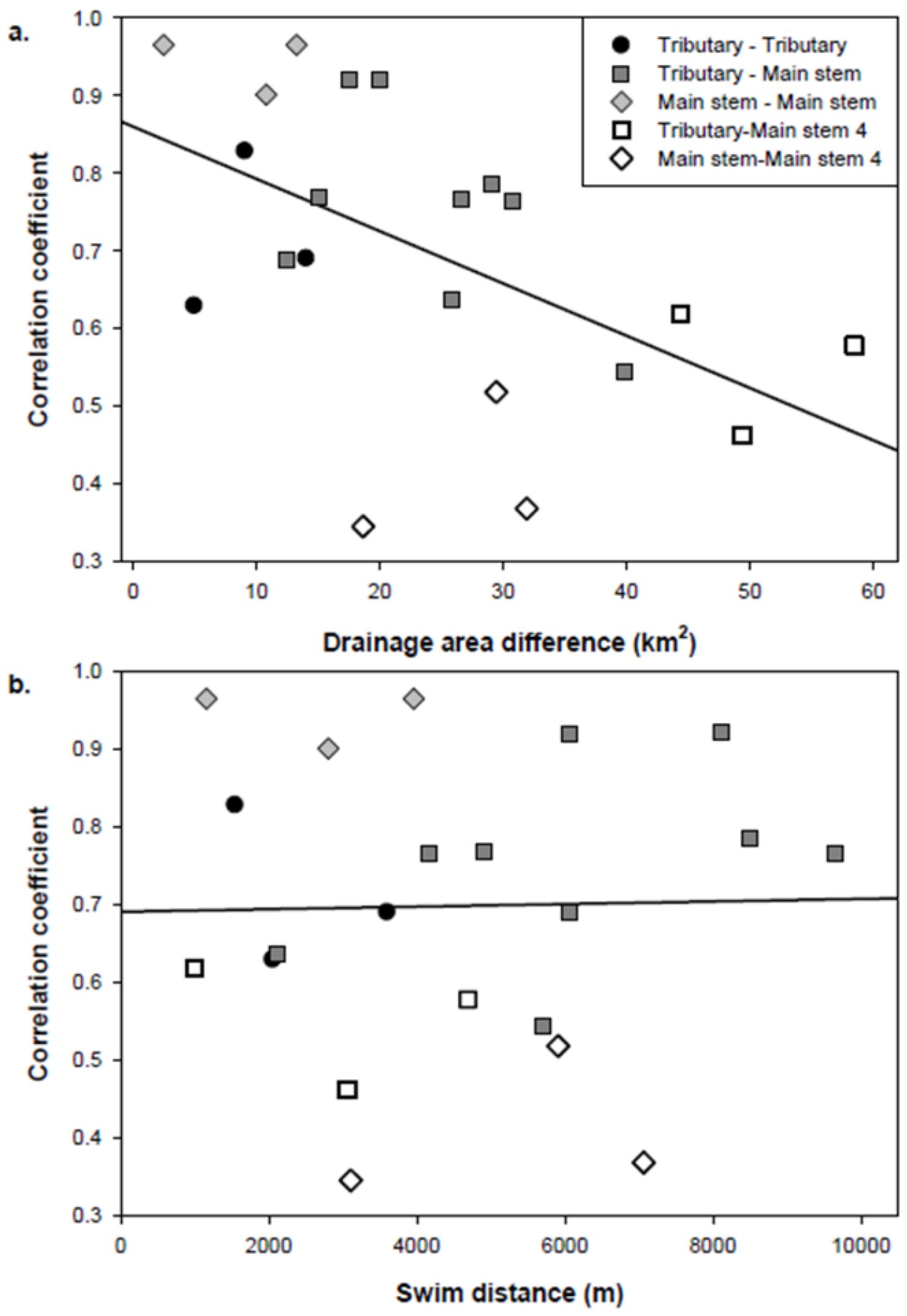

Figure 8 


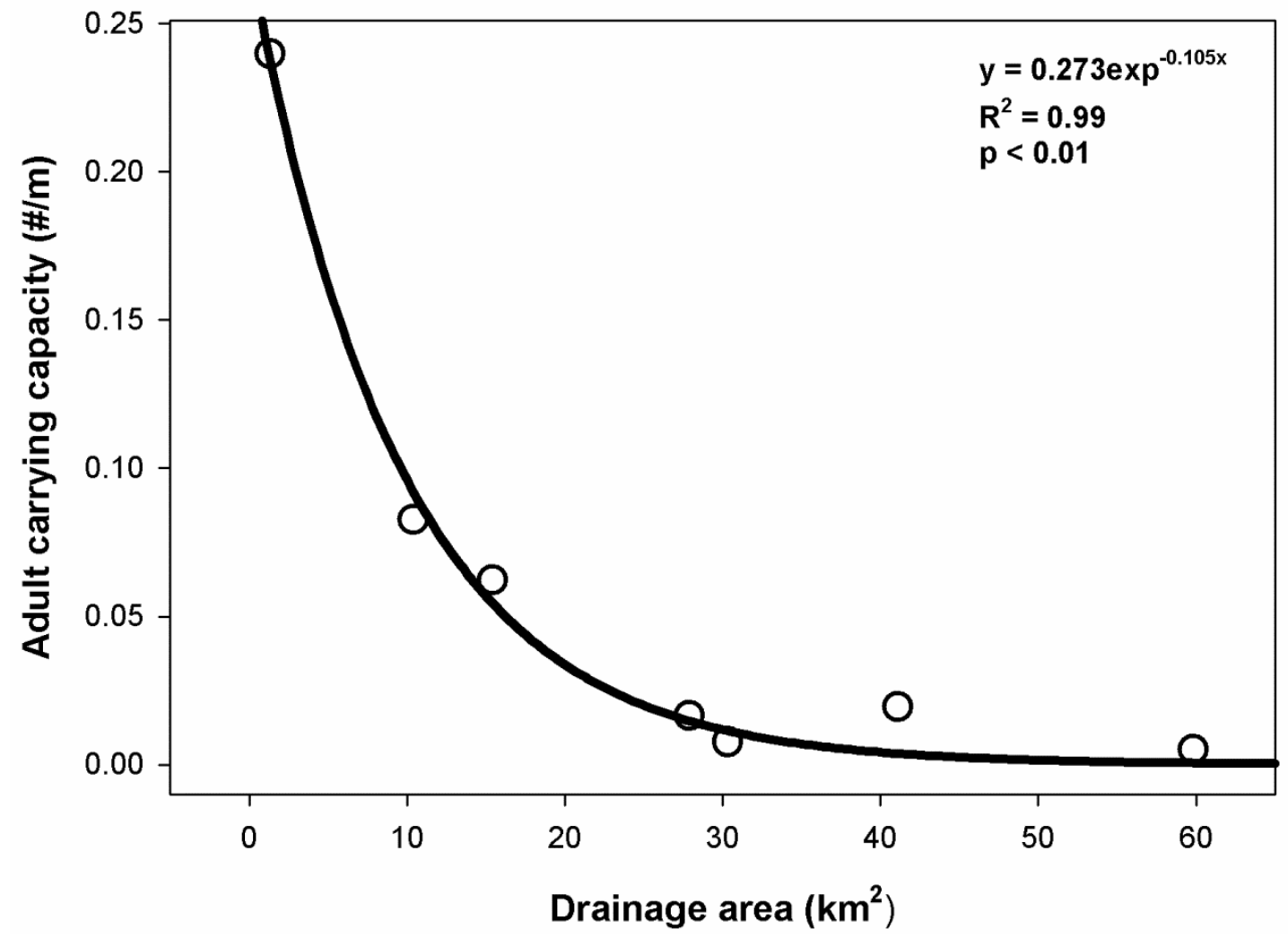

Figure 9 
Chapter 2: Brook trout distribution within peripheral habitat of an Appalachian watershed mediated by complex stream temperature dynamics and mass effects

Brock M. Huntsman* and J. Todd Petty

Division of Forestry and Natural Resources, West Virginia University, Morgantown, WV 26506, U.S.A.

*Corresponding author: brockhunts@gmail.com 


\begin{abstract}
:
Habitat selection and source-sink models provide important contributions towards the understanding of populations distributed over complex landscapes. The Shavers Fork brook trout population in WV is one such species with complex spatial distributions. We used a combination of regression analysis and an information theoretic model selection approach to reveal the complex brook trout spatial structure within this watershed. $\mathrm{AIC}_{\mathrm{c}}$ analysis showed adult brook trout densities at peripheral sites ( 3 of 6 ) were best explained by core (source) densities the previous year. Stream temperature from April-June, however was interpretable for most sites in explaining adult brook trout density. The same temperature metric also best explained mean brook trout size for 5 of 7 sites analyzed. Interestingly, a negative relationship between adult densities in larger sites and spring temperature, along with a positive relationship between standard length and spring temperature was observed. This suggests that only large brook trout were able to use peripheral habitat during warm years, providing evidence for pre-emptive habitat selection for thermal refugia at the periphery. This along with other studies from this watershed provides compelling evidence of brook trout source-sink structure within this watershed, mediated by complex temperature and habitat selection dynamics. Better understanding of these dynamics can lead towards better management practices to supplement brook trout productivity within the entire watershed.
\end{abstract}

\title{
Introduction:
}

Recently ecologists have recognized the importance of not only the local, but also the regional scale in contributing to habitat selection within populations (Gowan and Fausch 2002, Fausch et al. 2002, van Beest et al. 2014). For example, Falke et al. (2013) showed that steelhead 
(Oncorhynchus mykiss) abundances were best modeled as functions of both local habitat variables and the quality of the surrounding landscape. Similar patterns have also described the distributions of other organisms within landscapes based not only on local habitat quality, but similarly stress the importance of regional mechanisms (Pope et al. 2000, Van Buskirk 2005, Isaak et al. 2007, van Heezik and Ludwig 2012). An important component of habitat selection in such a system would then be the ability to move between habitat patches. This has strong application to metapopulation dynamics, since a metapopulation relies on movement between habitat patches (Thomas and Kunin 1999).

Movement provides numerous individual and population level advantages. On the individual scale, mobility may be a response to losing competitive trials (Olsson et al. 2006). Additionally, abiotic factors within the environment can instigate mobility, such as leaving physiologically stressful habitat patches (Hughes 1998, Young et al. 2010, Petty et al. 2012). Under metapopulation models, such as source-sink, dispersal may be directly related to local density-dependent dynamics. Specifically, habitats with densities exceeding a local source carrying capacity can provoke movement into sink patches, known as a density-dependent spillover effect or a mass effect (Abesamis and Russ 2005, Casini et al. 2012). Therefore, movement provides a means for an individual to cope with stressful local conditions, but also provides potential for supplementation at the population level through reducing densitydependent competition for resources (e.g. source-sink mass effects).

The riverscape concept proposed by Fausch and colleagues (2002) has strong application to both metapopulation and habitat selection theory as it pertains to aquatic dendritic systems. In particular, species that demonstrate unique spatial structure within a riverscape (e.g. headwater spawners and mainstem foragers) may utilize spatially distinct habitat for different purposes 
(Schlosser 1995). Relevant to habitat selection decisions on the riverscape is to understand the mechanisms driving the necessity for movement. Mass effects in source-sink models predict movement from sources to sinks, however, the subordinate fraction of the population may not always be the first to leave a crowded habitat. For example, many studies have supported preemptive habitat selection models to explain movement of dominant individuals from occupied habitats for potentially higher quality habitats in riverscapes (Gowan and Fausch 2002, Petty and Grossman 2010). However, local conditions within the new habitat may be too risky to warrant movement (Werner and Hall 1988). For example, Rypel et al. (2012) found variable floodplain use by blue gill (Lepomis macrochirus) populations within a complex river-floodplain ecosystem due to risks of floodplain dessication. Movement among habitat patches within riverscapes may be especially threatening outside of the core home-range of an aquatic population, because a species should be better adapted to characteristics common to the core of their distribution (Guo et al. 2005, van de Pol et al. 2010).

Identifying the mechanisms controlling a population's distribution within a riverscape is critical towards conservation of that species, especially due to the impending threats to aquatic environments (e.g. climate change, resource extraction, construction, etc.). At the periphery of a population's distribution, this may be exacerbated due to the species being more susceptible to local variability in environmental conditions (van de Pol et al. 2010). However, when peripheral habitats also provide supplementary resources, access to these habitats can have substantial impacts on the productivity of a fish population (Schlosser 1998, Limm and Marchetti 2009, Rypel et al. 2012). Huntsman and Petty (2014) showed that population dynamics in a strongly regulated system demonstrated a substantial decrease in carrying capacities at habitats from the core to the periphery of a brook trout population (i.e. from headwaters to the mainstem). 
However, the low density of brook trout at the highly productive peripheral habitat suggested limited peripheral use was influenced by one of two potential mechanisms, regional source-sink dynamics or un-inhabitable local conditions. Therefore, our objective for this study was to identify the important mechanisms influencing brook trout distributions within the Shavers Fork watershed, with particular focus towards supplementary peripheral habitats.

\section{Study Site and Predictions}

The Shavers Fork watershed in the central Appalachian mountains of WV was the focus for this study. Within this watershed, one core source (Headwater 1), two intermediate sized streams (Large tributary 1 and 2), and 4 peripheral reaches (Mainstem 1-4) were sampled (Figure 1). Details of each site can be found in Huntsman and Petty (2014) and Table 1. Brook trout are headwater specialists, where densities and reproduction are substantially greater in small headwater streams compared to streams with greater drainage areas (Petty et al. 2005). The two intermediate sites have drainage areas greater than $5 \mathrm{~km}^{2}$, but less than $16 \mathrm{~km}^{2}$, indicating some reproduction occurs at these sites, but much less than headwater tributaries (Petty et al. 2005). Because of this and the relative densities of young-of-the-year in these sites (Table 1), the large tributaries may act more like pseudo-sinks (Woodford and McIntosh 2010) than simply a source or sink. The large mainstem sites are greater than $16 \mathrm{~km}^{2}$, and have not shown signs of reproduction in the form of redd construction (Petty et al. 2005). High prey productivity and growth potential of brook trout found in the mainstem (Petty et al. 2012, 2014) suggests that the mainstem acts as supplementary foraging habitat at the periphery of brook trout distributions within this watershed. 
Huntsman and Petty (2014) observed strong density-dependent regulation of brook trout throughout the watershed, from small tributaries to large mainstem sites. Competition for limited thermal refugia has been suggested to be the regulating factor limiting brook trout use of the mainstem (Petty et al. 2014, Huntsman and Petty 2014). However, the small tributaries being the location of nearly all reproduction (Petty et al. 2005) indicates that the prevalence of densitydependence throughout this watershed may also be a result of source-sink mass effects. Huntsman and Petty (2014) hypothesized that 2 potential mechanisms could be driving regulation in the larger sites of this watershed: a regulated source of immigrants from the headwaters to the larger streams, or limited useable space in the form of thermal refugia. We developed 2 competing predictions to test these hypotheses: 1) If brook trout in the larger sites are controlled by a regulated source of immigrants from the headwaters, then a delayed positive relationship should exist between brook trout densities in the headwaters $(t-1)$ and brook trout densities at the larger sites $(t)$, alternatively, 2 ) if brook trout in the larger sites are controlled by a limited local resource (e.g. thermal refugia), then brook trout densities should be best modeled as a function of local habitat characteristics.

\section{Methods}

\section{Trout Population Sampling}

Brook trout sampling followed the same methods outlined in Huntsman and Petty (2014). Brook trout were sampled from each site in spring (end of May-early June) from 2002-2011, and measured for standard length (SL, mm) and weight (g). Fish were collected via backpack electrofishing (Smith-Root, CD, $60 \mathrm{~Hz} .400-600 \mathrm{~V}$ ) in an upstream direction using a single pass procedure (Hense et al. 2010). Due to relatively constant capture efficiencies among the different 
sites and across years (see Huntsman and Petty 2014), no correction factors were applied to fish densities.

\section{Water Temperature and Flow}

Stream temperature from each study site was collected from 2002-2011 using HOBO Water Temp Pro V2 data loggers. Similar stream temperature metrics were calculated as those outlined in Huntsman and Petty (2014) to model the effects of stream temperature on brook trout densities and standard lengths. The specific temperature metrics used were average maximum stream temperature for July at time $t-1$ and average maximum stream temperature from AprilJune at time $t$. Discharge metrics were similarly developed within this watershed. Mean stream discharge from March-June were estimated from a local U.S. Geological Survey stream gauging station at the Cheat bridge (USGS 03067510) as an important metric of mortality and prey delivery (Lobon-Cervia 2009, Wenger et al. 2011b, Huntsman and Petty 2014).

\section{Statistical Analyses}

General linear models were constructed to model the effects of different covariates on the densities and standard lengths (SL) of adult brook trout using the R statistical program (R Development Core Team 2011). Adult brook trout in particular were the focus of these analyses because they have been shown to be the most mobile fraction of the population (Sundt-Hansen et al. 2009, Stolarski and Hartman 2010) and young-of-the-year brook trout were rarely found in the mainstem sites. In order to differentiate size-classes in the Shavers Fork population, we used length-frequency histograms from Petty et al. (2005) to differentiate young-of-the-year (YOY, $\leq$ $60 \mathrm{~mm} \mathrm{SL}$ ) from small adults (between 60 and $100 \mathrm{~mm} \mathrm{SL}$ ), and large adults (greater than 100 
$\mathrm{mm}$ SL). Although YOY size-classes represent trout known to be produced the previous fall, the small and large adult size-classes likely DO not represent a true distinction of age (Petty et al. 2005). As such, all analyses represent a combination of both large and small adult size-classes, but do not represent a true age class or sexual maturity

A series of candidate models were constructed that considered temperature and discharge metrics, YOY densities, and combinations of these covariates as predictor variables influencing the density of adult brook trout within each site. In addition to local models, a final model in the candidate set was developed to consider how the source-sink spatial structure of this population influenced brook trout dynamics in larger streams. Each large tributary and mainstem adult brook trout population was modeled as a function of the total brook trout population in the source (Headwater 1) the previous year. Similar models were also constructed for adult brook trout standard lengths in all sites (including Headwater 1), with densities of YOY replaced by total brook trout densities. Lastly, no models were constructed relating brook trout adult standard lengths in large sites as a function of dynamics in headwater 1.

Candidate sets of models for both response variables were evaluated using Akaike's Information Criterion corrected for small sample size $\left(\mathrm{AIC}_{\mathrm{c}}\right.$, Burnham and Anderson 2002). $\mathrm{AIC}_{\mathrm{c}}$ weights $\left(w_{i}\right)$ were also constructed for each model in order to evaluate the strength of the best model in the candidate set. All models that were considered interpretable based on criteria used by Grossman et al. (2006, 2010). Specifically, models with the highest $w_{i}$ were compared to each model by dividing the best model by each model in the candidate set. Models with $w_{i}$ values greater than $10 \%$ of the best model's $w_{i}$ were then considered interpretable.

\section{Results}


Adult Brook Trout Densities - In 3 of 6 sites (large tributary 1, mainstem $1 \& 2$ ), adult brook trout densities (dadult) were best modeled as a function of brook trout density in the source of the previous year (Table 2). Additionally, this model was interpretable for all but 1 site (large tributary 2). For all source models across sites, there was a positive relationship between densities in the source and adult densities the following year (Figure 2, Table 2). In 2 of the 3 sites not best supported by source densities, a negative relationship between spring temperatures and adult brook trout density was the best model (large tributary 2 and mainstem 4, Figure 2, Table 2). Similar to source densities, spring temperatures $\left(\mathrm{sp}_{\mathrm{t}} \mathrm{T}\right)$ were interpretable in 5 of the 6 sites, where only mainstem 3 lacked enough evidence for the spring temperature model (Table 2). The final site (mainstem 3) was best modeled as a function of local recruitment of YOY into adult age classes, although nearly an identical amount of evidence was observed for the contribution of source densities at this site (Table 2).

Adult Brook Trout $S L$ - Brook trout SL was analyzed for only adult brook trout in order to avoid YOY influence on fish SL within a site. A total of 7 models were constructed for this analysis. For the SL response variable, five of seven sites were best modeled as functions of stream temperature from April $\mathrm{t}^{-} \mathrm{June}_{\mathrm{t}}\left(\right.$ Table 2). Brook trout SL was directly influenced by April $\mathrm{t}^{-}$ June $_{\mathrm{t}}$ water temperatures, where brook trout size increased with the local stream temperature (Table 2, Figure 3). At the other 2 sites (headwater 1 and large tributary 2), total brook trout densities were the best models accounting for mean adult brook trout SL (Table 2). Higher densities of brook trout at these sites showed a negative relationship with mean SL of adult brook trout.

\section{Discussion}




\section{Source-Sink Structure}

In source-sink models, sources that produce more individuals than the local carrying capacity can support an inflation of sink densities through movement of excess individuals from the source to the sink (Pullium 1988, Diffendorfer 1998, Amarasekare 2004, Jonzen et al. 2005, Casini et al. 2012). Based on our results for the three sites controlled by source dynamics (large tributary 1 , mainstem 1 and 2, Table 2), it is likely that source brook trout populations are living at or near a carrying capacity, and excess individuals from the core move to the periphery. Abesamis and Russ (2005) found that a no-take marine reserve supported extremely high productivity of the fish Naso viamingii. Productivity exceeded the carrying capacity and expanded outside the reserve. Likewise, Casini et al. (2012) found that under extremely productive years for Cod, spillover into sink habitat was strong enough to instigate a trophic cascade in the sink habitat. Similar mechanisms likely explain brook trout dynamics in the larger sites of the Shavers Fork watershed, where productivity in the source strongly influenced the density of adult brook trout in the sink.

Mobility in source habitats may be greatly reduced because the incentive to leave preferred habitat is minimal; or high when mobile populations exceed carrying capacities (Guo et al. 2005). For brook trout, preferred habitat is likely headwater sources since all reproduction occurs here (Petty et al. 2005). This is further supported by evidence of tributary brook trout populations being more sedentary than brook trout found in the mainstem (Petty et al. 2012), suggesting brook trout are unwilling to give up spawning habitat. This then indicates that less competitive individuals are pushed out of sources due to brook trout densities exceeding carrying capacities (Diffendorfer 1998, Amarasekare 2004). 
More competitive brook trout might not be "pushed" out of the sources but "pulled" into the sinks. Since the mainstem of Shavers Fork provides higher abundances of prey and greater brook trout growth (Bopp 2002, Tincher 2013, Petty et al. 2014), the mainstem acts more like a "productive" sink than a conventional sink. This means that the more mobile fraction of brook trout in the watershed might actually be superior competitors. Further support for this is provided by the fact that larger brook trout were found in the mainstem during this study (Table 1) and larger fish are often dominant competitors (Hughes 1998, Breau et al. 2007). Other studies have shown dominant competitors being more mobile, due to a preconceived knowledge that they could monopolize almost any resource patch (giving-up density, Olsson et al. 2006, Persson and Stenberg 2006, Petty and Grossman 2010). This could then explain why larger brook trout are more common in the productive sinks of this watershed, because they would be able to reestablish themselves in spawning habitat with relatively high success. Further investigation of the competitive abilities of the mobile and resident brook trout would be an important next step in order to better explain the source-sink mass effects observed in this study.

\section{Habitat Selection and Microhabitat}

Explaining brook trout distributions within this watershed were more complicated than being solely driven by source-sink mass effects. The prevalence of stream temperature metrics as not only interpretable models, but even the best supported models at some sites supports this. Density-dependent dispersal from the headwaters to the mainstem is likely an important mechanism driving brook trout from source headwater habitats. However, the quality of the local mainstem habitat also likely influences the number of brook trout residing within specific mainstem reaches. Both Petty et al. (2012) and Hansbarger et al. (2008) showed that brook trout 
within the mainstem of this watershed aggregate near very distinct microhabitats. Stream temperature in particular was shown to increase mobility in brook trout, where brook trout were shown to actively search for microhabitats with temperatures of approximately $16-19^{\circ} \mathrm{C}$ (Petty et al. 2012). Brook trout densities seem to increase in the mainstem following very productive years in tributaries, but brook trout also actively search for very specific microhabitats once they make it to the mainstem.

Evidence from this study suggests that competition may be a regulating process orienting larger fish downstream. The mean SL of adult brook trout in the mainstem were larger than those found in tributaries $($ mainstem $=128.3-148.3 \mathrm{~mm}$, headwater $1=96.5 \mathrm{~mm}$ ), and adult mean SL was larger with increasing stream temperature (Figure 3). Hughes (1998) showed that larger arctic grayling (Thymallus arcticus) found upstream can be explained through competition for energetically favorable habitat. Similar mechanisms may explain why larger adult brook trout are found downstream in our system. Since larger fish are often dominant competitors, they are likely able to monopolize thermal refuge in the mainstem where higher prey productivity is found (Bopp 2002). This would then provide greater growth potential for fish able to control thermal refugia in the highly productive mainstem. As spring temperatures increase at each site, temperatures begin to reach optimal metabolic ranges for brook trout $\left(\sim 18-19^{\circ} \mathrm{C}\right.$, Hartman and Cox 2008). Since temperatures in the mainstem are closer to this range than in the smaller tributaries, brook trout are capable of getting to larger sizes during this important growth period, assuming necessary consumption levels are reached (Utz and Hartman 2009, Xu et al. 2010, Petty et al. 2014, Chapter 4). Therefore, brook trout are able to get larger during warmer springs, especially in the mainstem. 
Another explanation for larger brook trout in larger sites during warm years is due to selection for limited microhabitat. In the Second Fork complex in Shavers Fork (Figure 3, headwater 1, large tributary 1 and 2, and mainstem 4), adult brook trout densities decreased with increasing temperature, but fish SL increased with temperature (Figure 3, especially in the larger 2 sites). This indicates that fewer brook trout use the larger Second Fork sites during warmer years (Petty et al. 2014), and the individuals using those sites are larger on average than when more brook trout are present. Ayllón et al. (2013) observed similar mechanisms distributing brown trout (Salmo trutta) within 3 Iberian rivers. They specifically found densities of large brown trout strongly influencing habitat selection by smaller size-classes, but there were no density effects of smaller size-classes on habitat selection by large fish. The reduced densities and larger mean size of fish during warm years from this study indicate that habitat selection within this watershed might be linked to pre-emptive habitat selection processes, with stream temperature being an important limiting factor.

Habitat selection by brook trout on the riverscape has been shown to be strongly influenced by temperature, which could have compounding effects on productivity. During warm years, brook trout are constricted to cool headwater tributaries (Petty et al. 2014, Chapter 4). Under this hypothesis, brook trout are susceptible to strong density-dependent mechanisms. With warmer conditions and elevated densities, instantaneous growth rates would be reduced due to negative density-dependence and elevated energetic demand in the tributaries (Utz and Hartman 2009, Petty et al. 2014). When the supplementary foraging habitat is available (mainstem), there is higher potential for elevated productivity. However, this also suggests elevated competition for limited thermal refugia during hot years, since thermal refugia is a limited resource in the mainstem (Petty et al. 2012, Huntsman and Petty 2014). Many studies have observed salmonids 
aggregating near cold-water sources when ambient stream temperatures exceed thermal tolerance ranges (Keefer et al. 2009, Young et al. 2010, Petty et al. 2012). This then suggests that there may also be negative density-dependent effects on growth for brook trout at microhabitat thermal refugia in the mainstem (Petty et al. 2014). Productivity within many complex riverscapes may be dependent on the diversity of available refuge at or near important supplementary habitat (Rypel et al. 2012). This warrants further exploration for the Shavers Fork brook trout population.

Results from this analysis suggest potentially complicated responses to climate change scenarios. At local spatial scales, increased temperature has the potential to reduce the number of brook trout able to consume mainstem forage (due to limitations in thermal refuge).

Additionally, increased temperatures could also reduce the growth potential of tributary fish because of increased densities and temperature influenced energetic demand (Petty et al. 2014). At broad spatial scales within this riverscape, an increase in temperature could cause a regional contraction of brook trout within the watershed, isolating fish within source habitat (McMahon et al. 2007, Petty et al. 2014, Chapter 4). Energetically, this could have substantial implications for brook trout productivity within this complex riverscape. In addition to the loss of large brook trout through isolating fish from high quality foraging habitat, brook trout abundance could also be reduced. Warren et al. (2012) showed that increased summer temperatures could reduce both brook trout redd counts in the fall as well as delay the timing of spawning. Not only would productivity of new recruits be reduced through limited energy availability, but early hatching could have substantial implications on survival rates of larval fish (Houde 1989). Climate change models often show loss of peripheral habitat for trout populations based on temperature extremes exceeding bioenergetic limits (Flebbe et al. 2006, Haak et al. 2010, Wenger et al. 2011a). 
Climate change could also have substantial implications for spatially distinct population dynamics. Here we have shown that factors controlling brook trout dynamics within this riverscape are dependent on both competition for microhabitat in sink habitats and complex source-sink dynamics. Morris (2003) points out that the loss of either source or sink habitat can significantly destabilize population dynamics through extinction from source losses, to magnified density fluctuations with the loss of sink spillover sites. In order to conserve such an important fishery, future direction must not only consider dynamics operating within source habitat, but also consider complex limiting factors operating within the productive sinks at the brook trout periphery.

Acknowledgements: We are grateful for the many people in the Petty lab from 2000-2011 who have contributed to making this research possible. We would also like to thank the WV Department of Natural Resources for gate access and for providing funding for this project (grant NRAC 387)

\section{Works Cited}

Amarasekare, P. 2004. The role of density-dependent dispersal in source-sink dynamics. Journal of Theoretical Biology 226:159-168.

Ayllón, D., G. G. Nicola, I. Parra, B. Elvira, and A. Almodóvar. 2013. Intercohort density dependence drives brown trout habitat selection. Acta Oecologica 46:1-9.

Bopp, J. A. 2002. Combined effects of water chemistry, canopy cover, and stream size on benthic macroinvertebrates along a Central Appalachian stream continuum. Thesis. West Virginia University, Morgantown, West Virginia, U.S.A. 
Breau, C., R.A. Cunjak, and G. Bremset. 2007. Age-specific aggregation of wild juvenile Atlantic salmon Salmo salar at cool water sources during high temperature events. Journal of Fish Biology 71:1179-1191.

Burnham, K. P., and D.R. Anderson. 2002. Model selection and inference: a practical information - theoretic approach. $2^{\text {nd }}$ edition.

Casini, M., T. Blenckner, C. Mollmann, A. Gardmark, M. Lindegren, M. Llope, G. Kornilovs, M. Plikshs, and N. C. Stenseth. 2012. Predator transitory spillover induces trophic cascades in ecological sinks. Proceedings of the National Academy of Sciences 109:8185-8189.

Charnov, E. I. 1976. Optimal foraging, the marginal value theorem. Theoretical Population Biology 9:129-136.

Differndorfer, J. E. 1998. Testing models of source-sink dynamics and balanced dispersal. Oikos 81:417-433.

Falke, J., J. Dunham, C. Jordan, K. McNyset, and G. Reeves. 2013. Spatial ecological processes and local factors predict the distribution and abundance of spawning by steelhead (Oncorhynchus mykiss) across a complex riverscape. PLoS One 8:e79232

Fausch, K.D., C.E. Torgersen, C.V. Baxter, and H.W. Li. 2002. Landscapes to riverscapes: Bridging the gap between research and conservation of stream fishes. Bioscience 52:483498.

Fausch, K. D., and R.J. White. 1981. Competition between brook trout (Salvelinus fontinalis) and brown trout (Salmo trutta) for positions in a Michigan stream. Canadian Journal of Fisheries and Aquatic Sciences 38:1220-1227. 
Flebbe, P. A., L.D. Roghair, and J.L. Bruggink. 2006. Spatial modeling to project Southern Appalachian trout distribution in a warmer climate. Transactions of the American Fisheries Society 135:1371-1382.

Fretwell, S. D., and H.L. Lucas Jr. 1970. On territorial behavior and other factors influencing habitat distribution in birds.1. Theoretical development. Acta Biotheor 1970:16-36.

Gilliam, J. F., and D.F. Fraser. 1987. Habitat selection under predation hazard: test of a model with foraging minnows. Ecology 68:1856-1862.

Gowan, C., and K.D. Fausch. 2002. Why do foraging stream salmonids move during summer? Environmental Biology of Fishes 64:139-153.

Grossman, G. D., R. E. Ratajczak, J.T. Petty, M.D. Hunter, J.T. Peterson, and G. Grenouillet. 2006. Population dynamics of mottled suclpin (Pisces) in a variable environment: information theoretic approaches. Ecological Monographs 76:217-234.

Grossman, G. D., R. E. Ratajczak, C. M. Wagner, and J. T. Petty. 2010. Dynamics and regulation of the southern brook trout (Salvelinus fontinalis) population in an Appalachian stream. Freshwater Biology 55:1494-1508.

Guo, Q., M. Taper, M. Schoenberger, and J. Brandle. 2005. Spatial-temporal population dynamcis across species range: from centre to margin. Oikos 108:47-57.

Haak, A. L., J.E. Williams, H.M. Neville, D.C. Dauwalter, and W.T. Colyer. 2010. Conserving peripheral trout populations: the values and risks of life on the edge. Fisheries 35:530549.

Hansbarger, J. L., J.T. Petty, and P.M. Mazik. 2008. Microhabitat use by brook trout inhabiting small tributaries and a large river mainstem: implications for stream habitat restoration in 
the Central Appalachians. Proceeding of the Annual Conference of the Southeastern Association of Fish and Wildlife Agencies 62:142-148.

Hanski, I. 1998. Metapopulation dynamics. Nature 396:41-49.

Hartman, K. J., and J. A. Cox. 2008. Refinement and testing of a brook trout bioenergetics model. Transactions of the American Fisheries Society 55:38-51.

Hense, Z., R.W. Martin, and J.T. Petty. 2010. Electrofishing capture efficiencies for common stream fish species to support watershed-scale studies in the central Appalachians. North American Journal of Fisheries Management 30:1041-1050.

Houde, E.D. 1987. Comparative growth, mortality, and energetics of marine fish larvae: temperature and latitudinal effects. Fishery Bulletin 87:471-495.

Hughes, N. F. 1998. A model of habitat selection by drift-feeding stream salmonids at different scales. Ecology 79:281-294.

Huntsman, B.M., and J.T. Petty. 2014. Density-dependent and density-independent mechanisms regulating brook trout population dynamics along a core-periphery distribution gradient. PLoS ONE 9:e91673. doi:10.1371/journal.pone.0091673.

Jonzen, N., J.R. Rhodes, and H.P. Possingham. 2005. Trend detection in source-sink systems: When should sink habitats be monitored? Ecological Applications 15:326-334.

Keefer, M. L., C.A. Peery, and B. High. 2009. Behavioral thermoregulation and associated mortality trade-offs in migrating adult steelhead (Oncorhynchus mykiss): variability among sympatric populations. Canadian Journal of Fisheries and Aquatic Sciences 66:1734-1747.

Levins, R. 1969. Some demographic and genetic consequences of environmental heterogeneity for biological control. Entomological Society of America 15:237-240. 
Limm, M.P., and M.P. Marchetti. 2009. Juvenile Chinook salmon (Oncorhynchus tshawytscha) growth in off-channel and main-channel habitats on the Sacramento River, CA using otolith increment widths. Environmental Biology of Fishes 85:141-151.

Lobon-Cervia, J. 2009. Why, when and how do fish populations decline, collapse and recover? The example of brown trout (Salmo trutta) in Rio Chaballos (northwestern Spain). Freshwater Biology 54:1149-1162.

McMahon, T.E., A.V. Zale, F.T. Barrows, J.H. Selong, and R.J. Danehy. 2007. Temperature and competition between bull trout and brook trout: a test of the elevation refuge hypothesis. Transactions of the American Fisheries Society 136:1313-1326.

Morris, D.W. 2003. Toward an ecological synthesis: a case for habitat selection. Oecologia 136:1-13.

Olsson, I. C., L.A. Greenberg, E. Bergman, and K. Wysujack. 2006. Environmentally induced migration: the importance of food. Ecology Letters 9:645-651.

Persson, A., and M. Stenberg. 2006. Linking patch-use behavior, resource density, and growth expectations in fish. Ecology 87:1953-1959.

Petty, J. T., P. J. Lamothe, and P. M. Mazik. 2005. Spatial and seasonal dynamics of brook trout populations inhabiting a central Appalachian watershed. Transactions of the American Fisheries Society 134:572-587.

Petty, J. T., and G.D. Grossman. 2010. Giving-up densities and ideal pre-emptive patch use in a predatory benthic stream fish. Freshwater Biology 55:780-793.

Petty, J. T., J.L. Hansbarger, B.M. Huntsman, and P.M. Mazik. 2012. Brook trout movement in response to temperature, flow, and thermal refugia within a complex Appalachian riverscape. Transactions of the American Fisheries Society 141:1060-1073. 
Petty, J.T., and E.P. Merriam. 2012. Brook trout restoration. Nature Education Knowledge 3:17.

Petty, J.T., D. Thorne, B.M. Huntsman, and P.M. Mazik. 2014. Effects of density and temperature regime on brook trout growth and consumption within a complex Appalachian riverscape. Hydrobiologia 727:151-166.

Pope, S.E., L. Fahrig, and H.G. Merriam. Landscape complementation and metapopulation effects on leopard frog populations. Ecology 81:2498-2508.

Pulliam, H. R. 1988. Sources, sinks, and population regulation. The American Naturalist 132:652-661.

Rypel, A. L., K. M. Pounds, and R. H. Findlay. 2012. Spatial and temporal trade-offs by bluegills in floodplain river ecosystems. Ecosystems 15:555-563.

Schlosser, I.J. 1995. Critical landscape attributes that influence fish population dynamics in headwater streams. Hydrobiologia 303:71-81.

Schlosser, I.J. 1998. Fish recruitment, dispersal, and trophic interactions in a heterogeneous lotic environment. Oecologia 113:260-268.

Stolarski, J. T., and K.J. Hartman. 2010. Comparisons of growth and condition of fluvial and resident brook trout within partially migratory populations. Fisheries Management and Ecology 17:33-39.

Sundt-Hansen, L., L. Neregard, S. Elnum, J. Hojesjo, B.T. Bhornsson, K. Hindar, F. Okland, and J.I. Johnsson. 2009. Growth enhanced brown trout show increased movement activity in the wild. Functional Ecology 23:551-558.

Thomas, C. D., and W.E. Kunin. 1999. The spatial structure of populations. Journal of Animal Ecology 57:536-546. 
Tincher, M. 2013. Modeling water temperatures and brook trout (Salvelinus fontinalis) growth potential within a complex Appalachian riverscape. Thesis. West Virginia University, Morgantown, West Virginia, U.S.A.

Utz, R. M., and K. J. Hartman. 2009. Density-dependent individual growth and size dynamics of central Appalachian brook trout (Salvelinus fontinalis). Canadian Journal of Fisheries and Aquatic Sciences 66:1072-1080.

van Beest, F.M., A. Uzal, E. Vander Wal, M.P. Laforge, A.L. Contasti, D. Colville, and P.D. McLoughlin. 2014. Increasing density leads to generalization in both coarse-grained habitat selection and fine-grained resource selection in a large mammal. Journal of Animal Ecology 83:147-156.

Van Buskirk, J. 2005. Local and landscape influence on amphibian occurrence and abundance. Ecology 86:1936-1947.

van de Pol, M., Y. Vindenes, B. Saether, S. Engen, B.J. Ens, K. Oosterbeek, and J.M. Tinbergen. 2010. Effects of climate change and variability on population dynamics in a long-lived shorebird. Ecology 91:1192-1204.

van Heezik, Y., and K. Ladwig. 2012. Proximity to source populations and untidy gardens predict occurrence of a small lizard in an urban area. Landscape and Urban Planning 104:253-259.

Warren, D. R., J.M. Robinson, D.C. Josephson, D.R. Sheldon, and C.E. Kraft. 2012. Elevated summer temperatures delay spawning reduce redd construction for resident brook trout (Salvelinus fontinalis). Global Change Biology 18:1804-1811.

Wenger, S. J., D.J. Isaak, J.B. Dunham, K.D. Fausch, C.H. Luce, H.M. Neville, B.E. Rieman, M.K. Young, D.E. Nagel, D.L. Horan, and G.L. Chandler. $2011^{\mathrm{a}}$. Role of climate and 
invasive species in structuring trout distributions in the interior Columbia River Basin, USA. Canadian Journal of Fisheries and Aquatic Sciences 68:988-1008.

Wenger, S. J., D.J. Isaak, C.H. Luce, H.M. Neville, K.D. Fausch, J.B. Dunham, D.C. Dauwalter, M.K. Young, M.M. Elsner, B.E. Rieman, A.F. Hamlet, and J.E. Williams. 2011 ${ }^{\text {b Flow }}$ regime, temperature, and biotic interactions drive differential declines of trout species under climate change. PNAS 108:14175-14180.

Werner, E.E., and D.J. Hall. 1988. Ontogenetic habitat shifts in bluegill: the foraging ratepredation risk trade-off. Ecology 69:1352-1366.

Woodford, D. J., and A.R. McIntosh. 2010. Evidence of source-sink metapopulations in a vulnerable native galaxiid fish driven by introduced trout. Ecological Applications 20:967-977.

Xu, C., B.H. Letcher, and K.H. Nislow. 2010. Context-specific influence of water temperature on brook trout growth rates in the field. Freshwater Biology 55:2253-2264.

Young, R. G., J. Wilkinson, J. Hay, and J. W. Hayes. 2010. Movement and mortality of adult brown trout in the Motupiko River, New Zealand: Effects of water temperature, flow, and flooding. Transactions of the American Fisheries Society 139:137-146. 


\section{Tables:}

Table 1: Site description of each reach in this study. Mean spring temperature was taken between April-June from 2002 to 2011.

Mean young-of-the-year (YOY), small adult (S.A.), and large adult (L.A.) densities were also taken from 2002 to 2011 . All standard errors are reported in parentheses.

\begin{tabular}{|c|c|c|c|c|c|c|c|}
\hline & \multirow{2}{*}{$\begin{array}{c}\text { Headwater } \\
1\end{array}$} & \multicolumn{2}{|c|}{ Large Tributary } & \multicolumn{4}{|c|}{ Mainstem } \\
\hline & & 1 & 2 & 1 & 2 & 3 & 4 \\
\hline Stream length $(\mathrm{m})$ & 150 & 306 & 315 & 944 & 863 & 919 & 1007 \\
\hline Drainage area $\left(\mathrm{km}^{2}\right)$ & 1.3 & 10.4 & 15.4 & 27.9 & 30.3 & 41.1 & 59.8 \\
\hline Mean spring temperature $\left({ }^{\circ} \mathrm{C}\right)$ & $9.22(0.15)$ & $8.94(0.17)$ & $9.68(0.17)$ & $12.14(0.21)$ & $12.48(0.22)$ & $12.46(0.22)$ & $12.20(0.22)$ \\
\hline YOY density (\#/m) & $0.077(0.023)$ & $0.030(0.023)$ & $0.008(0.004)$ & $0.003(0.002)$ & $0.003(0.002)$ & $0.001(0.001)$ & $0.001(0.000)$ \\
\hline S.A. density $(\# / m)$ & $0.154(0.029)$ & $0.039(0.011)$ & $0.034(0.008)$ & $0.007(0.003)$ & $0.004(0.002)$ & $0.004(0.001)$ & $0.001(0.001)$ \\
\hline L.A. density (\#/m) & $0.103(0.010)$ & $0.063(0.014)$ & $0.039(0.005)$ & $0.013(0.003)$ & $0.007(0.002)$ & $0.017(0.003)$ & $0.004(0.001)$ \\
\hline Mean adult SL (mm) & $96.5(1.7)$ & $114.3(2.5)$ & $117.4(5.6)$ & $133.2(7.1)$ & $133.3(10.3)$ & $148.3(7.0)$ & $128.3(16.1)$ \\
\hline
\end{tabular}


Table 2: Results from model selection using $\mathrm{AIC}_{\mathrm{c}}$ on adult densities (dadult) and adult standard lengths (SL). Values are $\mathrm{AIC} \mathrm{c}_{\mathrm{c}}$ weights ( $\left.w_{i}\right)$ with the $R^{2}$ value for the regression and direction of the relationship (Dir). Justification for each predictor variable (Pred. Var.) follows rationale outlined in Huntsman and Petty (2014). Density of young-of-the-year (dyoy), mean summer maximum temperature (suT), mean April-June maximum temperature (spT), mean March-June discharge (spQ), and brook trout densities in the source (dsource) are the predictor variables used for dadult analysis, where the total brook trout density (dtrout) was substituted for dyoy in the candidate set of models for SL. No source model was developed for headwater 1 site because values used for source models are based on densities found in headwater 1 . The best model at each site is presented in bold text, while all interpretable models are presented with an “*”. Missing values indicate that predictor variable was removed due to significant correlation with other variables in the candidate set.

\begin{tabular}{|c|c|c|c|c|c|c|c|c|c|c|c|c|c|c|c|c|c|c|c|c|c|c|}
\hline \multirow{3}{*}{$\begin{array}{l}\text { Resp. } \\
\text { Var. }\end{array}$} & \multirow{3}{*}{$\begin{array}{l}\text { Pred. } \\
\text { Var. }\end{array}$} & \multirow{2}{*}{\multicolumn{3}{|c|}{$\begin{array}{c}\text { Headwater } \\
1 \\
\end{array}$}} & \multicolumn{6}{|c|}{ Large Tributary } & \multicolumn{12}{|c|}{ Mainstem } \\
\hline & & & & & \multicolumn{3}{|c|}{1} & \multicolumn{3}{|c|}{2} & \multicolumn{3}{|c|}{1} & \multicolumn{3}{|c|}{2} & \multicolumn{3}{|c|}{3} & \multicolumn{3}{|c|}{4} \\
\hline & & $w_{i}$ & $R^{2}$ & Dir & $w_{i}$ & $R^{2}$ & Dir & $w_{i}$ & $R^{2}$ & Dir & $w_{i}$ & $R^{2}$ & Dir & $w_{i}$ & $R^{2}$ & Dir & $w_{i}$ & $R^{2}$ & Dir & $w_{i}$ & $R^{2}$ & Dir \\
\hline \multicolumn{23}{|l|}{ dadult } \\
\hline & dyoy $_{t-1}$ & & & & $0.162^{*}$ & 0.08 & + & 0.027 & 0.07 & - & & & & & & & $0.338 *$ & 0.27 & + & $0.070^{*}$ & 0.00 & + \\
\hline & $\mathrm{su}_{\mathrm{t}-1} \mathrm{~T}$ & & & & $0.190 *$ & 0.11 & - & 0.047 & 0.18 & + & $0.081^{*}$ & 0.00 & - & 0.051 & 0.02 & + & $0.083^{*}$ & 0.00 & + & $0.081^{*}$ & 0.03 & + \\
\hline & $\mathrm{sp}_{\mathrm{t}} \mathrm{Q}$ & & & & & & & 0.021 & 0.01 & + & $0.120^{*}$ & 0.09 & - & $0.084 *$ & 0.13 & - & $0.136^{*}$ & 0.10 & - & $0.080^{*}$ & 0.03 & + \\
\hline & $\mathrm{sp}_{\mathrm{t}} \mathrm{T}+\mathrm{sp}_{\mathrm{t}} \mathrm{Q}$ & & & & & & & $0.088^{*}$ & 0.68 & $-/+$ & 0.006 & 0.20 & $+/-$ & 0.002 & 0.14 & $-/-$ & 0.004 & 0.12 & $+/-$ & 0.026 & 0.44 & $-/+$ \\
\hline & $\mathrm{su}_{\mathrm{t}-1} \mathrm{~T}+$ dyoy $_{\mathrm{t}-1}$ & & & & 0.010 & 0.23 & $-/+$ & $0.098^{*}$ & 0.69 & $+/-$ & & & & & & & 0.009 & 0.27 & $+/+$ & 0.002 & 0.04 & $+/+$ \\
\hline & $\mathrm{sp}_{\mathrm{t}} \mathrm{T}+$ dyoy $_{\mathrm{t}-1}$ & & & & 0.006 & 0.14 & $+/+$ & 0.021 & 0.56 & $-/+$ & & & & & & & 0.013 & 0.32 & $+/+$ & 0.019 & 0.40 & $-/-$ \\
\hline & $\mathrm{sp}_{\mathrm{t}} \mathrm{Q}+$ dyoy $_{\mathrm{t}-1}$ & & & & & & & 0.001 & 0.07 & $+/-$ & & & & & & & 0.009 & 0.27 & $+/+$ & 0.002 & 0.04 & $+/+$ \\
\hline
\end{tabular}




\begin{tabular}{|c|c|c|c|c|c|c|c|c|c|c|c|c|c|c|c|c|c|c|c|c|c|}
\hline Global & & & & 0.000 & 0.51 & & 0.000 & 0.88 & & 0.000 & 0.66 & & 0.000 & 0.57 & & 0.000 & 0.43 & & 0.000 & 0.52 & \\
\hline dtrout $_{t}$ & $0.630 *$ & 0.34 & - & $0.065^{*}$ & 0.03 & + & $0.826^{*}$ & 0.58 & - & $0.176^{*}$ & 0.24 & - & 0.003 & 0.17 & + & $0.176^{*}$ & 0.08 & - & $0.245^{*}$ & 0.40 & - \\
\hline $\mathrm{sp}_{\mathrm{t}} \mathrm{T}$ & $0.124 *$ & 0.09 & + & $0.525^{*}$ & 0.36 & + & 0.049 & 0.26 & + & $0.559 *$ & 0.39 & + & $0.884 *$ & 0.73 & + & $0.625^{*}$ & 0.29 & + & $0.658^{*}$ & 0.51 & + \\
\hline $\mathrm{sp}_{t} \mathrm{Q}$ & $0.141^{*}$ & 0.11 & - & $0.116^{*}$ & 0.13 & + & 0.013 & 0.03 & - & 0.051 & 0.02 & + & 0.001 & 0.00 & + & $0.115^{*}$ & 0.00 & - & 0.026 & 0.01 & + \\
\hline $\mathrm{sp}_{\mathrm{t}} \mathrm{T}+\mathrm{sp}_{\mathrm{t}} \mathrm{Q}$ & 0.021 & 0.29 & $+/-$ & 0.036 & 0.40 & $+/+$ & 0.006 & 0.38 & $+/-$ & 0.032 & 0.41 & $+/+$ & 0.048 & 0.73 & +/+ & 0.031 & 0.29 & $+/-$ & 0.021 & 0.53 & +/+ \\
\hline $\mathrm{sp}_{\mathrm{t}} \mathrm{T}+\mathrm{dtrout}_{\mathrm{t}}$ & 0.039 & 0.37 & $+/-$ & $0.246^{*}$ & 0.59 & $+/+$ & 0.053 & 0.60 & $-/-$ & $0.171^{*}$ & 0.58 & $+/-$ & 0.063 & 0.75 & $+/-$ & 0.043 & 0.33 & $+/-$ & 0.043 & 0.60 & $+/-$ \\
\hline $\mathrm{sp}_{\mathrm{t}} \mathrm{Q}+\mathrm{dtrout}_{\mathrm{t}}$ & 0.045 & 0.39 & $-/-$ & 0.008 & 0.18 & $+/+$ & 0.053 & 0.60 & $-/-$ & 0.009 & 0.24 & $+/-$ & 0.000 & 0.17 & $-/-$ & 0.009 & 0.09 & $+/-$ & 0.007 & 0.40 & $+/-$ \\
\hline Global & 0.001 & 0.46 & & 0.005 & 0.63 & & 0.001 & 0.61 & & 0.002 & 0.58 & & 0.001 & 0.75 & & 0.000 & 0.34 & & 0.000 & 0.61 & \\
\hline
\end{tabular}




\section{Figure Legends:}

Figure 1: Location of the 7 study sites within the upper Shavers Fork watershed in Pocahontas and Randolph counties, WV.

Figure 2: Best regression models for adult brook trout densities in 4 study sites. Total density of brook trout in the source represents the density of brook trout the previous year in headwater 1.

Figure 3: Adult brook trout standard lengths (SL) as a function of spring stream temperatures within the Second Fork complex in the Shavers Fork watershed. 


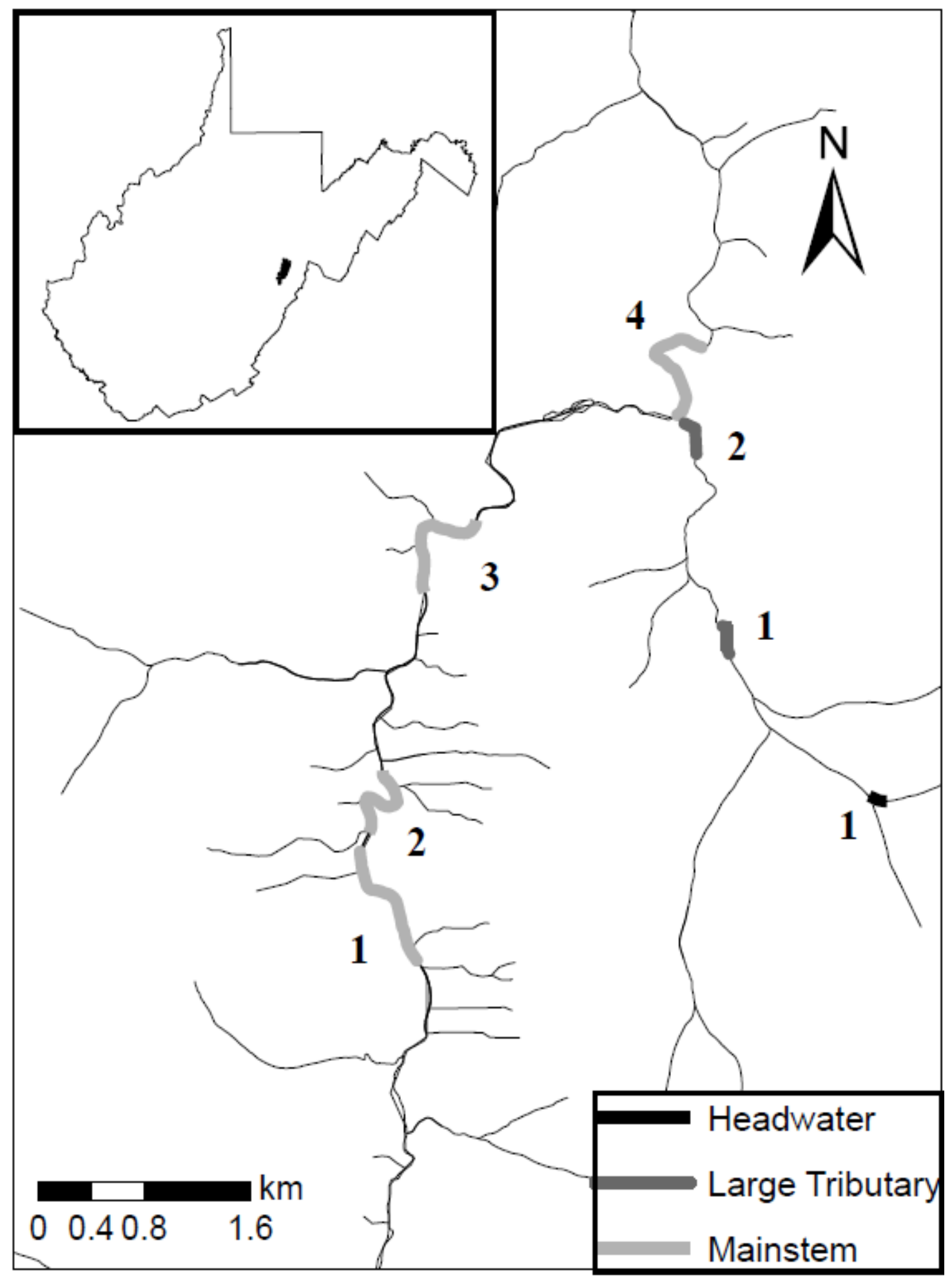

Figure 1: 

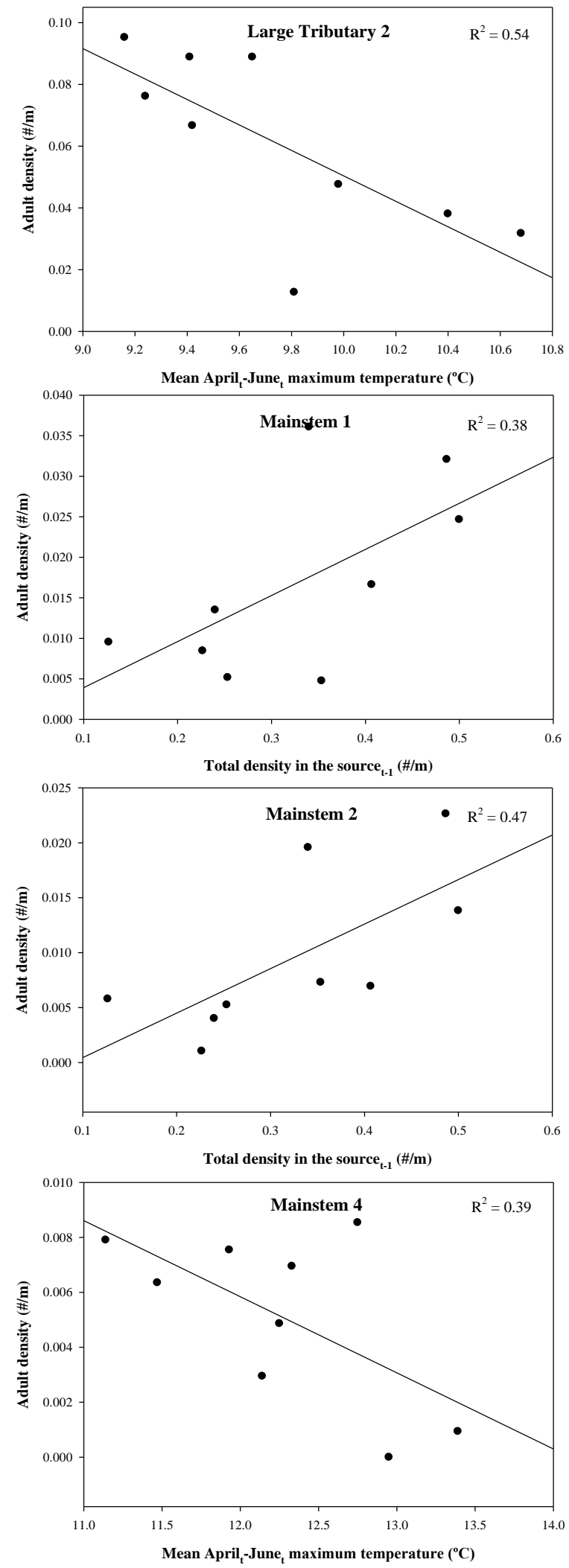

Figure 2 

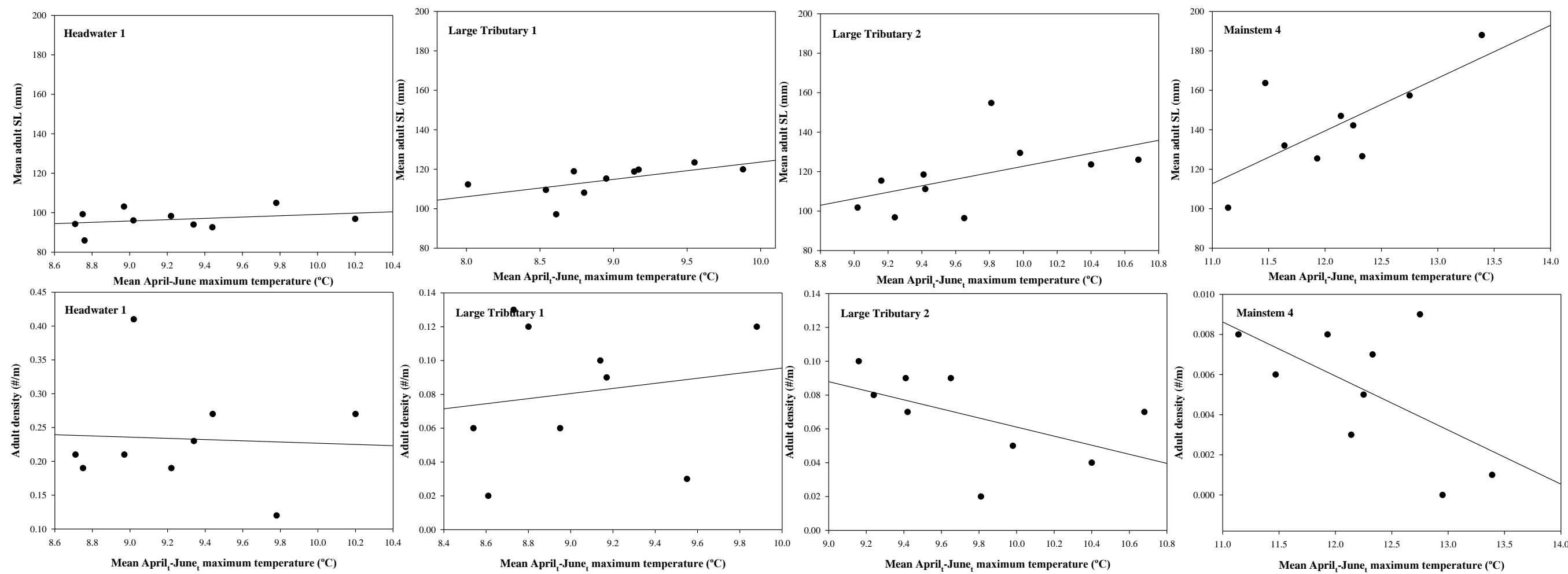

\section{Figure 3}


Chapter 3: Brook trout population dynamics within a complex riverscape: Identifying the relative strength of sources and sinks

Brock M. Huntsman ${ }^{1 *}$, Zachary W. Liller ${ }^{1,2}$, J. Todd Petty $^{1}$, and Roy W. Martin ${ }^{3}$

${ }^{1}$ Division of Forestry and Natural Resources, West Virginia University, Morgantown, WV 26506, U.S.A.

${ }^{2}$ Alaska Department of Fish and Game, Anchorage, AK 99518, U.S.A

${ }^{3}$ USEPA Office of Research and Development, Cincinnati, OH 45268 U.S.A.

*Corresponding author: brockhunts@gmail.com 


\begin{abstract}
:
Source-sink models are spatial models that account for differences in habitat quality and demographic heterogeneity among habitat patches on the landscape. These models are not only applicable to landscapes, but also riverscapes when considering mobile aquatic populations. Here we utilized source-sink modeling techniques to identify the relative strength of different habitat patches (sites) as sources and sinks for a brook trout population within a high elevation watershed in West Virginia. We used reverse-time mark-recapture techniques to identify the importance of local versus regional contributions to local adult population growth. We estimated the contribution of each site to the regional metapopulation for a range of emigration scenarios. Lastly, we combined estimates from both approaches to rank the relative strength of individual sites as sources within the watershed. We found that larger sites demonstrated a substantial amount of adult population growth contributed by immigration (> 80\%), while less than $25 \%$ was observed at any small headwater site. The larger sites were also identified as providing fewer individuals to the entire metapopulation relative to the majority of the small headwater sites. When both approaches were combined, the highest ranking sources were headwater tributaries that not only demonstrated large contributions to the region, but often consisted of the highest local densities of brook trout among all sites. By quantifying and characterizing sites in such a manner, our results provide a foundation and metapopulation context from which informed prioritization and conservation strategies can be implemented.
\end{abstract}

\title{
Introduction:
}

With increasing recognition of the importance of metapopulation dynamics to the conservation of different species (Kanda et al. 2009, Woodford and McIntosh 2010, Sanderlin et 
al. 2012, Falke et al. 2013), numerous population models have been developed that consider dynamics of spatially structured populations (Levins 1969, Fretwell and Lucas 1970, Pulliam 1988, Hanski 1998, Guo et al. 2005). Some of the first spatial population models demonstrated significant linkages between subpopulations within the landscape, illustrating the importance of concepts such as rescue effects (Levins 1969, Hanski 1998). However, early models (e.g. idealfree distributions) did not consider variability in habitat quality, which can strongly affect population success within individual habitats as well as on the landscape (Dias 1996, Nystrand et al. 2010).

One spatially structured population model that considers heterogeneity in habitat patches is the source-sink model (Pulliam 1988, Dias 1996). By definition, a source should have higher birth and emigration rates than death and immigration rates (Pulliam 1988). Source populations should be major contributors to the entire metapopulation (Runge et al. 2006), and be regulated by internal processes (e.g. local survival and recruitment, Nichols et al. 2000). Sink habitats should, on the other hand, support subpopulations that demonstrate the opposite in demographic rates (Pulliam 1988), where metapopulation contributions from these habitats should be reduced and show stronger support by regional mechanisms (e.g. immigration). Lastly, pseudo-sinks are an intermediate, where the habitat patch is often defined as a sink, but stochastic variability within the habitat may allow for rates to deviate away from a sink classification (Thomas and Kunin 1999). Such variability in demographic rates is not limited to pseudo-sink habitats, since heterogeneity in demographic rates can also occur among different subpopulations within a metapopulation (Thomas and Kunin 1999, Johnson 2004).

Thomas and Kunin (1999) stress that source-sink models should not be conceptualized as discrete classification units. Specifically, they emphasize-classifying population units along a 
demographic continuum (i.e. compensation axis). The compensation axis is based on densitydependent regulation, where at equilibrium $(\lambda=1)$ demographic loses (i.e. death and emigration) should be compensated for by demographic gains (i.e. birth and immigration), forcing population units to lie along the compensation axis (Figure 1). However, not all populations demonstrate strong density-dependence and therefore might not lie tightly along this line, or at the same location on this line. Because of this, some sources may be stronger than others, and some sinks may be weaker than others when referring to contributions to the entire metapopulation. When trying to conserve a spatially structured population, it would then be advantageous to not only identify the sources and sinks within a metapopulation, but may be just as important to identify which of the sources provide the greatest contribution to the entire metapopulation.

Numerous approaches have been used to identify the extent to which a subpopulation can be classified as a source or sink; however, many of these approaches are limited in applicability (Dias 1996, Runge et al. 2006). It is well known that source-sink application lags far behind theory, due to complexities in obtaining estimates of necessary demographic rates (i.e. birth, immigration, death, emigration, Diffendorfer 1998, Runge et al. 2006). One approach proposed by Nichols et al. (2000) uses a novel mark-recapture approach for multistate data to identify the importance of local vs. regional contributions to finite population growth. Based on whether local population growth has stronger support by local dynamics (population growth is sustained by survival and recruitment) or regional dynamics (immigration), it can be characterized as a source (local control) or a sink (regional control). For example, a source is expected to sustain itself in the absence of regional inputs (local control), while a sink is expected go extinct in the absence of regional support. A complementing approach introduced by Runge et al. (2006) proposes a metapopulation contribution metric $\left(C^{n}\right)$ based on an estimation of the number of 
emigrants from a local population. Therefore, though the approach of Nichols et al. (2000) focuses on demographic contributions to local population growth, $C^{n}$ focuses on the contribution of the local population to the surrounding metapopulation. Recent studies have begun to apply this approach to identify sources and sinks within landscapes due to its theoretical strength (Griffin and Mills 2009, Lampila et al. 2009, Newby et al. 2013). Additionally, both Nichols' et al. (2000) and Runge's et al. (2006) approaches can be combined to evaluate source-sink dynamics when all potential subpopulations have been sampled within a metapopulation (Sanderlin et al. 2012). Both approaches provide important details about source-sink dynamics, and their application can provide valuable information about subpopulations within a metapopulation.

Brook trout (Salvelinus fontinalis) are a mobile fish species native to the Eastern United States that likely demonstrates source-sink structuring. This species has been shown to move large distances in watersheds (greater than $6 \mathrm{~km}$, Petty et al. 2012), which likely exposes them to multiple habitat patches within a riverscape (Fausch et al. 2002). Brook trout reproduction is known to occur primarily within smaller tributaries $\left(<5 \mathrm{~km}^{2}\right.$ in drainage area, Petty et al. 2005), though larger mainstem habitats also complement their life history as productive sources of forage during cooler months/years (Petty et al. 2014). In larger streams considered at the periphery of brook trout distributions (Huntsman and Petty 2014), regional inputs (i.e. immigrants) have been shown to primarily support population growth, as opposed to local dynamics (i.e. survival and recruitment, Martin 2010). On the other hand, local dynamics such as birth rates are the major factor controlling brook trout population growth in small, source tributaries (Petty et al. 2005, Martin 2010). Therefore, it is highly likely that brook trout 
demonstrate source-sink dynamics within watersheds. However, it is equally likely that some habitats are stronger sources than others within brook trout home ranges.

Applying concepts such as Thomas and Kunin's (1999) “Compensation Axis” to subpopulations seems more appropriate to identifying important habitats compared to using discrete source-sink classification. When management decisions require preserving and/or especially restoring a metapopulation, identifying the strongest subpopulations contributing towards the entire metapopulation would be invaluable for identifying priority sites. In this manuscript, we use both Nichols' (2000) reverse-time approach and Runge et al.'s (2006) contribution metric approach to apply a more continuous classification scheme to a population that demonstrates source-sink structuring. In particular, our goal was to identify the relative strength of different brook trout subpopulations within Shavers Fork to the broader watershed. Specifically, our objectives for this study were to: 1) identify whether local or regional mechanisms show stronger contribution to population growth among tributaries and larger mainstem sites, 2) identify which streams contribute the greatest numbers of individuals to the entire watershed, and 3) combine both approaches in a continuous ranking scheme for classifying subpopulations within the watershed.

\section{Methods:}

Study Area:

The upper Shavers Fork is a high elevation $(>1100 \mathrm{~m})$ watershed located in the central Appalachian Mountains of eastern West Virginia. We selected 13 stream segments within this watershed for this study (Figure 2), consisting of 4 large mainstem sites (drainage area $>25 \mathrm{~km}^{2}$ ), 1 large tributary (drainage area $\sim 15 \mathrm{~km}^{2}$ ), and 8 headwater tributaries (drainage area $<3 \mathrm{~km}^{2}$ ). 
Previous research within this watershed suggests that sites greater than $15 \mathrm{~km}^{2}$ lack spawning activity by brook trout, and by definition, are likely sink habitats because death rates must exceed birth rates (Petty et al. 2005). Due to the limited number of recaptures in mainstem sites and the lack spawning activity, we combined all mainstem sites into a single large sink habitat in order to have sufficient data for mark-recapture analysis. Detailed habitat characteristics for each site can be found in Table 1.

\section{Brook Trout Sampling:}

Brook trout populations were sampled seasonally from each study location starting in the spring of 2004 until the spring of 2005. Spring samples were collected in early June, summer samples in August, and fall samples in October. In each of the 8 headwater tributary sites, brook trout were collected by 3-person teams using single pass procedures with backpack electrofishing units (Smith-Root, DC, 60 hz, 400-600V) and a combination of dip and seine nets. Each headwater site was continuously sampled each season, starting at its confluence with the mainstem moving upstream until no brook trout were collected after sampling for 300m from the last point of capture or the stream's origin was reached (Angermeier and Karr 1986, Yoder and Smith 1999). The 4 mainstem and 1 large tributary sites were sampled with 3 to 6-person teams at a fixed length, 40 times mean stream width (Yoder and Smith 1999, Freund and Petty 2007).

All brook trout captured were measured to standard length (SL, $\pm 1 \mathrm{~mm})$ and weighed ( \pm $0.1 \mathrm{~g}$ ). Trout that were greater than $60 \mathrm{~mm}$ SL were then given an elastomer dye tag (Northwest Marine Technology), consisting of a unique combination of 3-6 dye sequences in the caudal fin rays as described by Petty et al. (2005). Fish were also given a unique spatial batch mark, to identify marking origins. Each brook trout was then separated into 3 different size-classes based 
on length-frequency distributions found in Petty et al. (2005). A young-of-the-year (YOY) sizeclass was considered any brook trout less than $60 \mathrm{~mm} \mathrm{SL}$, and was a true representation of age (Petty et al. 2005). However, YOY trout were too small to be given a unique tag and were not used in mark-recapture analysis (see following sections). The small adult size-class was considered any fish between 60 and 100mm SL when first captured in the spring, or from 75$115 \mathrm{~mm}$ SL when first captured in the summer or fall. Although fish in the smaller fraction of this size-class do not likely reproduce (see Hutchings 1994 for different size at maturity estimates of brook trout), we classified them as small adults here based on length frequency histograms (Petty et al. 2005). Trout greater than $100 \mathrm{~mm}$ SL in the spring and greater than $115 \mathrm{~mm}$ SL in the summer and fall were then classified as large adults.

\section{Local vs. Regional Contributions to Population Growth:}

We used reverse-time multistate mark-recapture analysis as outlined by Nichols et al. (2000) to identify the relative importance of local versus regional contributions to population growth. We focused on the large adult size-class for this analysis, because the large adult fraction of the population is generally known to be more mobile (Gowan and Fausch 1996, Petty et al. 2005, Petty et al. 2012). We estimated the finite rate of population growth of the large adult sizeclass $\left(\lambda_{\text {Large }}\right)$ as the change in large adult abundance from the spring of 2004 to the spring of 2005 $\left(\mathrm{N}_{\mathrm{sp} 2005} / \mathrm{N}_{\mathrm{sp} 2004}\right)$. Due to the limited number of fish found moving between sampling locations in this study (see Table 2), only 2 potential states were modeled in our multistate modeling approach (small adult or large adults). By analyzing the large adult component of this multistate data in reverse-time, we estimated the contributing components for the large adult size-class based on their probabilities of being in 1 of 3 different potential states the previous time step 
(large adult, small adult, or immigrant; Nichols et al. 2000). A site that is likely a source was expected to be characterized by a stronger local contribution to population growth through local large adult survival $\left(\gamma_{L L}\right)$ and recruitment $\left(\gamma_{L S}\right)$; rather than immigration $\left(1-\gamma_{L L^{-}} \gamma_{L S}\right)$.

In order to obtain these estimates, we used program MSURGE (Choquet et al. 2006). MSURGE unlike program MARK allows for estimates of combined "survival and movement" parameters, which is required to estimate immigration (Nichols et al. 2000). Because we did not have information on capture probability for these sites for this particular study, we fixed capture probabilities at 0.72 based on previous studies from the watershed (Hense et al. 2010, Huntsman and Petty 2014). Hense et al. (2010) found capture probability to vary by stream width, gradient, specific conductance, and age (young-of-the-year versus large adult). However, the streams in this study represent a narrow range of gradients and widths close to the mean value reported in Hense et al. (2010). We developed 4 models with reduced complexity due to our limited sample size (Table 3). Each model had site as a factor influencing parameter estimates, where season was either included as an additive effect or constant. Since stream slope has been shown to influence mobility in brook trout (Adams et al. 2000), we grouped sites in one model based on the slope of the stream to account for immigration estimates. Adams et al. (2000) used a 6\% slope to classify a stream as steeply sloped or not. Additionally, they observed brook trout within one of their sampling sites unable to completely transcend a slope greater than $10 \%$ (although other sampled streams in the same study found brook trout transcending subsections with slopes greater than 10\%). Therefore, our study sites with a slope less than $6 \%$ were grouped together, sites with slope from 6-10\% were grouped together, and sites with slope greater than $10 \%$ were the final grouping (Table 1). A final model was created that grouped parameter estimates based on two time intervals (spring-fall and fall-spring) since size transitions mostly occurred during 
the fall-spring interval (see Contribution metric below). Akaike's information criterion corrected for small sample size $\left(\mathrm{AIC}_{\mathrm{c}}\right)$ was used to identify the best supported model in our candidate set (Burnham and Anderson 2002). Parameters from the best model were then used to estimate the local versus regional contributions to the finite rate of large adult population growth. A bootstrapping technique was used to estimate error terms for immigration estimates $\left(1-\gamma_{L L^{-}} \gamma_{L S}\right)$ (Efron and Tibshirani 1993). This technique randomly samples 1000 times from within the bounds of the $95 \%$ confidence intervals for each parameter. These 1000 estimates were then combined to receive 1000 estimates of immigration. From these 1000 estimates of immigration, $95 \%$ confidence intervals were estimated.

\section{Contribution Metric:}

The contribution metric $\left(C^{n}\right)$ proposed by Runge et al. (2006) estimates the per capita contribution of individuals from a subpopulation to the entire metapopulation. The following equation defines the demographic parameters necessary to estimate $C^{n}$ :

$$
C^{n}=\varphi_{L}^{n n}+\sum_{m \neq n} \varphi_{L}^{n m}+\beta^{n}\left(\varphi_{S}^{n n}+\sum_{m \neq n} \varphi_{S}^{n m}\right)
$$

where $\varphi_{L}^{n n}=$ apparent survival of large adults within patch $n, \varphi_{L}^{n m}=$ large adult emigration rate to patch $m$ from patch $n, \beta^{n}=$ per capita recruitment, $\varphi_{S}^{n n}=$ apparent survival of small adults, and $\varphi_{S}^{n m}=$ small adult emigration rate to patch $m$ from patch $n$. Using this criteria, a subpopulation is then defined as a source where $C^{n}>1$ and a sink subsequently would maintain a $C^{n}<1$. When all potential subpopulations within a metapopulation have been sampled, it is possible to use reverse time capture-mark-recapture (CMR) techniques in order to estimate all 
the parameters necessary to estimate $C^{n}$ (Sanderlin et al. 2012). However, all potential subpopulations within this watershed were not sampled in this study, requiring alternative approaches to estimate the necessary parameters.

In order to estimate apparent survival of both small adult and large adult size-classes, we used CMR methodologies for open populations (Lebreton et al. 1992) in program MARK. We specifically used the multistate approach for 2 size-classes (small adult and large adult) in forward time. We modeled $\varphi$ for both large adults and small adults to vary by site in all models because our goal was to rank sources relative to one another, and $\varphi$ is an important component of the $C^{n}$ metric used to rank sources. We used all combinations of site and additive season effects with $\psi$ parameters being either a function of site, season, or an additive effect of both. We constrained $\psi$ parameters when modeled as a function of season as either transitioning from spring-fall of 2004 or from fall 2004 to spring 2005. The majority of size transitions during this study occurred during the fall-spring period, which is why $\psi$ parameters were constrained to just 2 transition periods. Capture probabilities were similarly fixed to 0.72 , as outlined in the reversetime approach. Model selection was carried out using $\mathrm{AIC}_{c}$, as described in the reverse-time approach. Annual error terms were estimated using the delta method (Powell 2007). Estimates of per capita recruitment $\left(\beta^{n}\right)$ for each site was based on the number of YOY at each site in the spring of 2005 divided by the number of large adult brook trout in the fall of 2004 . This value was then multiplied by the site specific transition rate of YOY to small adults for each site $\left(\psi_{Y S}\right)$. The per capita recruitment value was multiplied by $\psi_{Y S}$ in order to maintain 2 states for our $C^{n}$ (small adult and large adult), therefore removing the YOY state. Due to limited ability to tag YOY brook trout, multistate CMR analysis was not possible to estimate $\psi_{Y S}$. However, all YOY that were given a unique tag in 2004 and subsequently recaptured in the spring of 2005 were 
used to estimate a minimum number alive over the transition period. Therefore, recaptured small adults in 2005 were divided by the total number of YOY marked in 2004 to estimate the transition probability of YOY to the small adult size-class at each site.

Because all potential subpopulations within this watershed were not sampled, emigration rates from each site were not possible using CMR techniques. As an alternative, we used estimates of effective number of migrants $\left(N_{E M}\right)$ as estimates of emigration from these locations. A recent study has shown through microsatellite genetics that the Shavers Fork brook trout metapopulation is well-mixed (Aunins et al. in review). However, they also found varying degrees of genetic differentiation among different tributaries, as indicated by pairwise analysis of molecular variance (AMOVA). From their study, pairwise $F_{S T}$ values derived from the AMOVA were used to estimate $N_{E M}$ according to the following relationship (Rannala 1996):

$$
N_{E M}=\frac{\frac{1}{F_{S T}}-1}{4}
$$

Not all sites sampled in our study were used in the Aunins et al. (in review) study, so site specific rates of emigration were not possible. Therefore, emigration rates were estimated from $N_{E M}$ values for 3 separate site types, representing different rates of emigration from subpopulations within the watershed (Low $=4$ emigrants, intermediate $=18$ emigrants, and high $=53$ emigrants). These values were then divided by the total abundance estimates at each site to get a site specific rate of emigration under these 3 scenarios. Additionally, we estimated $C^{n}$ under these three scenarios where only large adults were modeled as potential emigrants. Other studies have found that the larger fraction of a brook trout population tend to be the most mobile (Gowan and Fausch 1996), and small adult brook trout were much less common in the Shavers 
Fork mainstem (Huntsman and Petty 2014), where brook trout have been found to be highly mobile (Petty et al. 2012).

\section{Source Ranking}

We utilized the Thomas and Kunin (1998) concept of applying a continuous classification scheme to subpopulations within a metapopulation to rank the relative strength of our sites as sources vs sinks. We estimated the number of immigrants using the reverse-time approach $(I=$ per capita immigration rate $\left.* N_{\text {large adults }}\right)$ and the number of individuals contributed to the metapopulation $\left(C=C^{n} * N_{\text {large adults }+ \text { small adults }}\right)$ for each site. The number of immigrants were then subtracted from the number of individuals contributed to the metapopulation to rank sites as sources within this watershed. In order to estimate the number of individuals contributed to the metapopulation for ranking purposes, the lowest emigration rates were used for all headwater sites (HW) because telemetry (Petty et al. 2012) and genetics (Aunins et al. in review) suggest that individuals from the small tributaries are relatively sedentary compared to larger sites within this watershed. The large tributary (LT) and mainstem (MS) sites were ranked based on intermediate emigration rates, since these sites were suggested to have more mobile fish populations (Petty et al. 2012, Aunins et al. in review).

\section{Results:}

\section{Local vs. Regional Contributions to Population Growth:}

The best supported model using reverse-time modeling for large adult brook trout population growth was the fully parameterized model, where apparent survival and size-class transitions were influenced by both time and location $\left(w_{i}=0.93\right.$, Table 3$)$. Of the 10 sites 
analyzed, 6 consisted of large adult populations increasing in size or staying the same from 2004 to 2005 (see $\lambda_{\text {Large }}$ in Table 4 and Figure 3). Although the 2 largest sites showed increasing large adult populations over this time step, greater than $80 \%$ of this growth was contributed by immigration (Table 4, Figure 3). In all headwater sites, population growth was most strongly controlled by local dynamics. However, HW 6 showed the greatest contribution from immigration, where nearly $25 \%$ of population growth was due to immigration (Table 4). HW 5 and 7 showed the next highest regional contributions, where greater than $15 \%$ of large adult growth at these sites was dependent on immigration. All other HW sites showed $88 \%$ or greater contributions from local dynamics. Interestingly, the only subpopulation showing positive growth through local dynamics alone was HW 7, even though it had the $3^{\text {rd }}$ highest contribution towards population growth through immigration (out of all the HW sites, Figure 3).

\section{Contribution Metric:}

A total of six models were tested for the forward time mark-recapture analysis, due to both $\varphi$ and $\psi$ parameters being estimated separately (unlike in the reverse-time approach). The best supported model with this approach was the additive model of both site and time for both parameters, where $\psi$ was constrained to two time intervals: spring 2004-fall 2004 and fall 2004spring $2005\left(w_{i}=0.94\right.$, Table 3$)$. Annual estimates of $\varphi$ indicated that survival estimates were highest for small adults in HW 1, and highest for large adults in HW 5 (Table 4). Annual estimates were lowest for the two largest sites (MS and LT), although $\varphi_{L}$ in HW 8 was lower than either of the large sites (Table 4). However, $\varphi_{L}$ in HW 8 should be interpreted with caution since the apparent survival estimate for the fall-spring period was not estimable (see Appendix C). 
Under all potential simulations of emigration rates, all headwater sites provided a $C^{n}$ consistent with a source subpopulation $\left(C^{n}>1\right.$, Table 5), with the exception of HW 8 and 7 under the lowest emigration scenario. Three sites were classified as a sink subpopulation under intermediate and low emigration scenarios, where $C^{n}$ was always $<1$ (MS, LT and HW 8, Table 5). When the number of immigrants was subtracted from the number of individuals supplied to the metapopulation from each site, HW 4 ranked as the strongest source (Table 5). The two strongest sources after HW 4 were HW 5 and 6. The lowest ranked sites were the MS and LT sites, as well as the HW 7 and 8 sites. Both HW 7 and 8 had among the lowest estimates of recruitment and density (Table 4), which explains the low estimate of $C^{n}$ for this headwater site.

\section{Discussion:}

As expected, all 8 headwater tributaries showed a considerable amount of large adult population growth contributed by local dynamics. This is not surprising given that headwater tributaries less than $5 \mathrm{~km}^{2}$ have been shown to support nearly $80 \%$ of all reproduction within this watershed (Petty et al. 2005), and brook trout mobility has been shown to be drastically lower than that observed by mainstem trout (Petty et al. 2012). Furthermore, YOY densities in most of the headwater tributaries were much higher than in larger sites (Table 1), which is a metric that has been used to identify sources for other stream populations (Woodford and McIntosh 2010). Although half of the headwater sites showed a large adult population growth of 1 or greater (lambdas of 1 or greater have often been used to identify sources, see Runge et al. 2006), only one of the eight sites showed positive growth in the absence of immigration (HW 7, Figure 3). This indicates that nearly all sites sampled within this study would be extirpated without the support of the regional colonizers. Similar results were observed in a study of pumas (Puma 
concolor) by Newby et al. (2013), where 3 of 4 subpopulations demonstrated population growth greater than 1, but only one of four showed population growth greater than 1 when regional contributions were removed. Such results suggest that the population growth rate alone can be misleading when trying to identify sources within a complex metapopulation. However for our study, it is important to recognize that this analysis was only carried out over 1 year of sampling, which substantially limits our ability to conclude on the actual long-term health of these sites.

The reverse-time approach supported the notion that the larger sites act more like sinks than sources for brook trout populations. We expected the majority of the large adult population growth in the large sites to be supported by immigration, since brook trout are headwater specialists. In fact, greater than $80 \%$ of large adult population growth was supported by immigration at those sites. However, it is important to recognize that these populations did show increasing large adult population growth rates (Figure 3). It can be dangerous to simply interpret whether a subpopulation is a source or a sink based on whether the population is growing or not, especially under such a short time interval. Here we show that the two largest sites would be considered the strongest sources if simply analyzing large adult population growth. Without disentangling the components of the local large adult population's growth, these larger sites could easily be mistaken for two of the strongest sources in this study. When only considering local contributions however, we show that the population would have substantially decreased from 2004 to 2005. Comparing only local contributions across sites indicated that the two largest sites had the lowest lambda, suggesting these sites would be among the first to be extirpated in the absence of immigrants.

The $C^{n}$ approach suggested similar classifications of sources and sinks within this watershed. The $C^{n}$ approach indicated that the mainstem and large tributary sites were sinks 
within this watershed during this sampling period. Only when simulating these two sites at the highest observed emigration rates were $C^{n}$ values considered sources. It is not surprising that these sites were often considered sinks given the annual apparent survival for both small adults and large adults were substantially lower here compared to the headwater sites. For the headwater sites however, considerable variability suggests that some sites were likely stronger sources than others. However, we were unable to explore these spatial dynamics in full, since only one year of data was available for analysis.

When ranking all sites based on their strength as sources, the strongest sources were not always the sites with the highest brook trout densities. The three strongest sources were HW 4, HW 5 and HW 6, but HW 5 had the $4^{\text {th }}$ lowest density among all headwater sites (see Table 1 and Table 5). Headwater 5 however, did demonstrate the highest apparent survival for large adults and a relatively high apparent survival for small adults. When ranking their subpopulations, Sanderlin et al. (2012) found that the highest density sites were usually among the strongest contributors to the entire metapopulation for banner-tailed kangaroo rats (Dipodomys spectabilis). As they point out, this is an expected result for sites that share similar demographic estimates. In our study, small adults were in higher densities than large adults in the headwater sites. Since small adult survival in HW 4 was high, along with having the highest density of brook trout among all sites, it is no surprise why HW 4 was the highest ranked source.

Here we show that not all tributaries within this watershed show positive large adult growth from 2004 to 2005, and only one could be supported through local dynamics (even though 6 of 10 sites showed growth when considering regional contributions). A possible explanation for this is dispersal from highly productive sources into sink patches, known as mass effects or spillover (Wilson 1992, Diffendorfer 1998, Amarasekare 2004, Casini et al. 2012, 
Chapter 2). Based on the contribution metric for each site, the total number of brook trout contributed to the entire metapopulation was greatest from HW 4, HW 5, and then HW 6. However, all three of these sites would have demonstrated a declining large adult population in the absence of immigrants, and both HW 4 and 6 demonstrated substantial reductions in large adult population sizes from 2004 to 2005 . Because these sites are directly adjacent to either the mainstem or the large tributary site, they may be supplying a considerable number of large adult immigrants to these larger sites, given that large adult growth at these larger sites was much higher than all other sites and primarily supported by regional mechanisms. Another study within this watershed has found large adult brook trout densities in the mainstem to be best explained by mass effects from a source (Chapter 2). However, in that study, the mass effects were modeled with a year lag where this mass effect would have to occur on a faster time frame.

Previous research in this watershed has also acknowledged a complex interaction of mass effects and thermal refuge limitation being likely factors limiting mainstem habitat use by brook trout Huntsman and Petty 2014, (Petty et al. 2014, Ch. 2 and 4). It has also been shown that the mainstem of this watershed is an important complementary habitat (Schlosser 1995) for large brook trout, because the average tributary-dwelling fish are unable to reach sizes that mainstem fish are capable of reaching due to lower quality forage (Petty et al. 2014, Ch. 4). However, thermal stress in the mainstem during warm years prevent brook trout from expanding into the mainstem, providing a unique temperature-mediated expansion and contraction of brook trout at the watershed scale (Petty et al.2014). For this study, 2004 was a warmer year than 2005 (Huntsman and Petty 2014). Since 2005 was a cooler, high productivity year, it was not surprising to see high rates of immigration supporting a growing population in the mainstem. During warm periods (e.g. 2004), brook trout would be expected to withdraw into headwater 
tributaries for thermal refuge and expand back into the mainstem during cooler periods (e.g. 2005). This could then explain why positive large adult population growth was observed in the large sites from 2004 to 2005, while 4 of 8 headwater sites declined (see Figure 3). Additionally, seasonal rates of immigration in 4 of 8 headwater sites showed that immigration was greatest during the spring 2004 to summer 2004 sampling interval (Appendix D), suggesting brook trout may be moving back into tributaries during this hot summer. More mark-recapture data is needed, however, to allow for similar analyses under warmer and less productive years in order to further test this temperature-mediated mass effect hypothesis.

\section{Management Implications:}

The ability to identify the strength of sources and sinks within a metapopulation serves obvious benefits towards management strategies. Being able to identify which sources contribute the most to the entire metapopulation would undoubtedly be locations of preservation priority. This can be especially important for subpopulations in danger of becoming isolated through anthropogenic activities, or prioritizing sites for restoration (e.g. culverts replacements, Petty and Merriam 2012). Letcher et al. (2007) showed that a simulated isolation of important tributary sites for a brook trout metapopulation not only caused rapid extirpation of brook trout from local habitat, but led to the extinction of the entire metapopulation. Here we observed that not all headwater tributaries within this watershed demonstrate similar strength as sources. This information along with previous research from within this watershed paints an increasingly detailed picture of the complex spatial relationship among brook trout subpopulations, and provides important information for consideration in the development of management strategies. 
Acknowledgments: We would also like to thank the WV Department of Natural Resources for gate access and for providing funding for this project (grant NRAC 387).

\section{Works Cited:}

Adams, S.B., C. A. Frissell, and B.E. Rieman. 2000. Movements of nonnative brook trout in relation to stream channel slope. Transactions of the American Fisheries Society 129:623-638.

Amarasekare, P. 2004. The role of density-dependent dispersal in source-sink dynamics. Journal of Theoretical Biology 226:159-168.

Angermier, P.L., and J.R. Karr. 1986. Applying an index of biotic integrity based on stream-fish communities: Considerations in sampling and interpretation. North American Journal of Fisheries Management 6:418-427.

Aunins, A.W., J.T. Petty, T.L. King, M. Schilz, and P.M. Mazik. in review. Genetic differentiation and complex metapopulation structure of an Appalachian brook trout population. Conservation Genetics.

Burnham, K. P., and D.R. Anderson. 2002. Model selection and inference: a practical information - theoretic approach. 2 edition.

Casini, M., T. Blenckner, C. Mollmann, A. Gardmark, M. Lindegren, M. Llope, G. Kornilovs, M. Plikshs, and N. C. Stenseth. 2012. Predator transitory spillover induces trophic cascades in ecological sinks. Proceedings of the National Academy of Sciences 109:8185-8189.

Choquet, R., A.M. Reboulet, R. Pradel, O. Gimenez, and J.D. Lebreton. 2006. M-SURGE 1.8 user's manual. - CEFE, Montpellier, France. 
Dias, P. C. 1996. Sources and sinks in population biology. TREE 11:326-330.

Differndorfer, J. E. 1998. Testing models of source-sink dynamics and balanced dispersal. Oikos 81:417-433.

Efron, B., and R.J. Tibshirani. 1993. An introduction to the bootstrap. In: Monographs on Statistics and Applied Probability 57, pp. 436. Chapman and Hall, New York.

Falke, J.A., J.B. Dunham, C.E. Jordan, K.M. McNyset, and G.H. Reeves. 2013. Spatial ecological processes and local factors predict the distribution and abundance of spawning by steelhead (Oncorhynchus mykiss) across a complex riverscape. PLoS ONE 8:e79232. doi:10.1371/journal.pone.0079232.

Fausch, K.D., C.E. Torgersen, C.V. Baxter, and H.W. Li. 2002. Landscapes to riverscapes: Bridging the gap between research and conservation of stream fishes. BioScience 52:483498.

Fretwell, S. D., and H.L. Lucas Jr. 1970. On territorial behavior and other factors influencing habitat distribution in birds.1. Theoretical development. Acta Biotheor 1970:16-36.

Freund, J.G., and J.T. Petty. 2007. response of fish and macroinvertebrate bioassessment indices to water chemistry in a mined Appalachian watershed. Environmental Management 39:707-720.

Gowan, C., and K.D. Fausch. 1996. Mobile brook trout in two high-elevation Colorado streams: Re-evaluating the concept of restricted movement. Canadian Journal of Fisheries and Aquatic Sciences 53:1370-1381.

Griffin, P.C., and L.S. Mills. 2009. Sinks without borders: Snowshoe hare dynamics in a complex landscape. Oikos 118:1487-1498. 
Guo, Q., M. Taper, M. Schoenberger, and J. Brandle. 2005. Spatial-temporal population dynamcis across species range: from centre to margin. Oikos 108:47-57.

Hanski, I. 1998. Metapopulation dynamics. Nature 396:41-49.

Hense, Z., R.W. Martin, and J.T. Petty. 2010. Electrofishing capture efficiencies for common stream fish species to support watershed-scale studies in the central Appalachians. North American Journal of Fisheries Management 30:1041-1050.

Huntsman, B.M., and J.T. Petty. 2014. Density-dependent and density-independent mechanisms regulating brook trout population dynamics along a core-periphery distribution gradient. PLoS ONE 9:e91673. doi:10.1371/journal.pone.0091673.

Hutchings, J.A. 1994. Age- and size-specific costs of reproduction within populations of brook trout, Salvelinus fontinalis. Oikos 70:12-20.

Johnson, D.M. 2004. Source-sink dynamics in a temporally heterogeneous environment. Ecology 85:2037-2045.

Jonzén, N., J.R. Rhodes, and H.P. Possingham. 2005. Trend detection in source-sink systems: When should sink habitats be monitored? Ecological Applications 15:326-334.

Lampila, S., R. Wistbacka, A. Mäkelä, and M. Orell. 2009. Survival and population growth rate of the threatened Siberian flying squirrel (Pteromys volans) in a fragmented forest landscape. Ecoscience 16:66-74.

Lebreton, J., K.P. Burnham, J. Clobert, and D.R. Anderson. 1992. Modeling survival and testing biological hypotheses using marked animals: a unified approach with case studies. Ecological Monographs 62:67-118. 
Letcher, B. H., K. H. Nislow, J. A. Coombs, M. J. O'Donnell, T. L. Dubreui. 2007. Population response to habitat fragmentation in a stream-dwelling brook trout population. Plus One 11:1-11.

Levins, R. 1969. Some demographic and genetic consequences of environmental heterogeneity for biological control. Entomological Society of America 15:237-240.

Martin, R. 2010. Stream fish metacommunity and metapopulation ecology in a mined Appalachian watershed. West Virginia University, Morgantown, West Virginia, U.S.A.

Morris, D.W., and J.E. Diffendorfer. 2004. Reciprocating dispersal by habitat-selecting whitefooted mice. Oikos 107:549-558.

Morris, D.W., J.E. Diffendorfer, and P. Lundberg. 2004. Dispersal among habitats varying in fitness: Reciprocating migration through ideal habitat selection. Oikos 107:559-575.

Newby, J.R., L.S. Mills, T.K. Ruth, D.H. Pletscher, M.S. Mitchell, H.B. Quigley, K.M. Murphy, and R. DeSimone. 2013. Human-caused mortality influences spatial population dynamics: Pumas in landscapes with varying mortality risks. Biological Conservation 159:230-239.

Nichols, J. D., J.E. Hines, J. Lebreton, and R. Pradel. 2000. Estimation of contributions to population growth: a reverse-time capture-recapture approach. Ecology 81:3362-3376.

Nystrand, M., M. Griesser, S. Eggers, and J. Ekman. 2010. Habitat-specific demography and source-sink dynamics in a population of Siberian jays. Journal of Animal Ecology 79:266-274.

Petty, J. T., P. J. Lamothe, and P. M. Mazik. 2005. Spatial and seasonal dynamics of brook trout populations inhabiting a central Appalachian watershed. Transactions of the American Fisheries Society 134:572-587. 
Petty, J. T., J.L. Hansbarger, B.M. Huntsman, and P.M. Mazik. 2012. Brook trout movement in response to temperature, flow, and thermal refugia within a complex Appalachian riverscape. Transactions of the American Fisheries Society 141:1060-1073.

Petty, J.T., D. Thorne, B.M. Huntsman, and P.M. Mazik. 2014. The temperature-productivity squeeze: constraints on brook trout growth along an Appalachian river continuum. Hydrobiologia 727:151-166.

Powell, L.A. 2007. Approximating variance of demographic parameters using the delta method: A reference for avian biologists. The Condor 109:949-954.

Pulliam, H. R. 1988. Sources, sinks, and population regulation. The American Naturalist 132:652-661.

Rannala, B. (1996) The sampling theory of neutral alleles in an island population of fluctuating size. Theoretical Population Biology 50:91-104.

Runge, J. P., M.C. Runge, and J.D. Nichols. 2006. The role of local populations within a landscape context: defining and classifying sources and sinks. The American Naturalist 167:925-938.

Sanderlin, J.S., P.M. Waser, J.E. Hines, and J.D. Nichols. 2012. On valuing patches: estimating contributions to metapopulation growth with reverse-time capture-recapture modeling. Proceedings of the Royal Society B 279:480-488.

Schlosser, I. J. 1995. Critical landscape attributes that influence fish population dynamics in headwater streams. Hydrobiologia 303:71-81.

Thomas, C. D., and W.E. Kunin. 1999. The spatial structure of populations. Journal of Animal Ecology 57:536-546. 
Tincher, M. 2013. Modeling water temperatures and brook trout (Salvelinus fontinalis) growth potential within a complex Appalachian riverscape. Thesis. West Virginia University, Morgantown, West Virginia, U.S.A.

Watkinson, A.R., and W.J. Sutherland. 1995. Sources, sinks and psueo-sinks. Journal of Animal Ecology 64:126-130.

Wilson, D.S. 1992. Complex interactions in metacommunities, with implications for biodiversity and higher levels of selection. Ecology 73:1984-2000.

Woodford, D. J., and A.R. McIntosh. 2010. Evidence of source-sink metapopulations in a vulnerable native galaxiid fish driven by introduced trout. Ecological Applications 20:967-977.

Yoder, C.O., and M.S. Smith. 1999. Using fish assemblages in a state biological assessment and criteria program: Essential concepts and considerations. In Simon, T.P. Editor. 1999. Assessing the sustainability and biological integrity of water resources using fish communities. CRC press. New York, U.S.A. pp. 671. 


\section{Tables:}

Table 1: Site specific characteristics for each subpopulation sampled in this study. All density estimates are means over each sampling occasion as per unit stream length $(\# / \mathrm{m})$. “*” indicates values were taken from 2012 data and "^" indicates values were taken from GIS.

\begin{tabular}{|c|c|c|c|c|c|c|c|c|c|}
\hline $\begin{array}{l}\text { Site } \\
\text { Name }\end{array}$ & $\begin{array}{c}\text { Basin Area } \\
\left(\mathrm{km}^{2}\right)\end{array}$ & $\begin{array}{c}\text { Reach } \\
\text { Length }(\mathrm{m})\end{array}$ & $\begin{array}{c}\text { Wetted } \\
\text { Width (m) }\end{array}$ & \% Slope & pH & $\begin{array}{c}\text { YOY } \\
\text { Density }\end{array}$ & $\begin{array}{l}\text { S. Adult } \\
\text { Density }\end{array}$ & $\begin{array}{l}\text { L. Adult } \\
\text { Density }\end{array}$ & $\begin{array}{c}\text { Total } \\
\text { Density }\end{array}$ \\
\hline $\mathrm{MS}$ & $30-61$ & 4106 & 10-15 & $0.4-0.5^{\wedge}$ & $6.79-7.41 *$ & $0.001-0.005$ & $0.001-0.010$ & 0.004-0.012 & $0.007-0.027$ \\
\hline LT & 15.96 & 500 & 8 & $1.4^{\wedge}$ & $7.13 *$ & 0.024 & 0.055 & 0.034 & 0.113 \\
\hline HW 1 & 0.36 & 1305 & 2.1 & 16.8 & 6 & 0.031 & 0.073 & 0.021 & 0.126 \\
\hline HW 2 & 0.14 & 425 & 1 & 5.1 & 5.8 & 0.038 & 0.027 & 0.002 & 0.067 \\
\hline HW 3 & 0.3 & 600 & 2 & 10.5 & 6.6 & 0.070 & 0.068 & 0.028 & 0.166 \\
\hline HW 4 & 0.69 & 1300 & 2 & 8 & 6.2 & 0.049 & 0.061 & 0.018 & 0.128 \\
\hline HW 5 & 1.5 & 1400 & 1.8 & 15.7 & 6 & 0.019 & 0.046 & 0.020 & 0.085 \\
\hline HW 6 & 0.74 & 1710 & 2.1 & 9.5 & 5.2 & 0.064 & 0.046 & 0.011 & 0.121 \\
\hline HW 7 & 0.21 & 1050 & 1.3 & 13.7 & 5.9 & 0.004 & 0.004 & 0.003 & 0.011 \\
\hline HW 8 & 0.39 & 1200 & 1.3 & 7.3 & 6.8 & 0.014 & 0.025 & 0.008 & 0.047 \\
\hline
\end{tabular}


Table 2: Total number of brook trout captured and recaptured within the local habitat as well as in a different spot than first encountered. Numbers represent the total number of capture histories encountered over the duration of sampling.

\begin{tabular}{lcccr}
\hline \multirow{2}{*}{ SITE } & $\begin{array}{c}\text { \# } \\
\text { CAPTURED }\end{array}$ & $\begin{array}{c}\text { \# RECAPTURED } \\
\text { LOCAL }\end{array}$ & $\begin{array}{c}\text { \# RECAPTURED } \\
\text { ELSEWHERE }\end{array}$ & $\begin{array}{c}\text { \% } \\
\text { MOVED }\end{array}$ \\
\hline MS & 192 & 25 & 6 & 3.13 \\
LT & 152 & 30 & 3 & 1.97 \\
HW 1 & 254 & 152 & 7 & 2.76 \\
HW 2 & 179 & 84 & 6 & 3.35 \\
HW 3 & 139 & 73 & 4 & 2.88 \\
HW 4 & 249 & 139 & 4 & 1.61 \\
HW 5 & 200 & 118 & 1 & 0.50 \\
HW 6 & 226 & 108 & 6 & 2.65 \\
HW 7 & 26 & 11 & 4 & 15.38 \\
HW 8 & 87 & 48 & 4 & 4.60 \\
\hline
\end{tabular}


Table 3: Model ranking for mark-recapture analysis in program M-SURGE (reverse-time) and program MARK (forward time). The "g" represents groupings, based on site, the "slope" represents sites were grouped based on the slope of the site, "sp-fa and fa-sp" indicates that the seasons were grouped as spring to fall and fall to spring.

\begin{tabular}{|c|c|c|c|c|c|c|}
\hline Method & Model & $\mathrm{AIC}_{\mathrm{c}}$ & $\begin{array}{l}\text { Delta } \\
\text { AIC }_{c}\end{array}$ & $\begin{array}{c}\text { Model } \\
\text { Likelihood }\end{array}$ & $\begin{array}{c}\mathrm{AIC}_{\mathrm{c}} \\
\text { Weights }\end{array}$ & Deviance \\
\hline \multirow[t]{4}{*}{ Reverse Time } & $\varphi / \psi(g+t)$ & 2333.912 & 0.000 & 1.000 & 0.930 & 2305.912 \\
\hline & $\varphi / \psi(\mathrm{g})$ & 2339.070 & 5.159 & 0.076 & 0.070 & 2315.070 \\
\hline & $\varphi / \psi(g($ slope $)+t)$ & 2418.836 & 84.924 & 0.000 & 0.000 & 2404.836 \\
\hline & $\varphi / \psi(g+t(s p-f a$ and fa-sp $))$ & 2673.469 & 339.557 & 0.000 & 0.000 & 3647.469 \\
\hline \multirow[t]{6}{*}{ Forward Time } & $\varphi(g+t) \psi(g+t)-\psi$ with two transitions (sp-fa and fa-sp) & 6206.309 & 0.000 & 1.000 & 0.944 & 2097.205 \\
\hline & $\varphi(\mathrm{g}+\mathrm{t}) \psi(\mathrm{t})-\psi$ with two transitions (sp-fa and fa-sp) & 6211.945 & 5.636 & 0.060 & 0.056 & 2119.280 \\
\hline & $\varphi(\mathrm{g}) \psi(\mathrm{g}+\mathrm{t})-\psi$ with two transitions (sp-fa and fa-sp) & 6372.179 & 165.870 & 0.000 & 0.000 & 2271.310 \\
\hline & $\varphi(\mathrm{g}) \psi(\mathrm{t})-\psi$ with two transitions (sp-fa and fa-sp) & 6377.859 & 171.550 & 0.000 & 0.000 & 2293.368 \\
\hline & $\varphi(\mathrm{g}+\mathrm{t}) \psi(\mathrm{g})$ & 6417.172 & 210.863 & 0.000 & 0.000 & 2306.004 \\
\hline & $\varphi(\mathrm{g}) \psi(\mathrm{g})$ & 6691.809 & 485.500 & 0.000 & 0.000 & 2595.046 \\
\hline
\end{tabular}


Table 4: Annualized estimates of local and regional (immigration) contributions to adult population growth using the reverse-time approach as well as apparent survival of both small adult and large adult brook trout using the forward time approach. Recruitment was estimated as the number of YOY in 2005 divided by the number of adult brook trout in 2004 multiplied by YOY to small adult transition rates (see methods). Seasonal estimates of each parameter can be found in the appendix as Appendix C and D. Standard error (S.E.) estimates for immigration and local contributions to population growth are the same since Immigration $=1-$ Local.

\begin{tabular}{|c|c|c|c|c|c|c|c|c|c|}
\hline & \multicolumn{4}{|c|}{ Reverse-Time } & \multicolumn{5}{|c|}{ Forward Time } \\
\hline & Lambda & Local & S.E. & Immigration & $\varphi_{L}^{n n}$ & S.E. & $\varphi_{S}^{n n}$ & S.E. & Recruitment \\
\hline MS & 1.794 & 0.093 & 0.029 & 0.907 & 0.161 & 0.028 & 0.104 & 0.020 & 0.0 \\
\hline $\mathrm{LT}$ & 2.556 & 0.161 & 0.058 & 0.839 & 0.133 & 0.024 & 0.115 & 0.021 & 0.2 \\
\hline HW 1 & 1.036 & 0.911 & 0.260 & 0.089 & 0.556 & 0.077 & 0.564 & 0.078 & 1.2 \\
\hline HW 2 & 1.000 & 0.923 & 0.373 & 0.077 & 0.496 & 0.070 & 0.350 & 0.052 & 7.5 \\
\hline HW 3 & 0.591 & 0.886 & 0.306 & 0.114 & 0.491 & 0.069 & 0.470 & 0.067 & 1.5 \\
\hline HW 4 & 0.429 & 0.995 & 0.925 & 0.005 & 0.311 & 0.048 & 0.490 & 0.069 & 2.3 \\
\hline HW 5 & 1.097 & 0.825 & 0.206 & 0.175 & 0.582 & 0.080 & 0.464 & 0.066 & 2.6 \\
\hline HW 6 & 0.483 & 0.756 & 0.193 & 0.244 & 0.281 & 0.044 & 0.374 & 0.055 & 3.5 \\
\hline HW 7 & 1.250 & 0.844 & 0.554 & 0.156 & 0.459 & 0.065 & 0.462 & 0.065 & 0.6 \\
\hline HW 8 & 0.769 & 0.925 & 0.418 & 0.075 & 0.038 & 0.009 & 0.436 & 0.063 & 0.9 \\
\hline
\end{tabular}


Table 5: Estimates of the contribution metric $\left(C^{n}\right)$ under different simulated emigration scenarios. "Metapop. Contribution" represents the

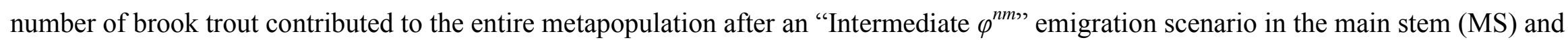
large tributary (LT) sites, and a "Lowest $\varphi^{n m}$ " emigration scenario for all headwater (HW) sites. The " $C$ - $I$ " represents the abundance of individuals contributed to the metapopulation after immigrants had been removed.

\begin{tabular}{|c|c|c|c|c|c|c|c|c|}
\hline \multirow[b]{2}{*}{ Site } & \multicolumn{3}{|c|}{$\varphi_{S}^{n m}=\mathbf{0}$} & \multicolumn{3}{|c|}{$\varphi_{S}^{n m}=\varphi_{L}^{n m}$} & \multicolumn{2}{|c|}{ Metapop. Contribution } \\
\hline & $\begin{array}{c}\text { Highest } \\
\varphi_{L}^{n m} \\
\end{array}$ & $\begin{array}{c}\text { Intermediate } \\
\varphi_{L}^{n m} \\
\end{array}$ & $\begin{array}{c}\text { Lowest } \\
\varphi_{L}^{n m} \\
\end{array}$ & $\begin{array}{c}\text { Highest } \\
\varphi_{L}^{n m} \\
\end{array}$ & $\begin{array}{c}\text { Intermediate } \\
\varphi_{L}^{n m} \\
\end{array}$ & $\begin{array}{c}\text { Lowest } \\
\varphi_{L}^{n m} \\
\end{array}$ & $C-I$ & Rank \\
\hline MS & 1.008 & 0.441 & 0.221 & 1.008 & 0.441 & 0.221 & -33 & 10 \\
\hline $\mathrm{LT}$ & 1.157 & 0.595 & 0.250 & 1.367 & 0.687 & 0.270 & 14 & 8 \\
\hline HW 1 & 1.507 & 1.335 & 1.267 & 1.824 & 1.439 & 1.290 & 228 & 4 \\
\hline HW 2 & 4.115 & 3.750 & 3.250 & 11.595 & 8.503 & 4.261 & 117 & 5 \\
\hline HW 3 & 1.875 & 1.432 & 1.260 & 2.892 & 1.769 & 1.332 & 84 & 6 \\
\hline HW 4 & 1.637 & 1.493 & 1.436 & 2.125 & 1.654 & 1.471 & 294 & 1 \\
\hline HW 5 & 2.122 & 1.913 & 1.832 & 2.947 & 2.186 & 1.890 & 285 & 2 \\
\hline HW 6 & 1.917 & 1.694 & 1.607 & 3.080 & 2.079 & 1.689 & 243 & 3 \\
\hline HW 7 & 1.750 & 1.250 & 0.975 & 2.380 & 1.565 & 1.117 & 9 & 9 \\
\hline HW 8 & 1.150 & 0.674 & 0.489 & 1.803 & 0.891 & 0.535 & 27 & 7 \\
\hline
\end{tabular}




\section{Figure Legends:}

Figure 1: Concept of a compensation axis from Thomas and Kunin (1999), for applying a continuous classification scheme for source-sink systems.

Figure 2: Locations of the 8 headwater tributaries, one large tributary, and main stem sites sampled within the upper Shavers Fork watershed, WV.

Figure 3: Local versus regional components of the adult finite population growth rate $\left(\lambda_{\text {Adult }}\right)$ for the 10 sites sampled in this study. Estimates are annual rates. The horizontal broken line represents the point of equilibrium, where the population has replaced itself on consecutive sampling intervals (spring 2004 - spring 2005). 


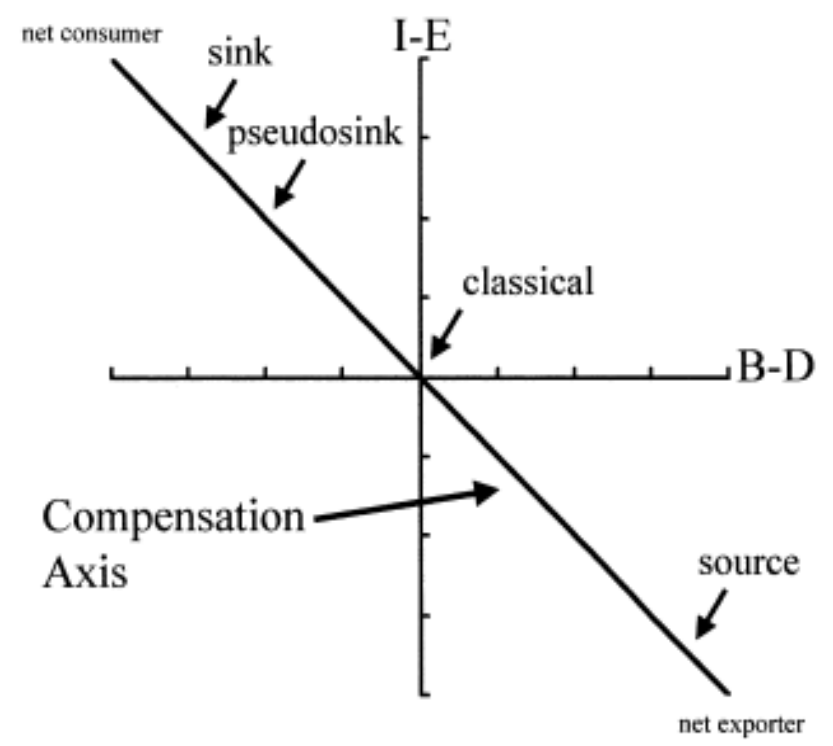

Figure 1 


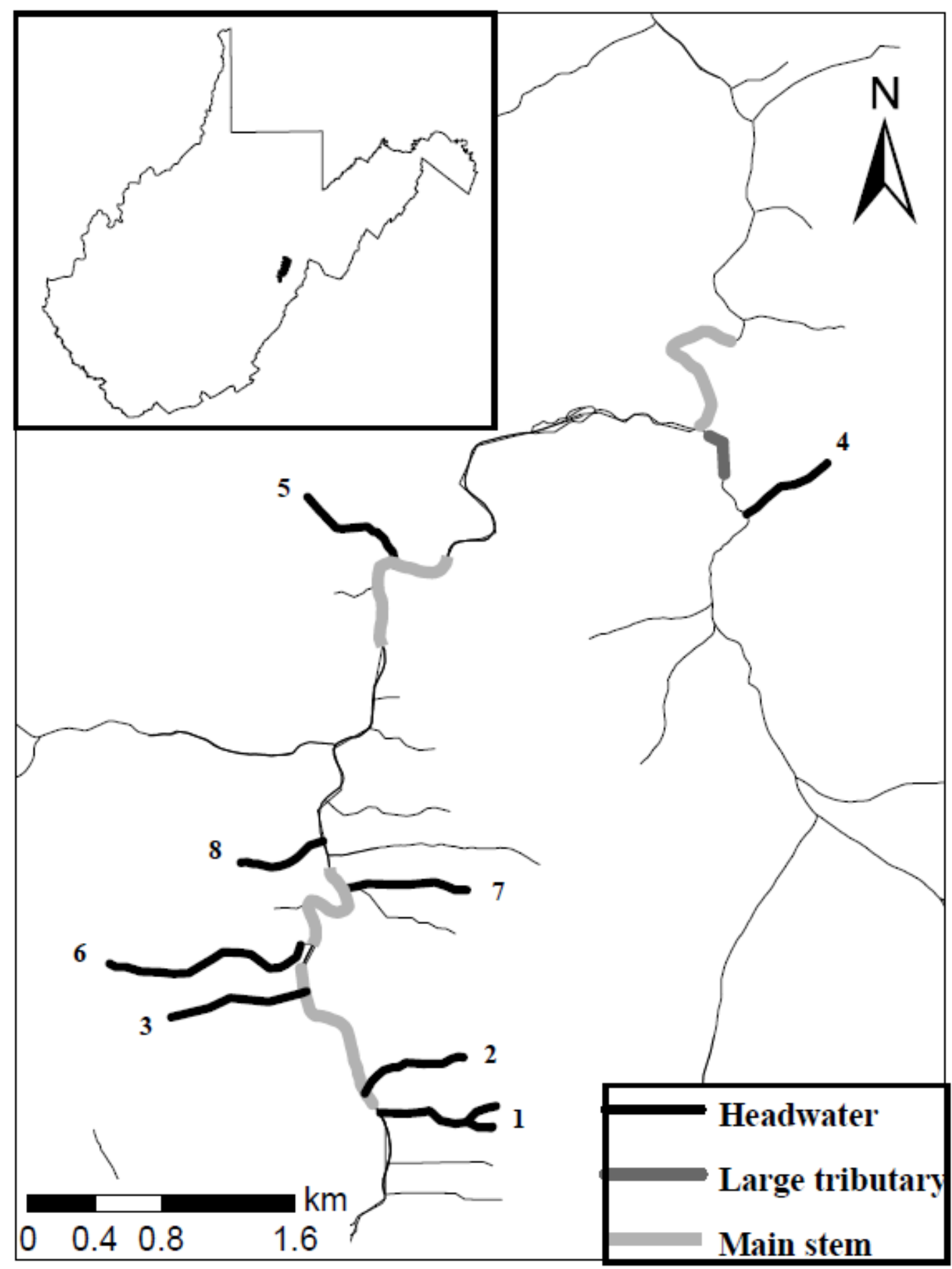

Figure 2 


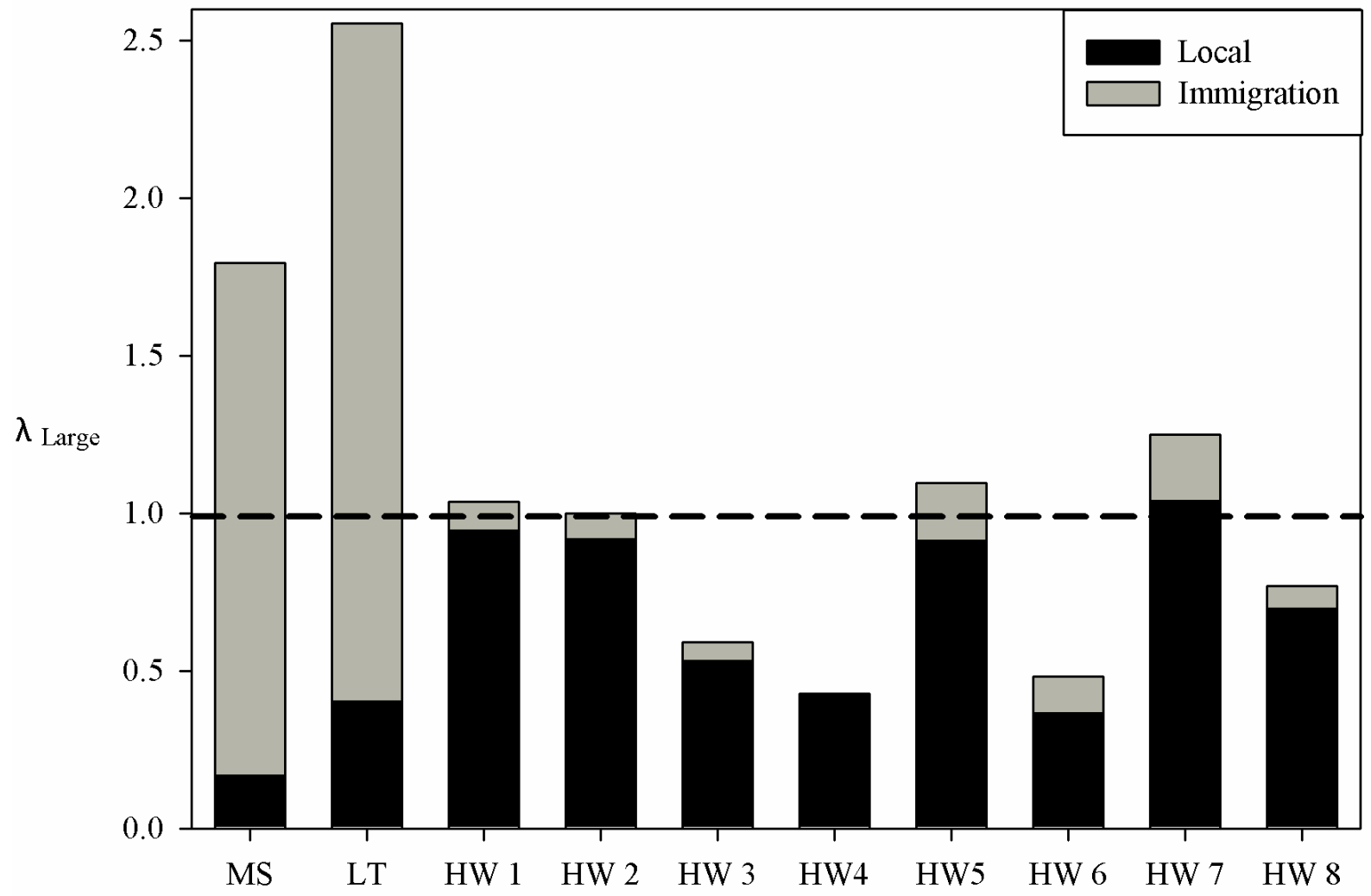

Figure 3 
Chapter 4: Brook trout habitat selection along a complex stream continuum: energetically regulated expansion and contraction

Brock M. Huntsman* and J. Todd Petty

Division of Forestry and Natural Resources, West Virginia University, Morgantown, WV 26506, U.S.A.

*Corresponding author: brockhunts@gmail.com 


\begin{abstract}
:
Energetic habitat modeling is a common method used to explain growth potential, habitat selection, and abundance distributions for stream fishes. We used bioenergetics software with stream temperature models, seasonal mark-recapture growth data, and published seasonal foraging data to explain brook trout habitat selection within the Shavers Fork watershed, WV. Habitat selection by brook trout was modeled as a function of habitat quality, where habitats that supported the best growth potential were considered to be of highest quality. We found that growth was best suited for brook trout using large mainstem habitat during cold years, while fewer habitats within the mainstem supported better growth than the average tributary foraging position in hotter years. Mean density estimates confirmed brook trout preference for higher quality foraging habitat in tributaries during hotter years. This was evident by increased brook trout densities in tributaries during hot years, while densities decreased in the mainstem under these conditions. Simulated increased temperatures, as expected with climate change, showed a consistent reduction of profitable habitat in the larger mainstem locations. In particular, large brook trout were confined to tributaries during summer months with a marginal increase in temperature (plus $1^{\circ} \mathrm{C}$ ). Our results suggest that the mainstem is an important supplementary foraging habitat for brook trout, that not only provides higher quality prey, but also reduces density-dependent foraging stress from crowded tributaries. With increases in stream temperatures predicted by climate change models, our results indicate brook trout will need to move into cooler tributaries to alleviate thermal stress. This could prove detrimental to brook trout productivity on the riverscape, by confining higher numbers of brook trout to already food and space limited tributaries.
\end{abstract}

\title{
Introduction:
}

Optimal foraging theory predicts that an organism will chose habitat that maximizes energy intake while minimizing risks (Charnov 1976, Gilliam and Fraser 1987, Young et al. 1998). However, some individuals within a population may be more susceptible to habitat specific characteristics than others within the same population. For example, a small organism may perceive competition as a greater 
threat for energetic intake than a larger individual (see Fausch and White 1981, Hughes 1998, Petty and Grossman 2010). Alternatively, larger individuals likely need to consider habitats where environmental characteristics have substantial effects on their energy intake. For instance, Hughes (1998) predicts larger fish will move upstream because bigger fish require colder temperatures to reduce metabolic costs.

Many criteria can influence energetic intake in aquatic ecosystems, few as important as temperature (Hughes and Grand 2000, Isaak and Hubert 2004, Rieman et al. 2007, Petty et al. 2012). Not only does temperature directly affect the growth potential of aquatic consumers (Hanson et al. 1997, Hartman and Cox 2008, Huryn et al. 2008), but may indirectly impact growth potentials. For example, Taniguchi et al. (1998) demonstrated that competition can be influenced by temperature changes. They specifically showed a cold water fish (brook trout, Salvelinus fontinalis) being less competitive under high temperatures than a warm water fish (creek chub, Semotilus atromaculatus). Common among aquatic ectotherms is the presence of optimal thermal performance ranges, in addition to having critical thermal maxima and minima (Jobling 1981). Many salmonids have been shown to aggregate near thermal refugia when ambient temperatures reach these thermal limits (Breau et al. 2007, Young et al. 2010, Petty et al. 2012). This suggests that access to finer scale thermal refugia may also be an important factor contributing to growth potential of aquatic ectotherms.

Habitat selection by fishes has frequently been modeled based on energetics (Grossman 2013, Piccolo et al. 2013, Rosenfeld et al. 2013). For salmonids that are commonly classified as drift-feeders, net energetic intake models (NEI) are valuable because they can incorporate habitat specific temperature regimes and prey delivery (i.e. drift), even though not all factors influencing habitat selection are always accounted for (Rosenfeld and Boss 2001, Grossman 2013). The utility of energetic models in predicting habitat quality, growth potentials, and fish distributions has been demonstrated at the microhabitat (Rosenfeld et al. 2005, Urabe et al. 2010), channel unit (Rosenfeld and Boss 2001, Jenkins and Keeley 2010, Kawai et al. 2014) and reach scales (Hughes 1998, Gowan and Fausch 2002). Consequently, energetics is often combined with spatial population models to describe fish distributions. Hughes (1998) used an ideal-free distribution along with NEI models to explain larger arctic grayling (Thymallus 
arcticus) being distributed in the upper sections of a stream continuum. Alternatively, Petty and Grossman (2010) demonstrated a pre-emptive habitat selection model (which uses social hierarchies to describe habitat selection) in combination with a profitable patch model to best explain mottled sculpin (Cottus bairdi) distributions in the Coweeta drainage in North Carolina.

Aquatic population distributions have been studied extensively in recent years, due to anticipated loss of habitat from climate change and invasive species introductions (Flebbe et al. 2006, Haak et al. 2010, Isaak et al. 2010, Wenger et al. 2011a, Wenger et al. 2011b). Often these impacts are modeled at broad spatial scales, where habitats become uninhabitable due to environmental and biological alterations. However, these mechanisms also operate at the riverscape (Faush et al. 2002), affecting not only whether a habitat can be occupied, but also the quality of the habitat (e.g. support of somatic growth). In particular, Petty et al. (2014) demonstrated a unique riverscape pattern in energetic response by brook trout during cold vs. warm years in the Shavers Fork watershed. They observed greater growth in brook trout during cold years when dispersed across the watershed, while reduced growth rates were observed when confined to small tributaries in warm years. They termed this response as the "temperatureproductivity squeeze", where a combination of density-dependent and density-independent mechanisms affected brook trout growth potential on the riverscape. Here we use energetic profitability criteria to explain brook trout habitat selection within the Shavers Fork watershed, with particular focus on the temperature-productivity squeeze. Understanding how brook trout may perceive this watershed in an energetic riverscape framework would be invaluable in lieu of impending climate change impacts. Our objectives for this study were to: 1) determine the locations of optimal growth potential for brook trout in the Shavers Fork watershed under cold, warm, and hot temperature regimes, 2) identify temperature scenarios in which different habitat types are no longer profitable for brook trout use within this watershed, and 3) use energetic criteria to explain the brook trout expansion and contraction at the watershed scale observed by Petty et al. (2014). 


\section{Methods}

Study Site:

Shavers Fork, WV, is a HUC 10 watershed that supports populations of three salmonid species, brook trout, brown trout (Salmo trutta), and rainbow trout (Oncorhynchus mykiss). Of these 3 trout species, only brook trout are native to the watershed. A unique spatial structure of the brook trout population has been identified, where small headwater tributaries serve as important nursery "source" habitats (Petty et al. 2005, Huntsman and Petty 2014, Chapters 2 and 3). The large mainstem habitats, however, do not support reproductive activity, but likely provide important supplementary foraging habitat for large brook trout (Petty et al. 2014, Chapter 2). Use of this supplementary habitat has been shown to be dependent on a combination of mass effects from source tributaries (Chapter 2) and limited thermal refugia in the mainstem (Petty et al. 2014, Huntsman and Petty 2014, Chapter 2). Evidence suggests that brook trout in the headwaters are likely limited by available foraging positions while mainstem fish are limited by available thermal refugia (Huntsman and Petty 2014).

\section{Temperature Data:}

Stream temperature has been monitored at multiple locations in the Shavers Fork watershed (Figure 1) since 2001 using HOBO Water Temp Pro V2 data loggers. Temperature data from 3 tributary locations (i.e. small tributary, large tributary 1, and large tributary 2) and 5 mainstem locations were selected to account for the variability in temperature regimes experienced by brook trout at the watershed scale. Five additional stream temperature loggers were deployed within Shavers Fork's mainstem on April 21, 2013, in an attempt to better represent all potential variability in mainstem temperatures. Mainstem temperature logger locations were selected to represent habitats that represent potential thermal refuge and susceptibility to warming along the mainstem continuum (Figure 1). Stream temperature within the smaller tributaries were assumed to be relatively homogenous (Hughes 1998) compared to mainstem temperatures (Torgerson et al. 1999), and therefore temperature loggers were not deployed to monitor fine scale temperature variability within the tributaries. The tributaries were also assumed to 
demonstrate thermal regimes typical of other similar sized tributaries within the watershed, therefore, only these tributary temperature regimes were used for growth simulations.

Multiple stepwise linear regression analysis, similar to that outlined in Tincher (2013), was used to develop temperature models for data collected from the 5 temperature loggers deployed in April 2013. Temperature models were constructed with the 7 day moving average of mean temperature as the response variable. Predictor variables used for model construction were collected from a local climate station in Elkins, WV (wunderground.com) and from a local U.S. Geological Survey stream gaging station at the Cheat Bridge (USGS 03067510). Climate variables used for model construction were also 7 day moving averages for the following variables: stream discharge, mean daily air temperature, minimum daily air temperature, barometric pressure, visibility, and wind velocity. Other variables extracted from the climate station had high correlation $(r \geq 0.90)$ with at least one of the previously mentioned predictor variables and were removed from model development (Tincher 2013). Variables were sequentially removed during model development using depletion tests within a stepwise regression framework. Deletion tests remove the least significant parameter from a model and then uses $F$-tests $(\alpha=0.15)$ to identify the most parsimonious model that balances complexity and variability explained (Merriam et al. 2013). We used an $\alpha$ of 0.15 and correlation values greater than or equal to 0.90 as criteria to remove variables in an attempt to preserve as many variables in model development as possible with the intentions to increase model predictability. The final models were then used to backcast temperatures at all temperature monitoring stations based on historic climatic variables. Specifically, temperatures were backcast for 3 years that demonstrated relatively cold, warm, and hot temperature regimes $(2001,2005$, and 2010).

\section{Consumption Estimates:}

We used seasonal daily growth estimates (grams of wet mass gained/grams of fish mass/day, g/g/day) from previously collected capture-mark-recapture (CMR) data (Petty et al. 2005, 2014, Chapter 
3, B. Huntsman unpublished data) to obtain reliable estimates of proportion of maximum consumption $\left(\mathrm{PrC}_{\max }\right.$ in bioenergetics). Daily growth estimates were calculated from the equation

$$
G=\left(\ln X_{t}-\ln X_{0}\right) / \Delta t, \quad(1)
$$

where $X_{t}$ is the final mass ( $\mathrm{g}$ ) at time $t, X_{0}$ is the initial mass, and $\Delta t$ is the number of days between recapture (Petty et al. 2014). To be sure that growth estimates represented growth experienced for the desired season, only brook trout that were recaptured during consecutive sampling intervals were used. For example, a summer growth estimate was taken from an individual first captured in June and recaptured in August of the same year.

The majority of growth data was collected from 2004-2005, therefore, backcasted temperature data for those sampling periods were used in bioenergetics 3.0 software to estimate the $\mathrm{PrC}_{\max }$ (henceforth “consumption”) at all temperature monitoring locations. A brook trout specific bioenergetics model developed by Hartman and Sweka (2001) and updated by Hartman and Cox (2008) was used for bioenergetics simulations. We simulated consumption estimates under the assumption that competition for foraging microhabitat was the limiting factor controlling growth in the tributaries, while thermal refugia was the limiting factor controlling growth potentials in mainstem habitats (Petty et al. 2014, Chapter 1 and 2). We simulated consumption estimates for 3 potential foraging positions in each tributary: "the best position" indicated by the maximum growth observed from CMR data in each tributary type (small and large tributary), "the average position" indicated by the average growth rate from the span of CMR data, and "the worst position" indicated by the lowest growth estimate observed from CMR. This then allowed for season specific estimates of consumption for each size-class, based on the distribution of growth observed from CMR data. For example, consumption at the best headwater foraging position during the spring would be represented by the amount of food needed for a fish to demonstrate the greatest spring growth observed from CMR data.

Consumption was similarly estimated for each mainstem temperature monitoring location to account for temperature heterogeneity common in larger water bodies (Hughes 1998, Torgerson et al. 1999) This was estimated only for the average growth observed in the mainstem by CMR data, because 
thermal refugia was considered the limiting factor in the mainstem, not foraging positions. Because brook trout within this watershed have been shown to aggregate near cold-water sources during times of elevated temperatures (especially in the mainstem, Petty et al. 2012), we adjusted mainstem temperature regimes at each monitoring station to never exceed $18^{\circ} \mathrm{C}$. This maximum temperature value was used because Petty et al. (2012) found brook trout in mainstem habitats to rarely reside in microhabitats with temperatures in excess of $18-19^{\circ} \mathrm{C}$ (Figure 2, from Petty et al. 2012). Therefore, consumption for brook trout in the mainstem was estimated from the likely temperature regimes a fish would experience in the mainstem. A final consumption was then estimated by taking the average estimate at each mainstem monitoring location after temperatures were adjusted.

Consumption was estimated for 3 seasons for both small and large adult size-classes. Small adult (SA) brook trout are classified as any fish between 60-100mm standard length (SL) in the spring and 75$115 \mathrm{~mm}$ in the summer and fall (Petty et al. 2005). Large adults (LA) were brook trout greater than $100 \mathrm{~mm}$ in the spring and greater than $115 \mathrm{~mm}$ in the summer and fall. We simulated consumption and growth (see following sections) estimates based on a fish of 10g (approximately 90mm SL) as a small adult and 50g for a large adult (based on the mean weight of all fish greater than 115mm SL from longterm monitoring in this watershed, see Tincher 2013). The spring simulation period was designated as April 1 to June 30, summer was from July 1 to August 31, and fall was from September 1 to October 31. Prey items that contributed to the diet of both size-classes by season were taken from Petty et al. (2014) to estimate consumption. Prey energy densities (Joules/g) were taken from Cummins and Wuycheck (1971). Values for prey items used can be found in Appendix E. Lastly, brook trout energy density (4317 J/g) used in bioenergetics simulations was taken from Hartman and Sweka (2001).

\section{Growth Simulations:}

Growth was simulated across 3 temperature regimes (cold, warm, and hot) for each site, each season, while holding consumption constant across thermal regimes. Growth was also simulated for each scenario for both brook trout size-classes. Growth in the tributaries was simulated based on the maximum, 
average, and minimum observed consumption to represent pre-emptive microhabitat selection by brook trout. Under the pre-emptive model, microhabitat quality should not be affected by density, since the most competitive individuals would maintain the best possible foraging position, unlike the ideal-free model that predicts reduced habitat quality as density within a patch increases (Rodenhouse et al. 1997).

Simulations were also run under the 3 temperature regimes with incremental increases in daily temperatures $\left(1,2\right.$, and $\left.3^{\circ} \mathrm{C}\right)$, while holding consumption estimates the same. For example, $1^{\circ} \mathrm{C}$ was added to each day of a growth simulation to identify how temperature increases would affect growth at each location. These simulations were run to identify when specific habitats within the watershed would no longer be profitable using the current consumption estimates.

\section{Watershed Expansion/Contraction:}

To explain the expansion and contraction of brook trout on the riverscape, we made the assumption that brook trout would stay in tributaries if tributary growth potential was greater than growth potential in the mainstem. Similar justification has been used by Gowan and Fausch (2002), where brook trout movement was explained by differences in growth potential between habitats of varying energetic quality. Additionally, since brook trout origins begin in small tributaries (Petty et al. 2005), this is likely a valid assumption for our modeling approach.

\section{Results}

\section{Temperature Models:}

Stepwise multiple linear regressions found 3 predictor variables common among all sites for model development at the 5 temperature logger locations deployed in April 2013 (mean daily air temperature, maximum humidity, and barometric pressure, Table 1). Visibility and discharge were also important variables for model development, however, not for every site. Observed vs. predicted mean 7 day moving averages showed relatively strong correlation between observed and predicted temperature values for all sites (Figure 3). Summary statistics and prediction equations can be found in Table 1. 
Backcasted mean daily temperatures for the spring were hottest in 2010 at all sites, while 2001 temperatures were coldest at 11 of 13 monitoring locations (Figure 4). Summer mean daily temperatures were also coldest in 2001 at all sites. The hottest temperatures were observed in 2010 for 6 sites, and in 2005 for the other 5 sites. Similar to spring, fall temperatures were also hottest in 2010 and coldest in 2001, with a few exceptions (Figure 4).

\section{CMR Growth and Consumption Estimates:}

Capture-mark-recapture data showed that the mainstem supported the greatest brook trout growth during the spring (fall $\mathrm{t}_{\mathrm{t}-1}$ to spring $_{\mathrm{t}}$ for both SA and LA (Figure 5, Table 2). The summer ( $\operatorname{spring}_{\mathrm{t}}$ to summer $_{t}$ ) on the other hand showed growth being greatest between the mainstem and larger tributaries for both size-classes (Figure 2). Capture-mark-recapture data for the fall ( summer $_{\mathrm{t}}$ to fall ${ }_{\mathrm{t}}$ ), demonstrated the highest growth rates in larger tributaries for SA, but in the mainstem for LA. However, large variability in maximum and minimum growth rates can be observed in the fall and summer for most of the site types (Figure 5, Table 2).

Consumption estimates from bioenergetics simulations showed an expected increase in consumption with increasing stream size (Table 2). Consumption estimates in SA were often greater than consumption by the LA size-class (mass-specific proportions of maximum consumption). Lastly, consumption estimates for both size-classes were greatest during the summer than either the spring or fall.

\section{Growth Simulations:}

Growth simulations found that spring growth was greatest for large adults during the warm temperature regime in each tributary (based on average consumption, Figure 6). At the mainstem sites, both cold and warm temperature regimes were interchangeable in supporting the best growth for LA sizeclasses. During the hot year, growth was lowest for all but one site (mainstem 3, Figure 6), which the warm temperature regime for that site showed among the greatest variability across years and sites (C.V. $=48 \%$, only large tributary 1 had a higher C.V. but a much lower mean temperature, Figure 4). Positive 
growth potential was observed at all sites under all temperature conditions, with the exception of large tributary 2 (hot year, Figure 4). Similar to patterns observed for LA, SA spring growth potential was also greatest during warm years in all tributary sites (Figure 7). Additionally, SA best growth conditions in the mainstem were also interchangeable. Lastly, large tributary 2 during the hottest year was again the only site demonstrating negative growth (Figure 7).

Summer growth simulations showed much greater disparity in profitable habitat under different temperature regimes, most notably for the LA size-class. The cold years showed the best growth conditions at all sites for both size-classes (Figure 6 and 7). The mainstem in particular, showed limited profitable growth during this season, especially during hot years. During the cold year in the mainstem, four sites supported positive growth for LA, while two were profitable during the warm year, and only 1 during the hottest year (Figure 6). Small adults however, demonstrated positive growth at all sites, but 2 mainstem sites during the hottest year (mainstem 3 and 8, Figure 7). Interestingly, tributary use seemed to be best suited for LA than SA in the summer since growth was positive under all temperature scenarios for LA in tributaries, while SA growth was greater in the mainstem than tributaries (Figure 6 and 7)

Fall growth simulations for both LA and SA were greatest during the cold year for nearly all locations (mainstem 8 as the exception for both size-classes), and lowest during the hottest year (Figure 6 and 7). Growth for the LA size-class seemed to be best in the mainstem, especially mainstem $1,4,5$, and 7, which happen to be the sites supporting positive LA growth during the summer. The best growth for SA on the other hand was observed in the large tributary sites. Lastly, the hot year for both SA and LA showed negative growth at multiple locations (small tributary, mainstem 2, 3, 6, 8, 9, and 10, Figure 6 and 7).

\section{Growth Under Increasing Temperatures:}

Spring growth simulations under increasing temperature regimes showed all sites for LA in a hot year to be un-suitable for growth with a $2^{\circ} \mathrm{C}$ increase (Figure 6). An increase of $3^{\circ} \mathrm{C}$ showed that all sites during a warm year become un-suitable for growth, while a cold year in the mainstem still supported 
many profitable locations. Similarly, SA demonstrated a complete loss in profitable growth habitat during a hot year with an increase in temperature by $2^{\circ} \mathrm{C}$, although the small tributary site was an exception (Figure 7). However, a $3^{\circ} \mathrm{C}$ increase indicated that nearly all locations in a warm year were unsuitable to support growth, and SA were only able to grow in the mainstem during cold years (Figure 7).

Summer growth simulations under increasing temperatures demonstrated that all mainstem locations were unsuitable for LA growth with only $1^{\circ} \mathrm{C}$ increase. With an increase of $2^{\circ} \mathrm{C}$, nearly all habitat (considering only the average tributary foraging positions) within the watershed demonstrated negative growth for a LA (large tributary 1 demonstrated little growth, Figure 6). Small adults on the other hand were less susceptible to increased summer temperatures. Three mainstem locations supported positive growth for SA during both warm and hot summers after a $2^{\circ} \mathrm{C}$ increase (Figure 7). With a $3^{\circ} \mathrm{C}$ increase, 3 mainstem locations still supported positive growth during warm years.

Large adult growth simulations during the fall showed that no location supported positive growth during a hot year after a $2^{\circ} \mathrm{C}$ increase (Figure 6). An additional degree increase in temperature during the fall supported positive growth for only 4 locations during a cold fall, while only 1 mainstem site (5) would support positive growth during a warm fall. Small adults demonstrated positive growth in only 4 locations in a cold fall and 1 location in a warm fall with a $2^{\circ} \mathrm{C}$ increase (Figure 7). After a $3{ }^{\circ} \mathrm{C}$ increase, only 1 location during a cold fall (large tributary 1) supported positive growth for the SA size-class.

\section{Watershed Expansion/Contraction:}

The SA and LA size-classes demonstrate similar responses to growth potential with changing temperatures across sites. Therefore, only patterns in growth potential for the LA size-class will be described (See Figure 8). During a cold spring, LA growth was greatest at the best foraging position in large tributary 1 and mainstem 1 and 4 (Figure 8). However, all mainstem locations supported better growing conditions than the average foraging positions in any tributary site. Fewer mainstem locations during a warm spring however, were found to be better foraging positions than the average position in both the small tributary and the large tributary 1 site. During a warm and hot spring, the average small 
tributary and large tributary 1 foraging positions were better than a few main stem location (8 and 3, Figure 8). However, differences between the average tributary foraging positions and the mean growth potential within mainstem sites (mean growth potential in the main stem was calculated as the average growth observed for the grouped sites) was less in the hot year than in the cold year.

During the summer, the best foraging positions at all tributary sites were better than all mainstem locations under each temperature scenario (Figure 8). Additionally, the average foraging position for both large tributary sites was as good if not better than that observed at the mainstem locations across all temperature regimes. Three mainstem locations $(1,4$, and 5) were shown to support greater growth than the average small tributary foraging location during a cold summer (Appendix F). This number of foraging locations in the mainstem consistently went down with increasing temperatures, from 2 during the warm summer to 1 during the hot summer (Figure 8).

The best foraging position at the small tributary site was much greater than all other sites during all fall temperature regimes (Figure 8). During the cold fall, all mainstem locations supported greater growth than the average small tributary foraging site. Seven of 10 mainstem locations during the cold fall were better foraging positions than either of the large tributary average foraging locations. Similar to the previous seasons, the warm year showed fewer mainstem locations being better for growth than the average positions available in the small and large tributaries. During the hottest year, only the average large tributary 1 site supported positive LA growth (out of the average positions available in all the tributaries). This foraging position supported better growth than 6 of 10 mainstem locations during the hot fall (Figure 8).

\section{Discussion}

Riverscape Growth Potential across Temperature Regimes:

Brook trout growth potential within the Shavers Fork tributaries demonstrated unique responses across seasons during different temperature regimes (both size-classes demonstrated similar patterns). Fish growth was on average greater during the warm spring than the cold spring. Optimal growth 
temperatures for a LA brook trout feeding at approximately $30 \%$ of maximum consumption would experience the greatest growth at around $8^{\circ} \mathrm{C}$ (Figure 9). Both the small tributary and large tributary 1 experienced spring temperatures of the warm year to be closer to $8^{\circ} \mathrm{C}$ (Figure 4), while also demonstrating an average $\operatorname{PrC}_{\max }$ of approximately $30 \%$ (Table 2). This likely explains why a warmer year in the tributaries would provide better growing conditions than a colder year. Xu et al. (2010) also observed greater growth rates for tributary brook trout during years of warm springs, as we have also shown with our growth simulations. Summer and fall growth potentials were highest during cold years under every temperature regime simulation, which similarly can be explained by the mean temperature and $\mathrm{PrC}_{\max }$ estimates for those sites (Figure 4, Figure 9, Table 2). Fall growth estimates are likely reduced during warm falls due to brook trout spawning at this time (Clark and Rose 1997), in addition to temperature regimes exceeding optimal temperatures for the simulated consumption estimates. Since we used consumption estimates from previously collected CMR data, loss of mass by spawning brook trout would be accounted for in the average consumption estimate used for our growth simulations, and likely contribute to the negative growth observed during hot years for both size-classes (Figure 7 and 8).

Mainstem locations showed greater variability in the best growth positions among temperature regimes. For example, growth simulations for both LA and SA were best in the warm spring for 6 of 10 locations, while 4 of 10 mainstem locations supported the best growth during the cold spring. This result however is likely due to a combination of factors. First, similar to that observed in the tributaries during the spring, the combination of local temperature regimes and $\mathrm{PrC}_{\max }$ could explain greater growth during the coldest spring in 4 of 10 mainstem locations (the coldest temperatures were often closest to $10^{\circ} \mathrm{C}$, where optimal growth would occur under a $\operatorname{PrC}_{\max }=40 \%$ ). However, this does not explain the patterns observed for the other 6 mainstem locations. In addition to mean temperatures approaching that required for optimal growth conditions (Figure 9), variability in temperature regimes can also affect growth. For example, we simulated growth for a LA with similar consumption and mean temperatures (consumption $=$ 0.41 and temperature $=11^{\circ} \mathrm{C}$ ), while only variability in temperature differed (standard deviation of $0^{\circ} \mathrm{C}$ and $\left.3^{\circ} \mathrm{C}\right)$. The results of this simulation showed lower growth for the higher variability simulation 
(standard deviation of $0=56.35 \mathrm{~g}$, standard deviation of $3=46.87 \mathrm{~g}$ ). This specific simulation represents the spring 2005 for mainstem 3, which happens to be among the highest variability observed in spring stream temperatures for any site or year (Figure 7).

During seasons with higher mainstem temperature, the importance of thermal refugia seemed to differ between brook trout size-classes. In the summer in particular, profitable growth for LA was only observed at mainstem locations that represented thermal refugia (Figure 4 and Figure 7), which supports the hypothesis that thermal refugia is a limiting resource in the mainstem in hot years (Petty et al. 2012, Petty et al. 2014, Huntsman and Petty 2014). This pattern was less important for the SA size-class based on simulated summer growth potentials (Figure 7 and Figure 8). Small adults in particular demonstrated positive growth at all mainstem locations, across all temperature regimes (except mainstem 3, 8, and 10 under the hottest scenario). The LA size-class on the other hand showed loss of all profitable growth locations during the hottest summer in the mainstem, and only 3 profitable locations were available during the warm summer (mainstem 1, 4, and 5). Hughes (1998) observed similar discrepancies in arctic grayling size-classes, where he was able to explain the greater size structure of grayling upstream as a function of mass specific metabolic rates. Here, LA growth simulations suggest that only the coldest mainstem locations can be used for positive growth during the summer, while most of the mainstem stays profitable for the smaller size-class.

\section{Profitable Habitat Loss with Increasing Temperatures:}

Simulated increases in the 3 temperature regimes (cold, warm, and hot) at all sites showed a substantial loss in profitable habitat for the LA size-class. This was especially noticeable in the summer, where a $1{ }^{\circ} \mathrm{C}$ increase in any temperature regime resulted in loss of weight at all mainstem locations (Figure 7). Under such scenarios in the summer, brook trout would be forced to find thermal refuge in the smaller, cold headwaters (see Energetic Habitat Selection on the Riverscape for more detail). With a temperature increase of $3^{\circ} \mathrm{C}$ (increase predicted for Randolph County, WV from 2050-2074, http://www.usgs.gov/climate_landuse/clu_rd/apps/nex-dcp30_viewer.asp), no location within the 
watershed would support positive growth for LA under current consumption levels in the summer. Spring and fall seasons however, would support positive growth for LA, especially during cold springs. This suggests that increased consumption estimates would be necessary for LA brook trout to maintain positive growth with temperature increases, or a potential thermal bottleneck could remove the less temperature tolerant brook trout populations. Stitt et al. (2014) showed that brook trout from northern populations demonstrated less thermal tolerance than more southern strains, suggesting brook trout found in warmer waters were better adapted to higher water temperatures. Investigation of finer scale variability in brook trout physiological and behavioral responses to climate change (e.g. critical thermal maximums of brook trout in tributaries versus mainstems) would provide a valuable next step in understanding the effects of climate change on brook trout populations, and warrants further investigation.

Not only would fewer locations within the mainstem be available for positive brook trout growth under predicted temperature increases, but fewer microhabitats within tributaries would be able to support positive growth. Under a pre-emptive habitat selection framework (Rodenhouse et al. 1997), the best possible growth would be demonstrated by the most dominant fish monopolizing the highest quality microhabitat (foraging position within the tributaries, Petty et al. 2014). We found through bioenergetic simulations that the maximum consuming individual in each tributary would lose weight during the summer of the hottest simulated year $\left(3^{\circ} \mathrm{C}\right.$ increase, Appendix F). In order for growth to occur, it would be necessary for brook trout in all habitats of this watershed to increase consumption to account for metabolic losses due to temperature (Ries and Perry 1996). This would be more realistic in the mainstem, where brook trout are more limited by thermal refugia than food (Petty et al. 2014). However, in some of the warmest mainstem sites (e.g. mainstem 8 and 10, Figure 4), temperatures exceeded critical thermal tolerance ranges $\left(25^{\circ} \mathrm{C}\right.$, Hartman and Sweka 2001). Therefore, a brook trout within the mainstem would either die or more realistically move to different microhabitats with more suitable thermal regimes (see Petty et al. 2012).

Energetic Habitat Selection on the Riverscape: 
Habitat selection based on pre-emption for the highest quality growing locations suggested that cold years provided more useable mainstem habitat than warm or hot years. This was evident by higher growth in more mainstem locations than supported by the average tributary positions. Mean annual growth showed that mainstem foraging locations supported the best habitat within the watershed during cold years, while the best growing habitat during hot years was in the tributaries (Figure 10). By assuming a fish has knowledge of all available habitats (Hughes 1998), we would expect brook trout to expand into mainstem locations during cold years and contract into cooler tributaries during hot years. Brook trout abundance estimates from a representative cold and hot year within this watershed, along with optimal growth estimates, provides evidence towards this hypothesis (Figure 10). It is not unrealistic to assume a mobile species like brook trout would have knowledge of habitats at a greater scale than the local microhabitat. Gowan and Fausch (2002) showed through NEI models that brook trout selected optimal foraging positions at the reach scale. Specifically, they were able to show through exclusion experiments that a dominant brook trout, when displaced from its optimal foraging position within a pool, would leave the occupied channel unit for another channel unit, as opposed to maintaining a less profitable position within the same channel unit. Similar justification was used by Hughes (1998) to describe size distributions of arctic grayling along a stream continuum, and provides reasonable justification for our approach to explain brook trout expansion and contraction within the Shavers Fork watershed first identified by Petty et al. (2014).

Increased temperatures are expected to have substantial effects on brook trout productivity at multiple spatial scales. Higher frequency of warm years is expected to result from climate change predictions in the mid-Atlantic (IPCC 2007), which would reduce the occurrence of brook trout expanding into mainstem supplementary habitats (Petty et al. 2014). As has been predicted by many fish distribution models, cold water fishes like brook trout are anticipated to lose much habitat and consequently be restricted to higher elevation refuge (Flebbe et al. 2006, McMahon et al. 2007, Wenger et al. 2011a). This would be expected to increase energetic stress on the brook trout population through elevated density-dependent effects on instantaneous growth (Petty et al. 2014). In the tributaries, fewer 
individuals would likely be able to satisfy the energetic demands required to support positive growth, since brook trout in tributaries have often been shown to be limited by food and habitat (Utz and Hartman 2009, Grossman et al. 2010, Xu et al. 2010, Grossman et al. 2012, Petty et al. 2014, Huntsman and Petty 2014). Within the mainstem, loss of thermal refugia is expected in addition to increased competition for the limited refugia remaining (Petty et al. 2014, Huntsman and Petty 2014). Competition would not be limited to intraspecific brook trout competition, but also extend into interspecific competition. Other studies have shown competition with brown trout can negatively impact brook trout occupancy and productivity within a watershed (Fausch and White 1981, Waters 1983, Wagner et al. 2013), and would likely affect Shavers Fork's brook trout population. Although brown and rainbow trout are most common in the mainstem of this watershed and likely would compete for important thermal refugia in the mainstem (Huntsman and Petty 2014), it is equally likely that these competitors would move into smaller tributaries to cope with thermal stress, further reducing available brook trout habitat (i.e. elevation refuge hypothesis, McMahon et al. 2007). Limited space and food in the tributaries as well as limited thermal refugia in the mainstem would then reduce the overall brook trout productivity within the entire watershed.

\section{Management Implications:}

Climate change scenarios predict a detrimental impact on many populations, especially on home range shifts and habitat loss (Flebbe et al. 2006, Rieman et al. 2007, Gibson et al. 2009, Isaak et al. 2010, Wenger et al. 2011a), as well as energetic consequences (Hill and Magnuson 1990, Ries and Perry 1995, Jenkins and Keeley 2010). These impacts are also anticipated to shift the timing of important life-history events, such as spawning runs in stream fishes like brook trout (Warren et al. 2012). Here we found temperature increases would likely reduce local brook trout productivity, and also affect productivity within the entire watershed. The mainstem in particular provides a very important habitat for brook trout. Not only does it serve as an important corridor to support brook trout movement among different tributaries, but has also been shown to greatly supplement growth potential for brook trout (Petty et al. 
2014, Chapter 2). Unlike other similar sized watersheds in this region, Shavers Fork is supported by a well-mixed patchy metapopulation (Aunins et al. in review). It has been suggested that this is likely due to the high elevation of Shavers Fork mainstem $(\sim 1100 \mathrm{~m})$, supported by temperature regimes much lower than surrounding watersheds (Aunins et al. in review). Maintaining this profitable connection between the mainstem and tributaries is undoubtedly an important strategy in order to preserve brook trout productivity (Petty et al. 2014). Restoration strategies that focus on improving thermal conditions in the mainstem (e.g. restoring riparian zones, deepening channels to access groundwater) will be imperative to keeping the mainstem accessible to the brook trout population of the Shavers Fork watershed due to impending alterations predicted by climate change (Petty and Merriam 2012).

\section{Acknowledgments:}

We would like to acknowledge numerous contributors to the development of this research, including Michael Tincher, Eric Merriam, Eric Miller, and Allison Anderson for help maintaining temperature loggers over the years. We would also like to thank Dr. Kyle Hartman for sharing his expertise with using Fish Bioenergetics 3.0.

\section{Works Cited:}

Aunins, A. W., J.T. Petty, T.L. King, M. Schilz, and P.M. Mazik. in review. Genetic differentiation and complex metapopulation structure of an Appalachian brook trout population. Conservation Genetics.

Breau, C., R.A. Cunjak, and G. Bremset. 2007. Age-specific aggregation of wild juvenile Atlantic salmon Salmo salar at cool water sources during high temperature events. Journal of Fish Biology 71:1179-1191.

Charnov, E. I. 1976. Optimal foraging, the marginal value theorem. Theoretical Population Biology 9:129-136. 
Clark, M.E., and K.A. Rose. 1997. Individual-based model of stream-resident rainbow trout and brook char: model description, corroboration, and effects of sympatry and spawning season duration. Ecological Modelling 94:157-175.

Cummins, K. W., and J. C. Wuycheck. 1971. Caloric equivalents for investigations in ecological energetics. International Association of Theoretical and Applied Limnology 18.

Fausch, K. D., and R.J. White. 1981. Competition between brook trout (Salvelinus fontinalis) and brown trout (Salmo trutta) for positions in a Michigan stream. Canadian Journal of Fisheries and Aquatic Sciences 38:1220-1227.

Fausch, K. D., C.E. Torgersen, C.V. Baxter, and H.W. Li. 2002. Landscapes to riverscapes: Bridging the gap between research and conservation of stream fishes. BioScience 52:483-498.

Flebbe, P. A., L.D. Roghair, and J.L. Bruggink. 2006. Spatial modeling to project Southern Appalachian trout distribution in a warmer climate. Transactions of the American Fisheries Society 135:13711382.

Gibson, S. Y., R.C. Van der Marel, and B.M. Starzomski. 2009. Climate change and conservation of leading-edge peripheral populations. Conservation Biology 23:1369-1373.

Gilliam, J.F., and D.F. Fraser. 1987. Habitat selection under predation hazard: test of a model with foraging minnows. Ecology 68:1856-1862.

Gowan, C., and K.D. Fausch. 2002. Why do foraging stream salmonids move during summer? Environmental Biology of Fishes 64:139-153.

Grossman, G. D., R. E. Ratajczak, C. M. Wagner, and J. T. Petty. 2010. Dynamics and regulation of the southern brook trout (Salvelinus fontinalis) population in an Appalachian stream. Freshwater Biology 55:1494-1508.

Grossman, G. D., A. Nuhfer, T. Zorn, G. Sundin, and G. Alexander. 2012. Population regulation of brook trout (Salvelinus fontinalis) in Hunt Creek, Michigan: a 50-year study. Freshwater Biology 57:1434-1448. 
Grossman, G. D. 2013. Not all drift feeders are trout: a short review of fitness-based habitat selection models for fishes. Environmental Biology of Fish:1-9.

Haak, A.L., J.E. Williams, H.M. Neville, D.C. Dauwalter, and W.T. Colyer. 2010. Conserving peripheral trout populations: the values and risks of life on the edge. Fisheries 35:530-549.

Hanson, P., T. Johnson, J. Kitchell, and E.E. Schindler. 1997. Fish bioenergetics [version] 3.0. University of Wisconsin Sea Grant Institute, Wisconsin, USA.

Hartman, K. J., and J. A. Sweka. 2001. Development of a bioenergetics model for Appalachian brook trout. Proceeding of the Annual Conference of the Southeastern Association of Fish and Wildlife Agencies 55:38-51.

Hartman, K. J., and K.M. Cox. 2008. Refinement and testing of a brook trout bioenergetics model. Transactions of the American Fisheries Society 137:357-363.

Hill, D. K., and J.J. Magnuson. 1990. Potential effects of global climate warming on the growth and prey consumption of great lakes fish. Transactions of the American Fisheries Society 119:265-275.

Hughes, N. F. 1998. A model of habitat selection by drift-feeding stream salmonids at different scales. Ecology 79:281-294.

Hughes, N. F., and T.C. Grand. 2000. Physiological ecology meets the ideal-free distribution: predicting the distribution of size-structured fish populations across temperature gradients. Environmental Biology of Fish 59:285-298.

Huntsman, B.M., and J.T. Petty. 2014. Density-dependent and density-independent mechanisms regulating brook trout population dynamics along a core-periphery distribution gradient. PLoS ONE 9:e91673. doi:10.1371/journal.pone.0091673.

Huryn, A. D. 1998. Ecosystem-level evidence for top-down and bottom-up control of production in a grassland stream system. Oecologia (1998) 115:173-183. 
IPCC (Intergovernmental Panel on Climate Change). 2007. Climate change 2007. Synthesis report. A contribution of Working Groups I, II, and III to the Fourth Assessment Report of the Intergovernmental Panel on Climate Change. Cambridge, UK: Cambridge University Press.

Isaak, D. J., and W.A. Hubert. 2004. Nonlinear response of trout abundance to summer stream temperatures across a thermally diverse montane landscape. Transactions of the American Fisheries Society 133:1254-1259.

Isaak, D. J., C.H. Luce, B.E. Rieman, D.E. Nagel, E.E. Peterson, D.L. Horan, S. Parkes, and G.L. Chandler. 2010. Effect of climate change and wildfire on stream temperatures and salmonid thermal habitat in a mountain river network. Ecological Applications 20:1350-1371.

James, D.A., I.J. Csargo, A. Von Eschen, M. D. Thul, J. M. Baker, C. Hayer, J. Howell, J. Krause, and A. Letvin. 2012. A generalized model for estimating the energy density of invertebrates. Freshwater Science 31:69-77.

Jenkins, A. R., and E.R. Keeley. 2010. Bioenergetic assessment of habitat quality for stream-dwelling cutthroat trout (Oncorhynchus clarkii bouvieri) with implications for climate change and nutrient supplementation. Canadian Journal of Fisheries and Aquatic Sciences 67:371-385.

Jobling, M. 1981. Temperature tolerance and the final preferendum - rapid methods for the assessment of optimum growth temperatures. Journal of Fish Biology 19:439-455.

Kawai, H., S. Nagayama, H. Urabe, T. Akasaka, and F. Nakamura. 2014. Combining energetic profitability and cover effects to evaluate salmonid habitat quality. Environmental Biology of Fishes:1-12.

McMahon, T. E., A.V. Zale, F.T. Barrows, J.H. Selong, and R.J. Danehy. 2007. Temperature and competition between bull trout and brook trout: a test of the elevation refuge hypothesis. Transactions of the American Fisheries Society 136:1313-1326.

Merriam, E.R., J.T. Petty, M.P. Strager, A.E. Maxwell, and P.F. Ziemkiewicz. 2013. Scenario analysis predicts context-dependent stream response to landuse change in a heavily mined central Appalachian watershed. Freshwater Science 32:1246-1259. 
Petty, J. T., P. J. Lamothe, and P. M. Mazik. 2005. Spatial and seasonal dynamics of brook trout populations inhabiting a central Appalachian watershed. Transactions of the American Fisheries Society 134:572-587.

Petty, J. T., and G.D. Grossman. 2010. Giving-up densities and ideal pre-emptive patch use in a predatory benthic stream fish. Freshwater Biology 55:780-793.

Petty, J. T., J.L. Hansbarger, B.M. Huntsman, and P.M. Mazik. 2012. Brook trout movement in response to temperature, flow, and thermal refugia within a complex Appalachian riverscape. Transactions of the American Fisheries Society 141:1060-1073.

Petty, J. T., and E.P. Merriam. 2012. Brook trout restoration. Nature Education 3:17.

Petty, J. T., D. Thorne, B.M. Huntsman, and P. Mazik. 2014. The temperature-productivity squeeze: contraints on brook trout growth along an Appalachian river continuum. Hydrobiologia 727:151166.

Piccolo, J. J., B.M. Frank, and J.W. Hayes. 2013. Food and space revisited: the role of drift-feeding theory in predicting the distribution, growth, and abundance of stream salmonids. Environmental Biology of Fishes:1-14.

Rieman, B. E., D. Isaak, S. Adams, D. Horan, D. Nagel, C. Luce, and D. Myers. 2007. Anticipated climate warming effects on bull trout habitats and populations across the interior Columbia River basin. Transactions of the American Fisheries Society 136:1552-1565.

Ries, R. D., and S. A. Perry. 1995. Potential effects of global climate warming on brook trout growth and prey consumption in central Appalachian streams, USA. Climate Research 5:197-206.

Rodenhouse, N. L., T.W. Sherry, and R.T. Holmes. 1997. Site-dependent regulation of population size: a new synthesis. Ecology 78:2025-2042.

Rosenfeld, J. S., and S. Boss. 2001. Fitness consequences of habitat use for juvenile cutthroat trout: energetic costs and benefits in pools and riffles. Canadian Journal of Fisheries and Aquatic Sciences 58:585-593. 
Rosenfeld, J. S., T. Leiter, G. Lindner, and L. Rothman. 2005. Food abundance and fish density alters habitat selection, growth, and habitat suitability curves for juvenile coho salmon (Oncorhynchus kisutch). Canadian Journal of Fisheries and Aquatic Sciences 62:1691-1701.

Rosenfeld, J. S., N. Bouwes, C.E. Wall, and S.M. Naman. 2013. Successes, failures, and opportunities in the practical application of drift-foraging models. Environmental Biology of Fishes:1-24.

Stitt, B. C., G. Burness, K.A. Burgomaster, S. Currie, J.L. McDermid, and C.C. Wilson. 2014. Intraspecific Variation in Thermal Tolerance and Acclimation Capacity in Brook Trout (Salvelinus fontinalis): Physiological Implications for Climate Change. Physiological and Biochemical Zoology, 87:15-29.

Sotiropoulos, J. C., K.H. Nislow, and M.R. Ross. 2006. Brook trout, Salvelinus fontinalis, microhabitat selection and diet under low summer stream flows. Fisheries Management and Ecology 13:149155.

Taniguchi, Y., F.J. Rahel, D.C. Novinger, and K.G. Gerow. 1998. Temperature mediation of competitive interactions among three fish species that replace each other along longitudinal stream gradients. Canadian Journal of Fisheries and Aquatic Sciences 55:1894-1901.

Tincher, M. 2013. Modeling water temperatures and brook trout (Salvelinus fontinalis) growth potential within a complex Appalachian riverscape. West Virginia University, Morgantown.

Urabe, H., M. Nakajima, M. Torao, and T. Aoyama. 2010. Evaluation of habitat quality for stream salmonids based on a bioenergetics model. Transactions of the American Fisheries Society 139:1665-1676.

Utz, R. M., and K. J. Hartman. 2009. Density-dependent individual growth and size dynamics of central Appalachian brook trout (Salvelinus fontinalis). Canadian Journal of Fisheries and Aquatic Sciences 66:1072-1080.

Wagner, T., J. T. Deweber, J. Detar, and J. A. Sweka. 2013. Landscape-Scale Evaluation of Asymmetric Interactions between Brown Trout and Brook Trout Using Two-Species Occupancy Models. Transactions of the American Fisheries Society 142:353-361. 
Warren, D. R., J.M. Robinson, D.C. Josephson, D.R. Sheldon, and C.E. Kraft. 2012. Elevated summer temperatures delay spawning reduce redd construction for resident brook trout (Salvelinus fontinalis). Global Change Biology 18:1804-1811.

Waters, T. F. 1983. Replacement of brook trout by brown trout over 15 years in a Minnesota stream: production and abundance. Transactions of the American Fisheries Society 112:137-146.

Wenger, S. J., D.J. Isaak, C.H. Luce, H.M. Neville, K.D. Fausch, J.B. Dunham, D.C. Dauwalter, M.K. Young, M.M. Elsner, B.E. Rieman, A.F. Hamlet, and J.E. Williams. 2011 ${ }^{\text {a }}$. Flow regime, temperature, and biotic interactions drive differential declines of trout species under climate change. PNAS 108:14175-14180.

Wenger, S.J., D.J. Isaak, J.B. Dunham, K.D. Fausch, C.H. Luce, H.M. Neville, B.E. Rieman, M.K. Young, D.E. Nagel, D.L. Horan, and G.L. Chandler. 2011 ${ }^{\mathrm{b}}$. Role of climate and invasive species in structuring tout distributions in the interior Columbia River Basin, USA. Canadian Journal of Fisheries and Aquatic Sciences 68:988-1008.

Xu, C., B.H. Letcher, and K.H. Nislow. 2010. Context-specific influence of water temperature on brook trout growth rates in the field. Freshwater Biology 55:2253-2264.

Young, M. K., K.A. Meyer, D.J. Isaak, and R.A. Wilkison. 1998. Habitat selection and movement by individual cutthroat trout in the absence of competitors. Journal of Freshwater Ecology 13:371381.

Young, R. G., J. Wilkinson, J. Hay, and J. W. Hayes. 2010. Movement and mortality of adult brown trout in the Motupiko River, New Zealand: Effects of water temperature, flow, and flooding. Transactions of the American Fisheries Society 139:137-146. 


\section{Tables:}

Table 1: Best models predicting mean 7 day moving average temperatures for the 5 mainstem locations where temperature loggers were deployed on April 21, 2013. Data was collected from temperatures loggers deployed to record stream temperature hourly.

\begin{tabular}{lccc}
\hline Site & p-value & $\mathbf{R}^{2}$ & Equation \\
\hline Mainstem 1 & $<0.001$ & 0.83 & $\mathrm{y}=0.6916$ temperature +0.1898 humidity +6.3686 pressure + \\
& & & 0.3031 visibility -210.3539 \\
Mainstem 4 & $<0.001$ & 0.83 & $\mathrm{y}=0.7035$ temperature +0.1877 humidity +6.4230 pressure + \\
& & & 0.3379 visibility -212.2449 \\
Mainstem 5 & $<0.001$ & 0.84 & $\mathrm{y}=0.7201$ temperature +0.1541 humidity +5.3080 pressure + \\
& & & 0.3404 visibility -0.0024 discharge -175.7000 \\
Mainstem 8 & $<0.001$ & 0.83 & $\mathrm{y}=0.7481$ temperature +0.1452 humidity +5.5920 pressure + \\
& & & 0.2766 visibility -0.0033 discharge -182.8000 \\
Mainstem 9 & $<0.001$ & 0.85 & $\mathrm{y}=0.7993$ temperature +0.0755 humidity +2.9064 pressure -0.0052 \\
& & & discharge -93.5521
\end{tabular}


Table 2: Growth (g/g/day) from capture-mark-recapture analyses and associated proportions of maximum consumption $\left(\operatorname{PrC}_{\max }\right)$ estimates from bioenergetics simulations. Each simulation is for the maximum, average, and minimum growth estimates for each site type (small tributary, large tributary, or mainstem) for each season and brook trout size-class.

\begin{tabular}{|c|c|c|c|c|c|c|c|c|c|c|c|c|}
\hline \multirow[b]{3}{*}{ SITE } & \multicolumn{4}{|c|}{ Spring } & \multicolumn{4}{|c|}{ Summer } & \multicolumn{4}{|c|}{ Fall } \\
\hline & \multicolumn{2}{|c|}{ Small Adult } & \multicolumn{2}{|c|}{ Large Adult } & \multicolumn{2}{|c|}{ Small Adult } & \multicolumn{2}{|c|}{ Large Adult } & \multicolumn{2}{|c|}{ Small Adult } & \multicolumn{2}{|c|}{ Large Adult } \\
\hline & Growth & $\mathbf{P r C}_{\max }$ & Growth & $\mathbf{P r C}_{\max }$ & Growth & $\mathbf{P r C}_{\max }$ & Growth & $\mathbf{P r C}_{\max }$ & Growth & $\mathbf{P r C}_{\max }$ & Growth & $\operatorname{PrC}_{\text {max }}$ \\
\hline $\begin{array}{l}\text { Small Tributary } \\
(\mathrm{min})\end{array}$ & 0.000 & 0.30 & 0.000 & 0.21 & -0.005 & 0.34 & -0.005 & 0.35 & -0.010 & 0.12 & -0.008 & 0.08 \\
\hline $\begin{array}{l}\text { Small Tributary } \\
\text { (avg) }\end{array}$ & 0.003 & 0.40 & 0.002 & 0.25 & 0.002 & 0.41 & 0.000 & 0.43 & 0.002 & 0.35 & -0.001 & 0.27 \\
\hline $\begin{array}{l}\text { Small Tributary } \\
(\max )\end{array}$ & 0.015 & 0.65 & 0.005 & 0.33 & 0.010 & 0.56 & 0.008 & 0.60 & 0.015 & 0.52 & 0.011 & 0.50 \\
\hline $\begin{array}{l}\text { Large Tributary } \\
(\mathrm{min})\end{array}$ & 0.000 & 0.28 & 0.001 & 0.33 & -0.002 & 0.39 & -0.004 & 0.50 & -0.002 & 0.28 & -0.003 & 0.19 \\
\hline $\begin{array}{l}\text { Large Tributary } \\
\text { (avg) }\end{array}$ & 0.002 & 0.33 & 0.002 & 0.35 & 0.005 & 0.47 & 0.002 & 0.71 & 0.005 & 0.39 & 0.001 & 0.29 \\
\hline $\begin{array}{l}\text { Large Tributary } \\
(\max )\end{array}$ & 0.005 & 0.39 & 0.005 & 0.53 & 0.008 & 0.51 & 0.008 & 0.86 & 0.013 & 0.49 & 0.006 & 0.38 \\
\hline Mainstem & 0.005 & 0.47 & 0.004 & 0.41 & 0.006 & 0.61 & 0.002 & 0.56 & 0.002 & 0.28 & 0.003 & 0.39 \\
\hline
\end{tabular}


Table 3: Mean density estimates (\#/m stream length) across seasons for 3 different temperature regimes for 5 site types and 2 size-classes (small adult "SA" and large adult "LA"). Densities were taken from 2002-2004, due to consistent sampling across the 3 season types (spring, summer, and fall). In the tributaries, the coldest year was in 2004 and the hottest in 2003. In the mainstem, the coldest year was in 2003 while the hottest year was in 2002. The upper mainstem sites consisted of mainstem 1 and 2 from Huntsman and Petty (2014) and the lower mainstem consisted of mainstem 3 and 4 from Huntsman and Petty (2014).

\begin{tabular}{|c|c|c|c|c|c|c|c|c|c|c|}
\hline \multirow[t]{2}{*}{ Site } & \multicolumn{2}{|c|}{ Small Tributary } & \multicolumn{2}{|c|}{ Large Tributary 1} & \multicolumn{2}{|c|}{ Large Tributary 2} & \multicolumn{2}{|c|}{ Upper Mainstem } & \multicolumn{2}{|c|}{ Lower Mainstem } \\
\hline & $\mathbf{S A}$ & LA & $\mathbf{S A}$ & LA & $\mathbf{S A}$ & LA & SA & LA & $\mathbf{S A}$ & LA \\
\hline Cold & $\begin{array}{l}0.396 \\
(0.120)\end{array}$ & $\begin{array}{l}0.049 \\
(0.021)\end{array}$ & $\begin{array}{l}0.093 \\
(0.017)\end{array}$ & $\begin{array}{l}0.052 \\
(0.008)\end{array}$ & $\begin{array}{l}0.093 \\
(0.012)\end{array}$ & $\begin{array}{l}0.026 \\
(0.008)\end{array}$ & $\begin{array}{l}0.017 \\
(0.005)\end{array}$ & $\begin{array}{l}0.015 \\
(0.004)\end{array}$ & $\begin{array}{l}0.008 \\
(0.002)\end{array}$ & $\begin{array}{l}0.012 \\
(0.004)\end{array}$ \\
\hline Warm & $\begin{array}{l}0.393 \\
(0.040)\end{array}$ & $\begin{array}{l}0.067 \\
(0.012)\end{array}$ & $\begin{array}{l}0.150 \\
(0.039)\end{array}$ & $\begin{array}{l}0.087 \\
(0.029)\end{array}$ & $\begin{array}{l}0.130 \\
(0.034)\end{array}$ & $\begin{array}{l}0.035 \\
(0.007)\end{array}$ & $\begin{array}{l}0.009 \\
(0.003)\end{array}$ & $\begin{array}{l}0.009 \\
(0.001)\end{array}$ & $\begin{array}{l}0.006 \\
(0.003)\end{array}$ & $\begin{array}{l}0.009 \\
(0.003)\end{array}$ \\
\hline Hot & $\begin{array}{l}0.300 \\
(0.107)\end{array}$ & $\begin{array}{l}0.077 \\
(0.003)\end{array}$ & $\begin{array}{l}0.118 \\
(0.049)\end{array}$ & $\begin{array}{l}0.085 \\
(0.036)\end{array}$ & $\begin{array}{l}0.111 \\
(0.061)\end{array}$ & $\begin{array}{l}0.061 \\
(0.023)\end{array}$ & $\begin{array}{l}0.022 \\
(0.004)\end{array}$ & $\begin{array}{l}0.007 \\
(0.002)\end{array}$ & $\begin{array}{l}0.015 \\
(0.005)\end{array}$ & $\begin{array}{l}0.008 \\
(0.003)\end{array}$ \\
\hline
\end{tabular}




\section{Figure Legends:}

Figure 1: Temperature logger locations for each site used in bioenergetics modeling.

Figure 2: Temperature mediated microhabitat selection by brook trout taken from Petty et al.

2012. Brook trout were rarely observed at temperatures greater than $19^{\circ} \mathrm{C}$, even when ambient temperatures exceeded $19^{\circ} \mathrm{C}$.

Figure 3: Observed vs. predicted mean 7 day moving average temperatures for the 5 deployed temperature data loggers.

Figure 4: Mean 7 day moving average backcasted temperatures from Tincher (2013) and from developed temperature models from the 5 recently deployed temperature loggers.

Figure 5: Cumulative frequency distributions of season specific growth estimates from capturemark-recapture data.

Figure 6: Simulated seasonal growth estimates for large adult brook trout under cold, warm, and hot temperature regimes under multiple increased temperature scenarios. Only the average foraging locations in the tributary sites (headwater and large tributaries) are provided.

Figure 7: Simulated seasonal growth estimates for small adult brook trout under cold, warm, and hot temperature regimes under multiple increased temperature scenarios. Only the average foraging locations in the tributary sites (headwater and large tributaries) are provided.

Figure 8: Growth potential at each foraging position across each season and temperature simulation for the large adult (50g) and small adult (10g) brook trout size-class. Circles represent the average foraging position at each site while the lines represent the range from the maximum to the minimum growth at those sites. The "headwater" site 
Figure 9: Growth curves for a large adult brook trout simulated under constant temperature regimes under multiple proportion of maximum consumption scenarios (PrCmax). Growth estimates are potential gains or losses to a $50 \mathrm{~g}$ fish over a 91 day simulation period.

Figure 10: Diagram showing best position for growth within the stream continuum over a cold and hot temperature year (averages over 3 seasons). Large fish represent abundances of large adults and small fish represent abundances of small adults. All abundances are standardized by the lowest observed abundance within a site type between all years in which abundances were collected every season (2002-2004). 


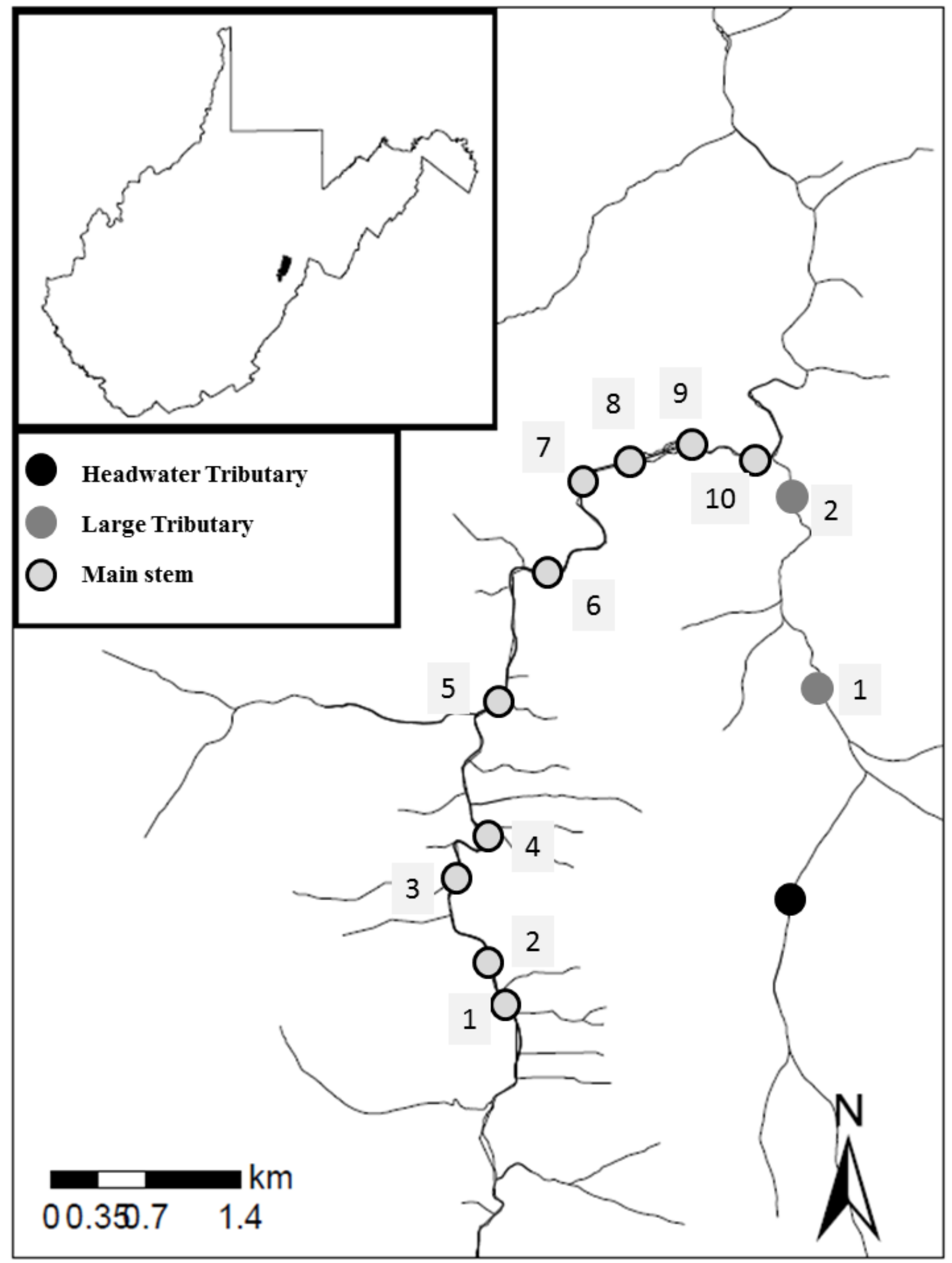

Figure 1 


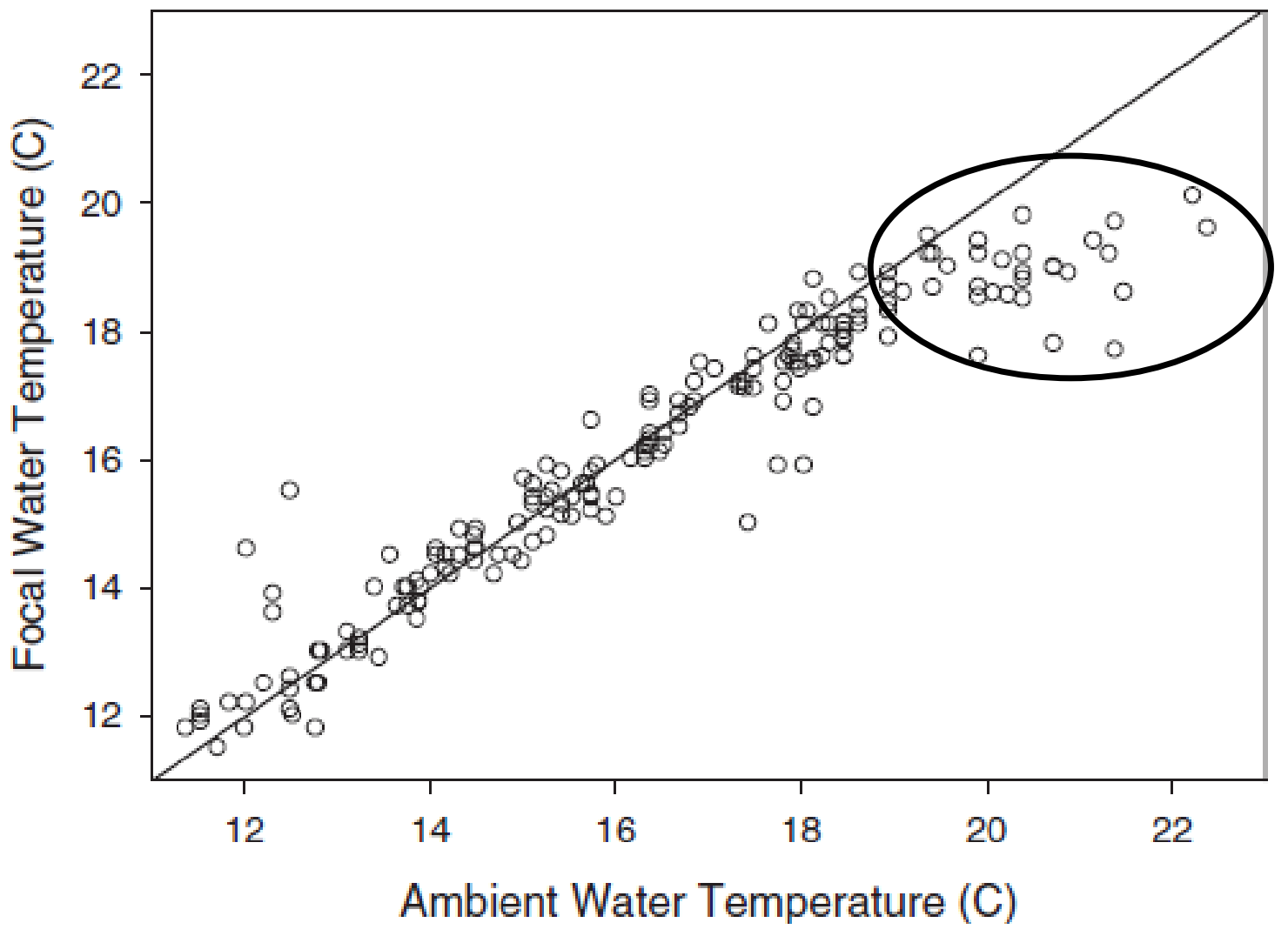

Figure 2 

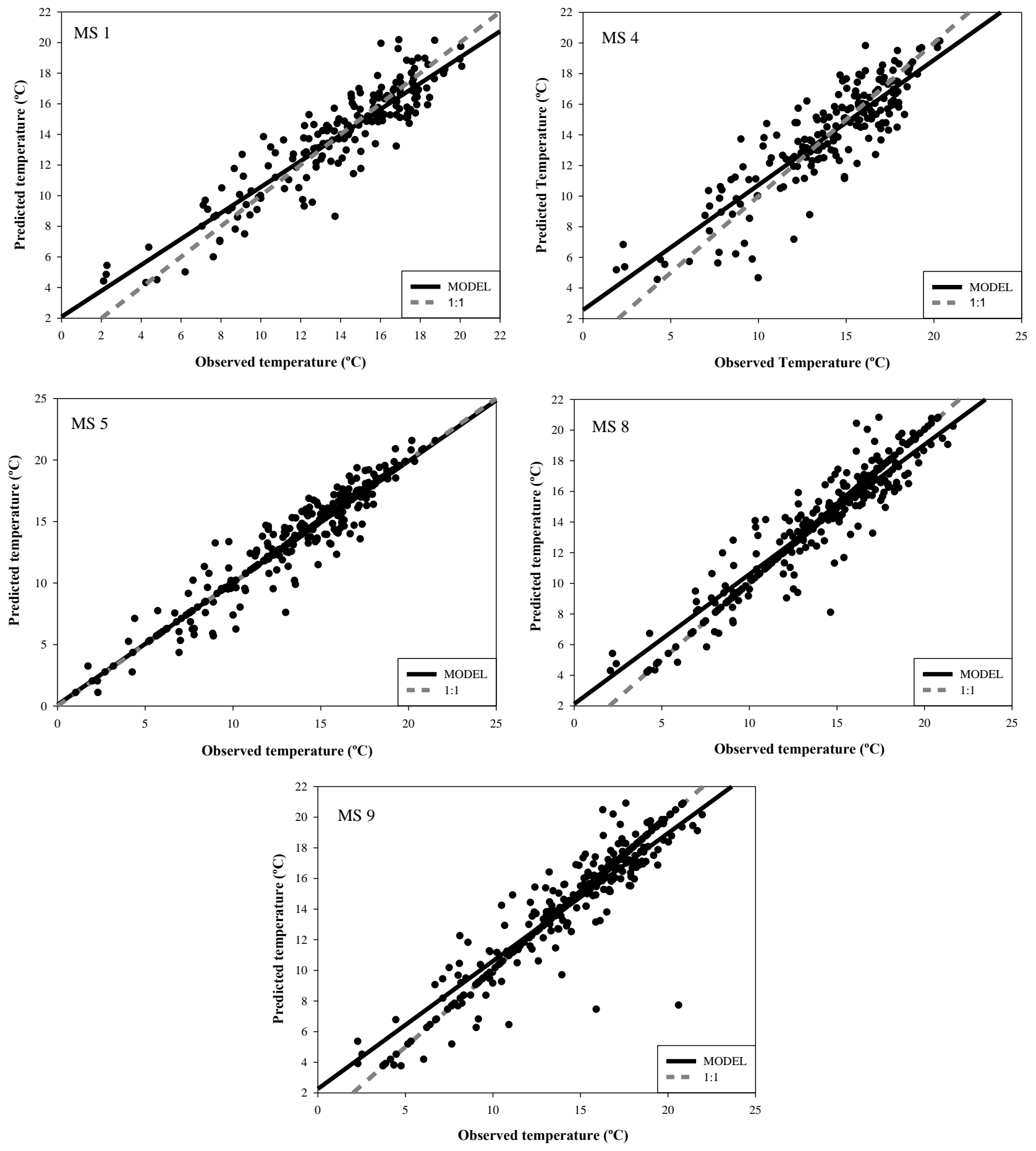

Figure 3 

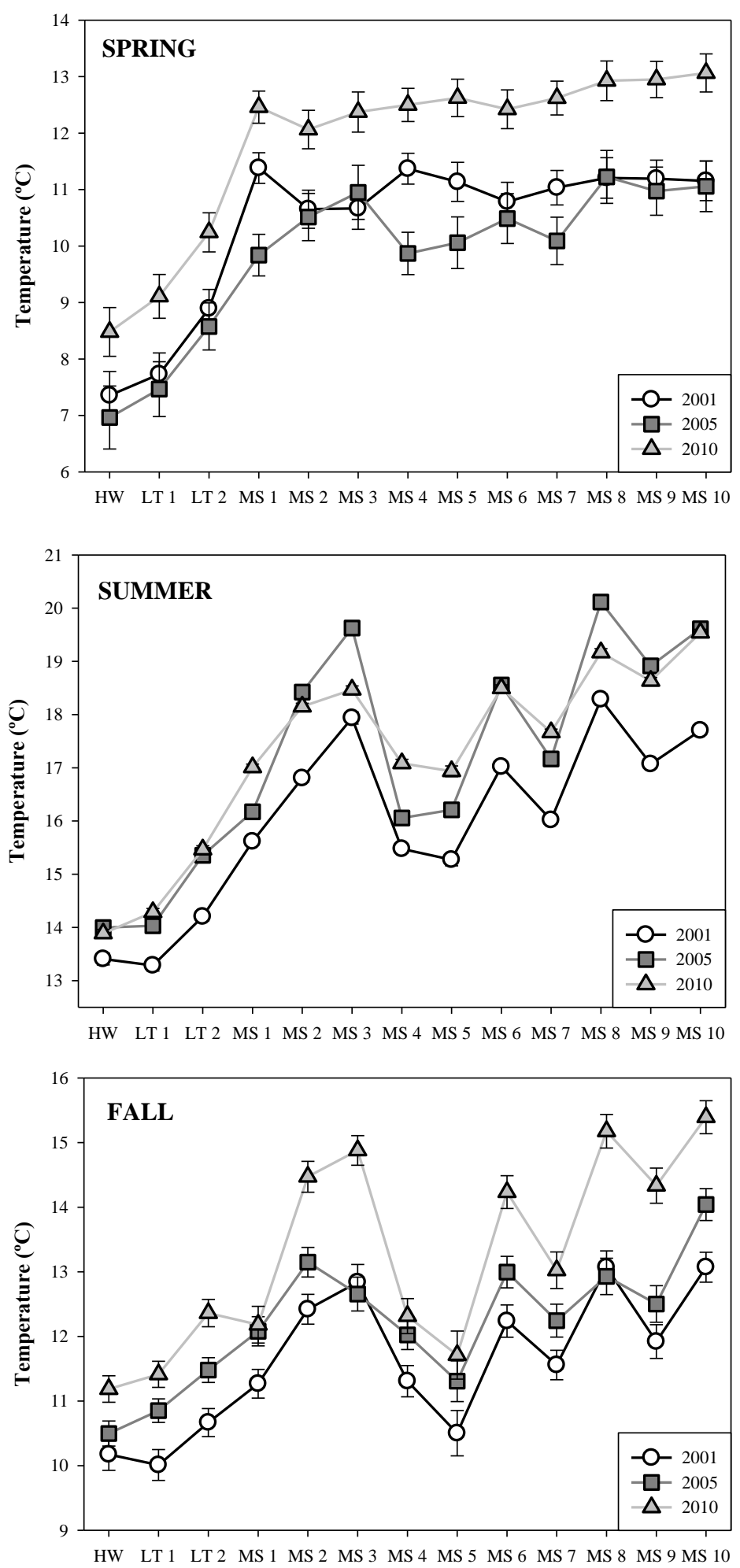

\section{Figure 4}



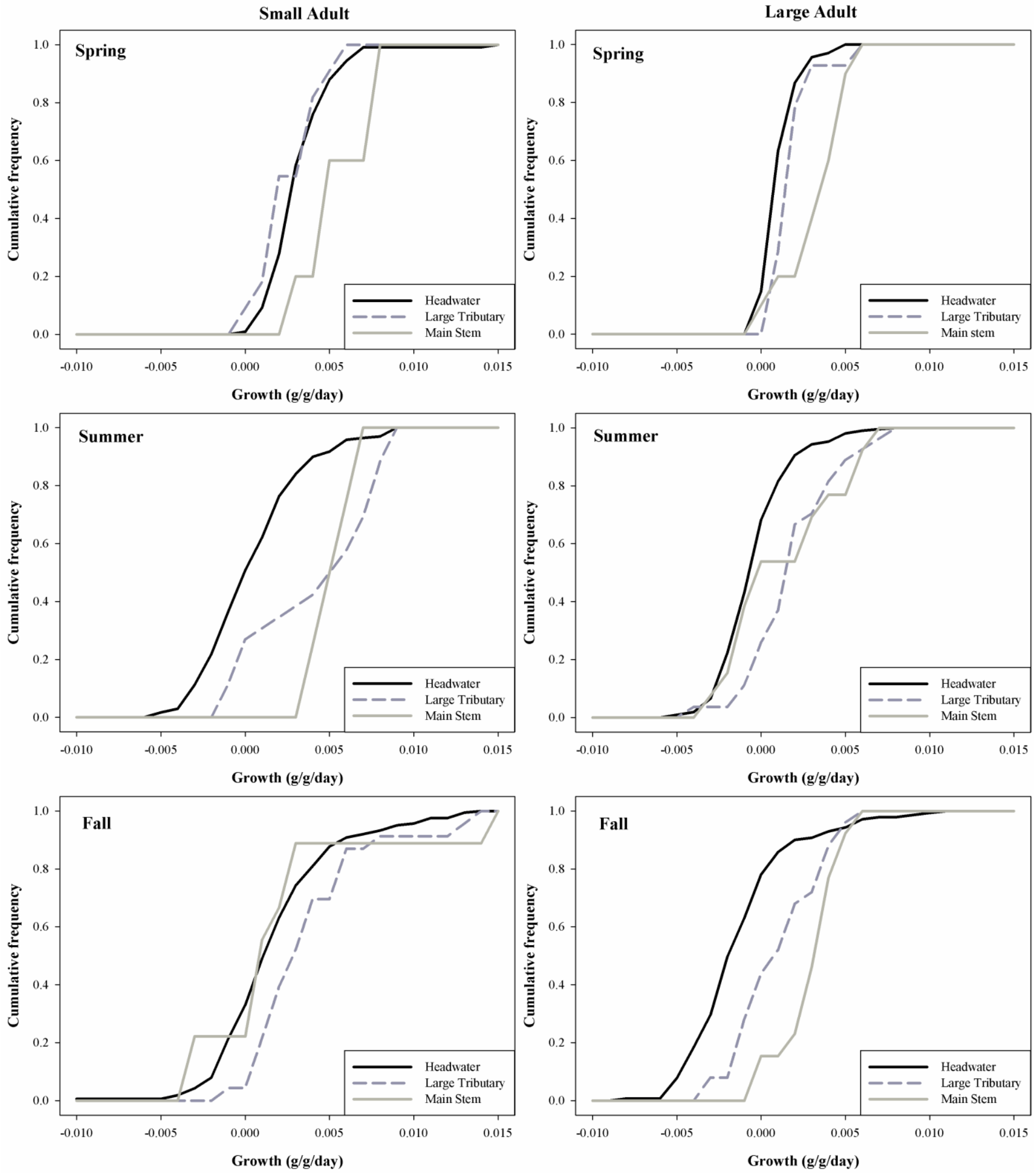

Figure 5 

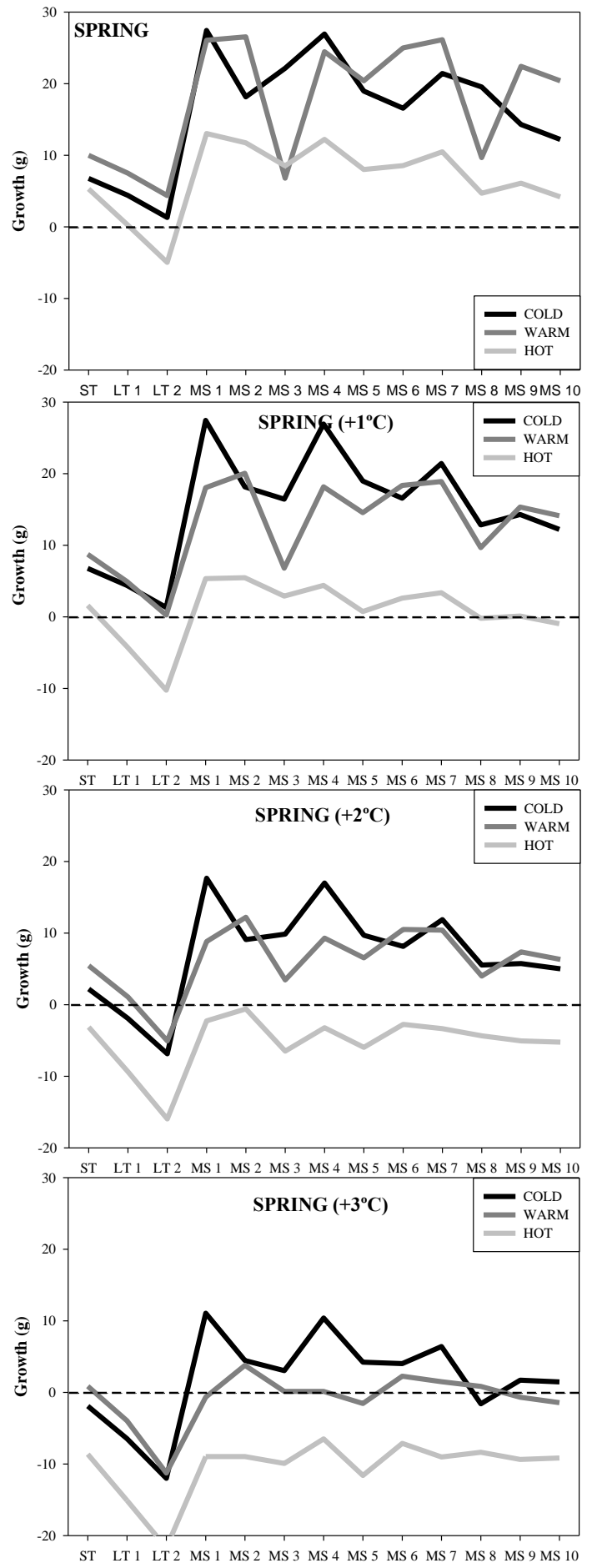

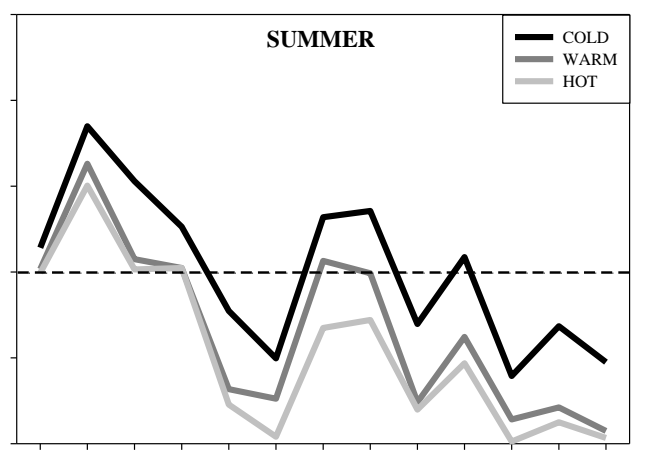

ST LT 1 LT 2 MS 1 MS 2 MS 3 MS 4 MS 5 MS 6 MS 7 MS 8 MS 9 MS 10
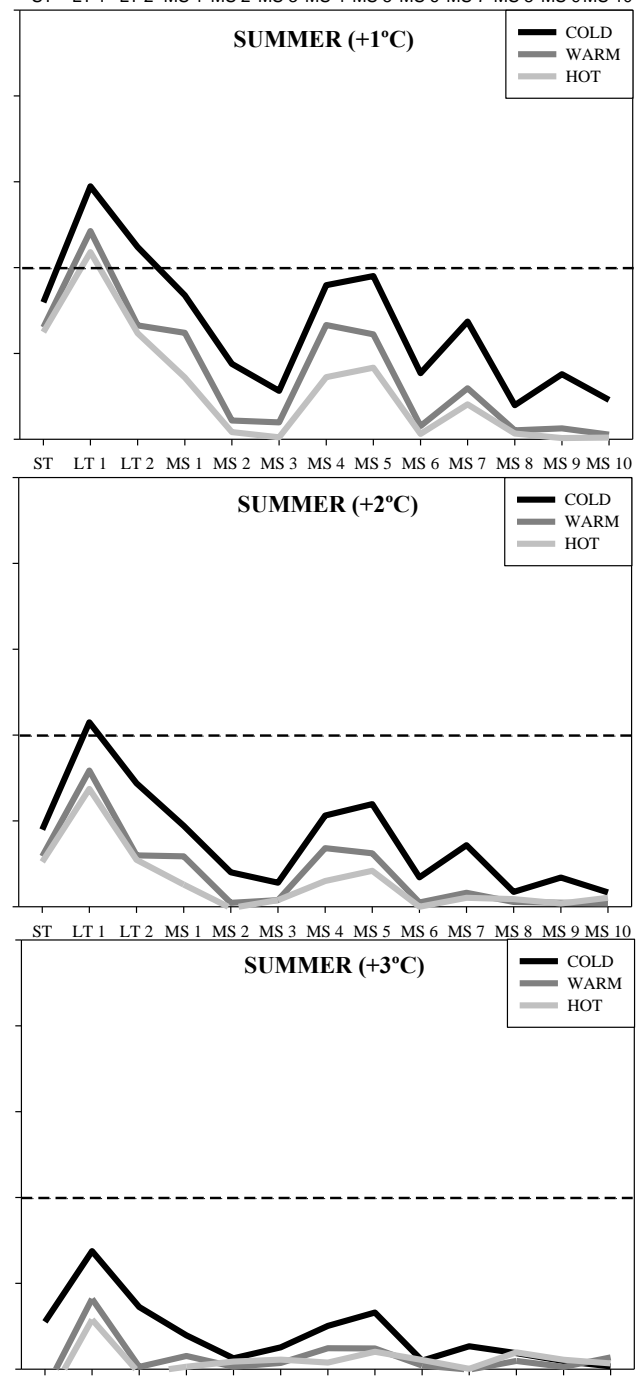

ST LT 1 LT 2 MS 1 MS 2 MS 3 MS 4 MS 5 MS 6 MS 7 MS 8 MS 9 MS 10

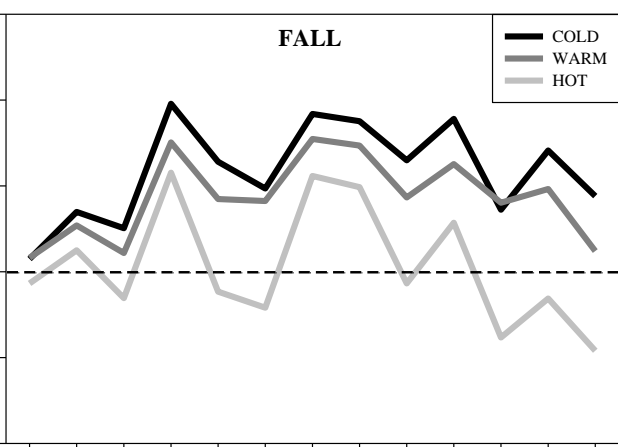

ST LT 1 LT 2 MS 1 MS 2 MS 3 MS 4 MS 5 MS 6 MS 7 MS 8 MS 9 MS 10
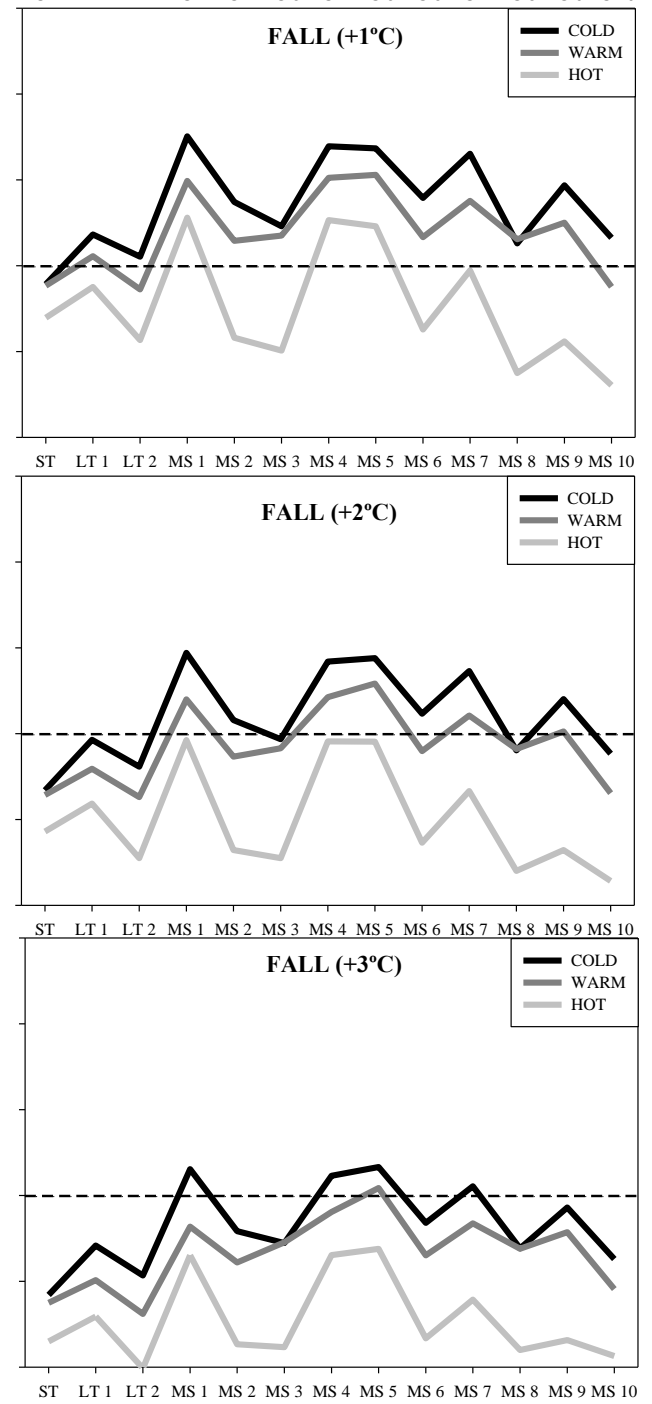

Figure 6 


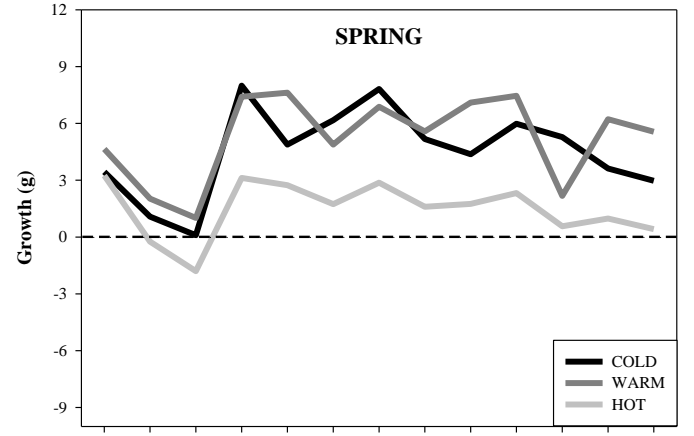

HW LT 1 LT 2 MS 1 MS 2 MS 3 MS 4 MS 5 MS 6 MS 7 MS 8 MS 9 MS 10

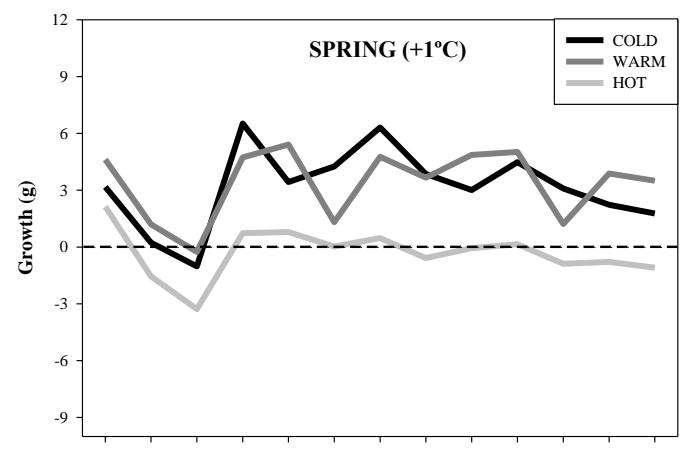

HW LT 1 LT 2 MS 1 MS 2 MS 3 MS 4 MS 5 MS 6 MS 7 MS 8 MS 9 MS 10

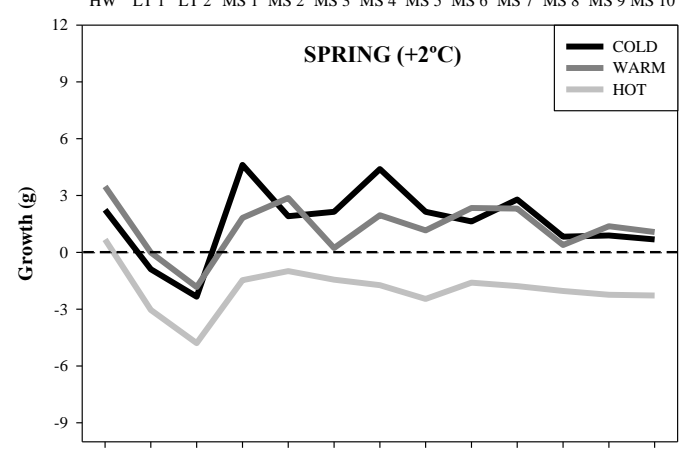

HW LT 1 LT 2 MS 1 MS 2 MS 3 MS 4 MS 5 MS 6 MS 7 MS 8 MS 9 MS 10

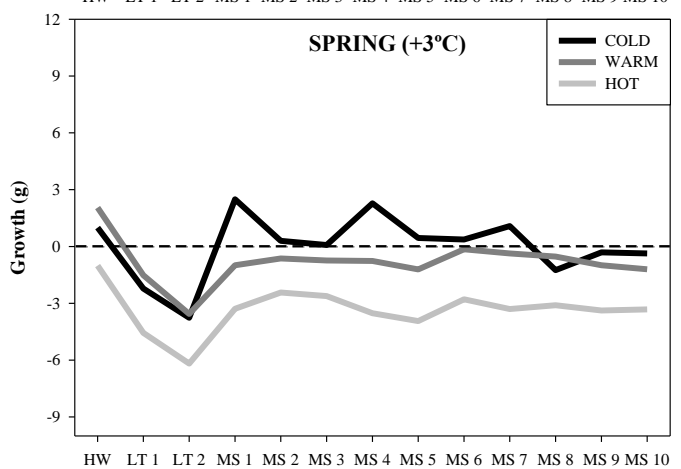

HW LT 1 LT 2 MS 1 MS 2 MS 3 MS 4 MS 5 MS 6 MS 7 MS 8 MS 9 MS 10

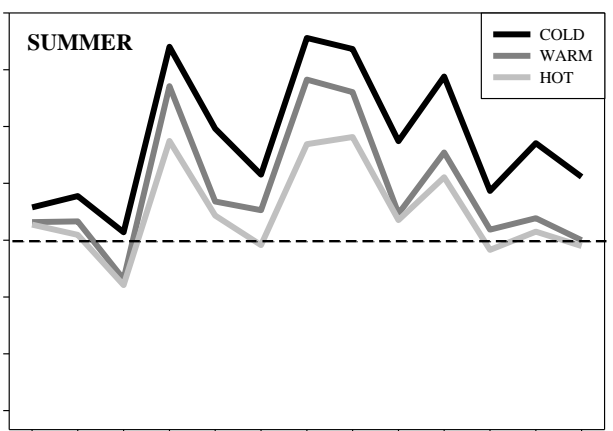

HW LT 1 LT 2 MS 1 MS 2 MS 3 MS 4 MS 5 MS 6 MS 7 MS 8 MS 9 MS 10

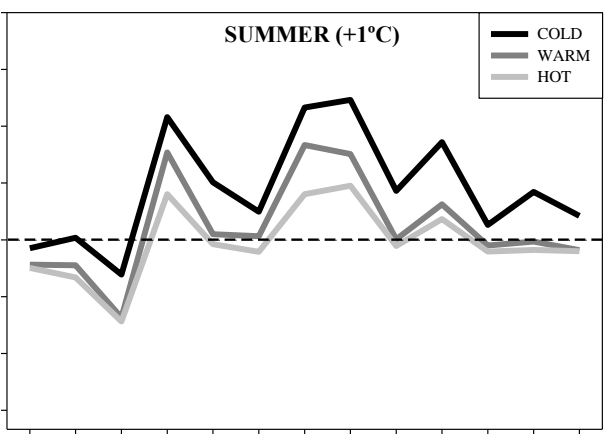

HW LT 1 LT 2 MS 1 MS 2 MS 3 MS 4 MS 5 MS 6 MS 7 MS 8 MS 9 MS 10

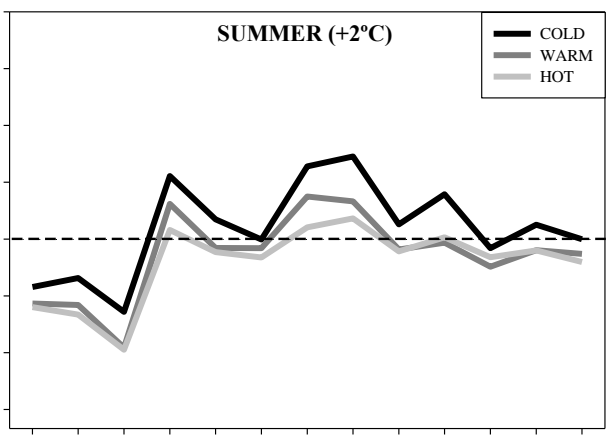

HW LT 1 LT 2 MS 1 MS 2 MS 3 MS 4 MS 5 MS 6 MS 7 MS 8 MS 9 MS 10

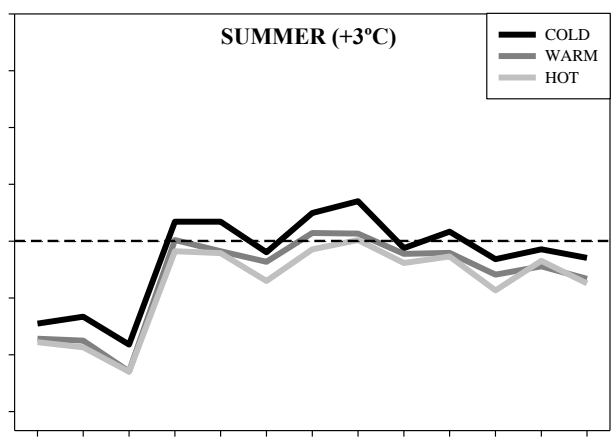

HW LT 1 LT 2 MS 1 MS 2 MS 3 MS 4 MS 5 MS 6 MS 7 MS 8 MS 9 MS 10

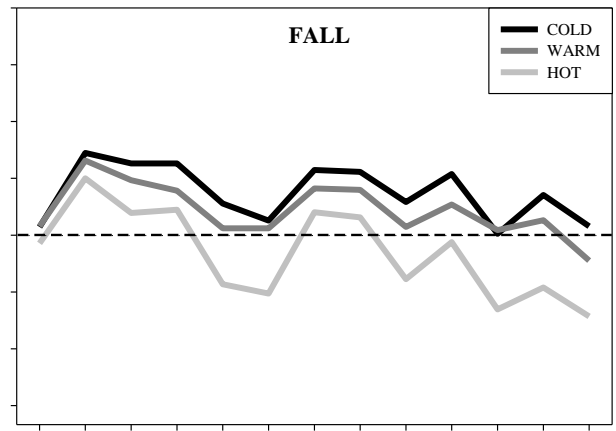

HW LT 1 LT 2 MS 1 MS 2 MS 3 MS 4 MS 5 MS 6 MS 7 MS 8 MS 9 MS 10

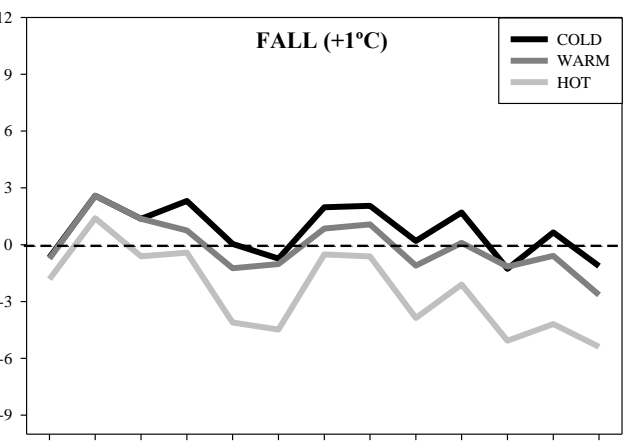

HW LT 1 LT 2 MS 1 MS 2 MS 3 MS 4 MS 5 MS 6 MS 7 MS 8 MS 9 MS 10

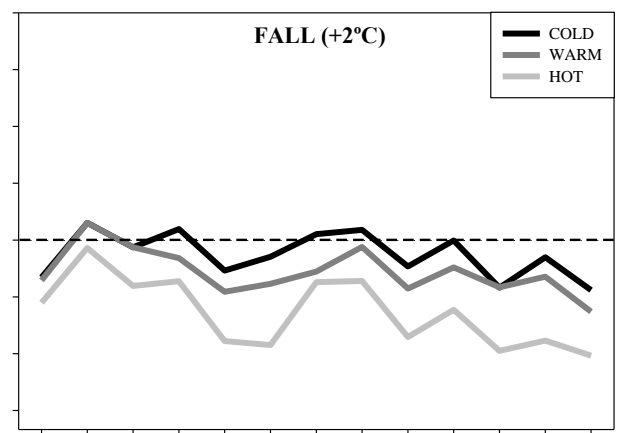

HW LT 1 LT 2 MS 1 MS 2 MS 3 MS 4 MS 5 MS 6 MS 7 MS 8 MS 9 MS 10

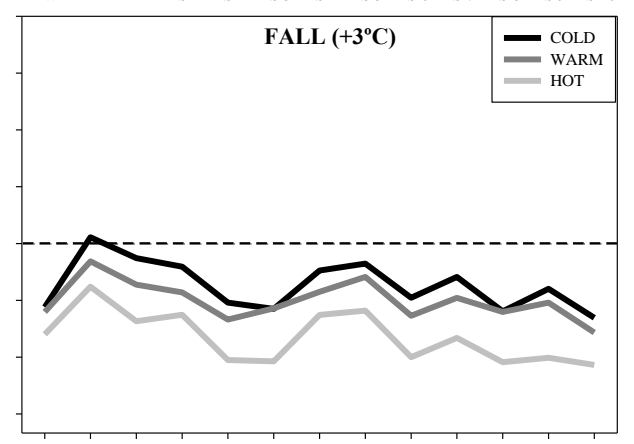

HW LT 1 LT 2 MS 1 MS 2 MS 3 MS 4 MS 5 MS 6 MS 7 MS 8 MS 9 MS 10

Figure 7 

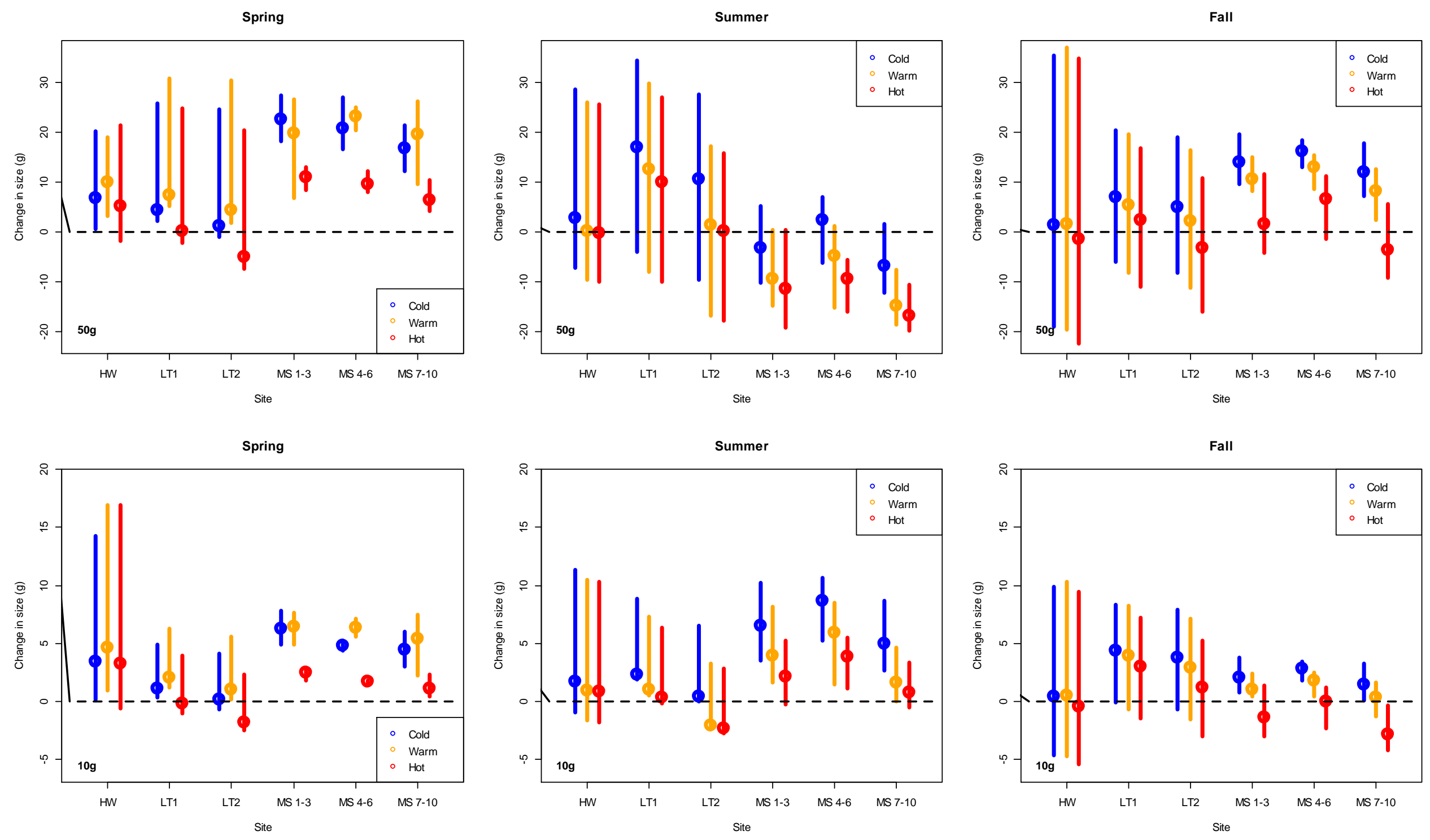

Figure 8 


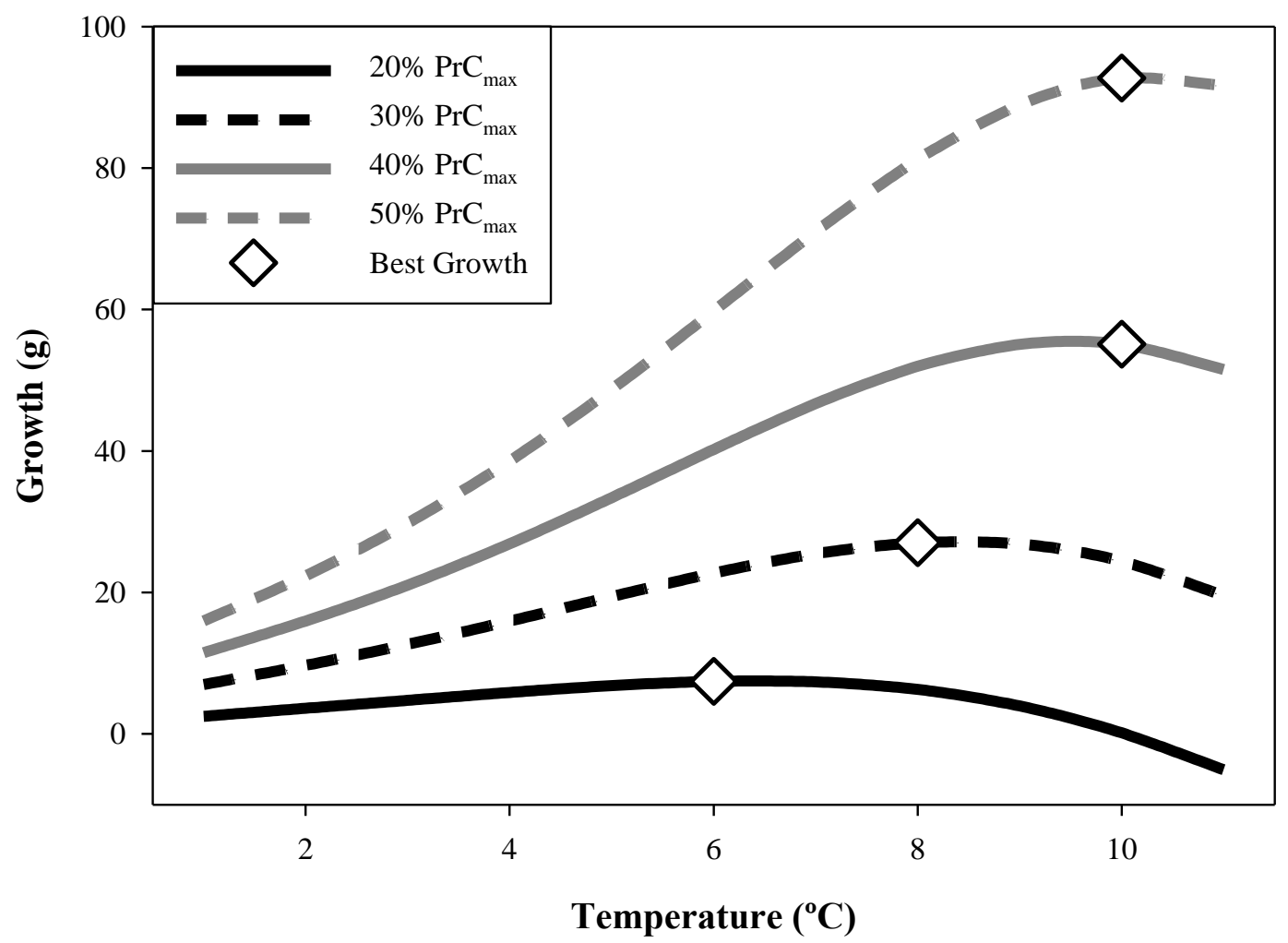

Figure 9 


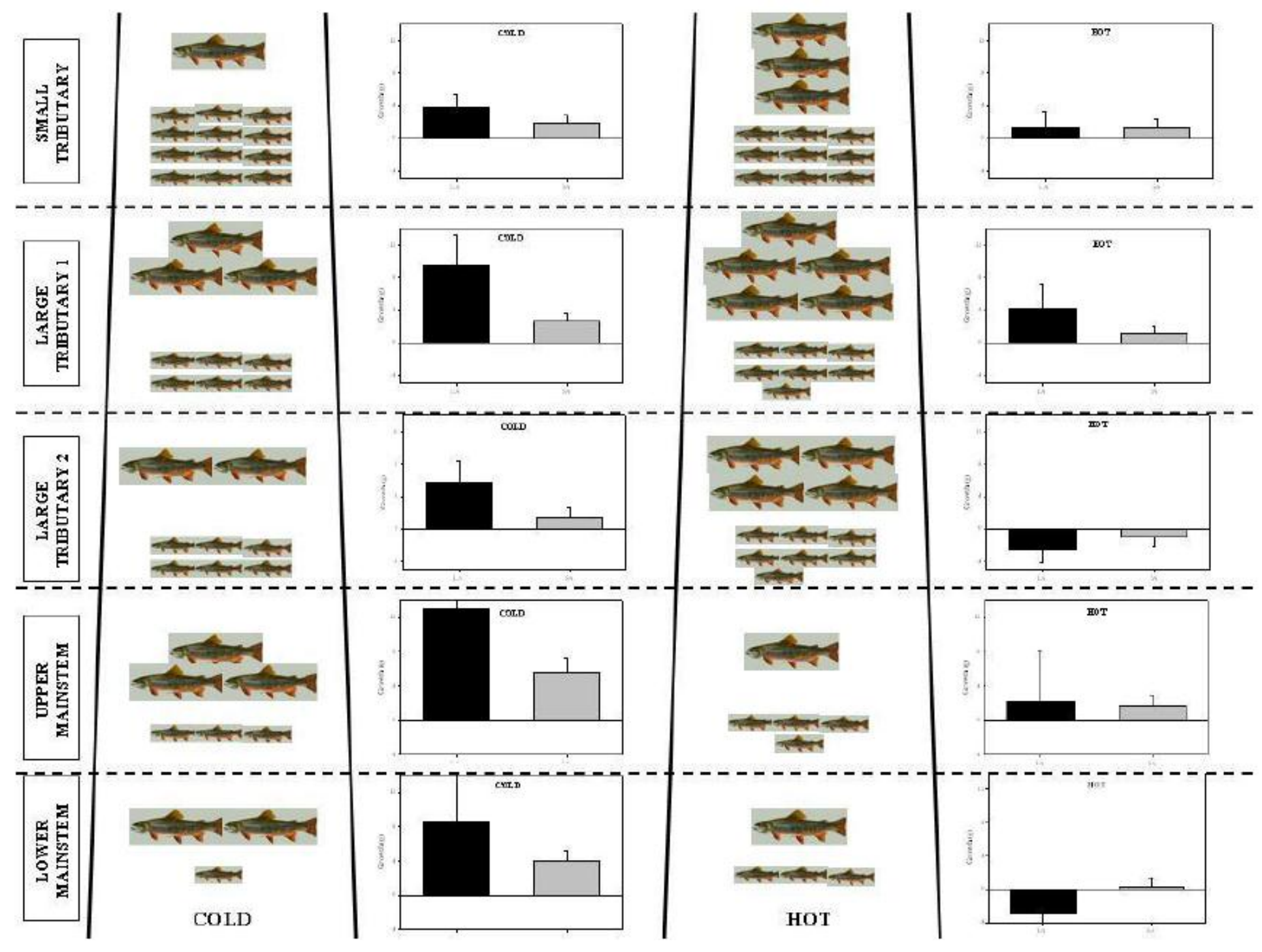

Figure 10 


\section{APPENDICES}

Appendix A: A priori models explaining response variables of brook trout time series data at different study sites.

\section{Location}

Headwater, Large

Tributary,

Mainstem

Headwater, Large

Tributary,

Mainstem

Headwater, Large

Tributary

Headwater, Large

Tributary

\section{Explanatory Mechanism}

Simple density-dependence (DD): interspecific competition for thermal refuge and food limits response variables

Simple recruitment limitation ( $\mathrm{RL}$ ): YOY densities at $\mathrm{t}-1$ limits adult growth rates, and adult densities at $\mathrm{t}-1$ limits YOY growth rates and densities

Simple density-independence (DI): 1) decreased emigration rates during elevated spring growth temperatures, thermal refuge during harsh summer temperatures, and elevated mortality during high flow events limit response variables

2) Elevated survival and prey delivery during high flow events limit response variables

\section{Statistical Hypotheses}

Negative relationship between

response variables and densities of trout

Positive relationship between response variables and densities of

trout

\section{Positive relationship between} response variables and both temperature variables. Negative relationship between response variables and flow

Positive relationship between response variables and flow

\section{Response}

Variable

\section{Candidate Models}

rpop, radult, ryoy*

-dtrout $\mathrm{t}_{\mathrm{t}-1}$, -dadult $_{\mathrm{t}-1}$, - dyoy $_{\mathrm{t}-1}$

rpop, radult, ryoy*, dadult $_{\mathrm{t}-1}$, dyoy $_{\mathrm{t}-1}$

rpop, radult,

rpop, radult, ryoy

$\mathrm{sp}_{\mathrm{t}} \mathrm{Q}$ 
Simple density-independence (DI): optimal growth conditions during elevated spring growth temperatures, increased emigration due to limited thermal refuge during harsh summer temperatures, and elevated mortality during high flow events

Mainstem limit response variables
Positive relationship between response variables and growth temperature. Negative relationship between response variables and both summer temperatures and flow

Positive relationship between response variables and both growth temperature and flow and flow conditions limit response variables
Headwater, Large Tributary, Mainstem

Headwater, Large Tributary, Mainstem

Headwater, Large Tributary, Mainstem
2) high survival rates due to optimal growth temperature and high mortality rates during high flow conditions limit response variables

Complex multi-mechanism models (MM): multiple DD, DI, and RL mechanisms limit response variables
Positive relationship between growth temperature and response variables and negative relationship between response variables and flow

Negative or Positive relationships between response variables and multiple DD, DI, and RL effects rpop, radult $\mathrm{sp}_{\mathrm{t}} \mathrm{T},-\mathrm{su}_{\mathrm{t}-1} \mathrm{~T},-\mathrm{sp}_{\mathrm{t}} \mathrm{Q}$ rpop, radult, ryoy

$$
\mathrm{sp}_{\mathrm{t}} \mathrm{T}, \mathrm{sp}_{\mathrm{t}} \mathrm{Q}
$$

rpop, radult

rpop, radult, ryoy*

rpop, radult, ryoy*
dtrout $_{\mathrm{t}-1}$, dadult $_{\mathrm{t}-1}$, dyoy $_{\mathrm{t}-1}$, $\mathrm{sp}_{\mathrm{t}} \mathrm{T}, \mathrm{su}_{\mathrm{t}-1} \mathrm{~T}, \mathrm{sp}_{\mathrm{t}} \mathrm{Q}$

Global: DD, RL, and DI 
Abbreviations are as follows: $r$ pop $=$ per capita growth rate $\left(r=\ln \left(n_{t} / n_{t-1}\right)\right)$ for the total brook trout population, radult $=r$ for adults, ryoy $=r$ for young-of-the-year, dtrout $=$ density of all brook trout, dadult $=$ density of adult brook trout, dyoy $=$ density of young-of-the-year brook trout, $\mathrm{sp}_{\mathrm{t}} \mathrm{T}$ $=$ mean April-June maximum temperature, $\mathrm{su}_{\mathrm{t}-1} \mathrm{~T}=$ mean July maximum temperature, and $\mathrm{sp}_{\mathrm{t}} \mathrm{Q}=$ mean March-June discharge. The $*$ indicates that the response variable was not analyzed in the mainstem. 
Appendix B: All results from candidate models using $\mathrm{AIC}_{\mathrm{c}}$ for 7 sites.

\begin{tabular}{|c|c|c|c|c|c|c|c|c|}
\hline \multirow{2}{*}{$\begin{array}{l}\text { Response } \\
\text { Variable }\end{array}$} & \multirow{2}{*}{$\begin{array}{l}\text { Predictor } \\
\text { Variable }\end{array}$} & \multirow{2}{*}{$\begin{array}{c}\text { HEADWATER } \\
1\end{array}$} & \multicolumn{2}{|c|}{ LARGE TRIBUTARY } & \multicolumn{4}{|c|}{ MAINSTEM } \\
\hline & & & 1 & 2 & 1 & 2 & 3 & 4 \\
\hline \multirow[t]{13}{*}{ rpop } & dtrout $_{\mathrm{t}-1}$ & $0.225(-0.28)^{*}$ & $0.491(-0.29)^{*}$ & $0.465(-0.41)^{*}$ & $0.709(-0.46)^{*}$ & $0.253(-0.16)^{*}$ & $0.588(-0.38)^{*}$ & $0.710(-0.50) *$ \\
\hline & dyoy $_{t-1}$ & $0.069(-0.07)^{*}$ & & $0.156(-0.25)^{*}$ & & & $0.072(-0.01)^{*}$ & \\
\hline & $\mathrm{su}_{\mathrm{t}-1} \mathrm{~T}$ & $0.074(+0.08)^{*}$ & $0.139(+0.06)^{*}$ & $0.043(-0.00)$ & $0.068(-0.09)$ & $0.122(-0.01)^{*}$ & & $0.031(+0.00)$ \\
\hline & $\mathrm{sp}_{\mathrm{t}} \mathrm{T}$ & $0.050(-0.00)^{*}$ & $0.109(+0.01)^{*}$ & $0.112(-0.19)^{*}$ & $0.077(+0.12)^{*}$ & $0.464(+0.27)^{*}$ & $0.213(+0.22)^{*}$ & $0.041(-0.07)$ \\
\hline & $\mathrm{sp}_{\mathrm{t}} \mathrm{Q}$ & $0.110(+0.16)^{*}$ & $0.108(+0.01)^{*}$ & $0.044(+0.00)$ & $0.054(-0.04)$ & $0.118(+0.01)^{*}$ & $0.074(-0.02)^{*}$ & $0.049(+0.10)$ \\
\hline & $\mathrm{sp}_{\mathrm{t}} \mathrm{T}+\mathrm{sp}_{\mathrm{t}} \mathrm{Q}$ & $0.003(-/+0.19)$ & $0.004(+/+0.01)$ & $0.004(-/+0.23)$ & $0.003(+/-0.16)$ & $0.014(+/+0.27)$ & $0.006(+/-0.24)$ & $0.002(-/+0.18)$ \\
\hline & $\mathrm{su}_{\mathrm{t}-1} \mathrm{~T}+\mathrm{dtrout}_{\mathrm{t}-1}$ & $0.450(+/-0.72)^{*}$ & $0.123(+/-0.57)^{*}$ & $0.016(+/-0.44)$ & $0.025(+/-0.49)$ & $0.007(+/-0.17)$ & & $0.042(+/-0.58)$ \\
\hline & $\mathrm{sp}_{\mathrm{t}} \mathrm{T}+\mathrm{dtrout}_{\mathrm{t}-1}$ & $0.006(-/-0.29)$ & $0.013(-/-0.29)$ & $0.133(-/-0.65)^{*}$ & $0.035(+/-0.53)$ & $0.017(+/-0.31)$ & $0.021(+/-0.42)$ & $0.106(-/-0.66)^{*}$ \\
\hline & $\mathrm{sp}_{\mathrm{t}} \mathrm{Q}+\mathrm{dtrout}_{\mathrm{t}-1}$ & $0.020(+/-0.37)$ & $0.014(-/-0.30)$ & $0.013(+/-0.41)$ & $0.029(-/-0.51)$ & $0.007(+/-0.16)$ & $0.017(-/-0.39)$ & $0.020(-/-0.51)$ \\
\hline & $\mathrm{su}_{\mathrm{t}-1} \mathrm{~T}+\mathrm{dyoy}_{\mathrm{t}-1}$ & $0.003(+/-0.16)$ & & $0.004(-/-0.25)$ & & & & \\
\hline & $\mathrm{sp}_{\mathrm{t}} \mathrm{T}+\mathrm{dyoy}_{\mathrm{t}-1}$ & $0.002(+/-0.07)$ & & $0.006(-/-0.29)$ & & & $0.006(+/-0.22)$ & \\
\hline & $\operatorname{sp}_{t} Q+$ dyoy $_{t-1}$ & $0.004(+/-0.23)$ & & $0.004(-/-0.25)$ & & & $0.002(-/-0.07)$ & \\
\hline & global & $0.000(0.87)$ & $0.000(0.60)$ & $0.000(0.73)$ & $0.000(0.60)$ & $0.000(0.32)$ & $0.000(0.62)$ & $0.000(0.82)$ \\
\hline \multirow[t]{2}{*}{ radult } & dadult $_{\mathrm{t}-1}$ & $0.240(-0.17)^{*}$ & $0.456(-0.22)^{*}$ & $0.289(-0.28)^{*}$ & $0.766(-0.51)^{*}$ & $0.364(-0.26)^{*}$ & $0.670(-0.43)^{*}$ & $0.707(-0.55)^{*}$ \\
\hline & dyoy $_{\mathrm{t}-1}$ & $0.143(-0.07)^{*}$ & & $0.236(-0.25)^{*}$ & & & $0.056(-0.01)$ & $0.038(-0.14)$ \\
\hline
\end{tabular}




\begin{tabular}{|c|c|c|c|c|c|c|c|c|}
\hline & $\mathrm{su}_{\mathrm{t}-1} \mathrm{~T}$ & $0.153(+0.08)^{*}$ & $0.193(+0.06)^{*}$ & $0.066(-0.00)^{*}$ & $0.046(-0.09)$ & $0.102(-0.01)^{*}$ & & $0.019(+0.00)$ \\
\hline & $\mathrm{sp}_{\mathrm{t}} \mathrm{T}$ & $0.104(-0.00)^{*}$ & $0.152(+0.01)^{*}$ & $0.170(-0.19)^{*}$ & $0.052(+0.12)$ & $0.385(+0.27)^{*}$ & $0.164(+0.22)^{*}$ & $0.026(-0.07)$ \\
\hline & $\mathrm{sp}_{\mathrm{t}} \mathrm{Q}$ & $0.228(+0.16)^{*}$ & $0.151(+0.01)^{*}$ & $0.066(+0.00)^{*}$ & $0.037(-0.04)$ & $0.098(+0.01)^{*}$ & $0.057(-0.02)$ & $0.031(0.10)$ \\
\hline & $\mathrm{sp}_{\mathrm{t}} \mathrm{T}+\mathrm{sp}_{\mathrm{t}} \mathrm{Q}$ & $0.007(-/+0.19)$ & $0.004(+/+0.01)$ & $0.006(-/+0.23)$ & $0.002(+/-0.16)$ & $0.011(+/+0.27)$ & $0.005(+/-0.24)$ & $0.001(-/+0.18)$ \\
\hline & $\mathrm{su}_{\mathrm{t}-1} \mathrm{~T}+$ dadult $_{\mathrm{t}-1}$ & $0.087(+/-0.53)^{*}$ & $0.016(+/-0.27)$ & $0.009(+/-0.31)$ & $0.027(+/-0.54)$ & $0.010(+/-0.26)$ & & $0.032(+/-0.60)$ \\
\hline & $\mathrm{sp}_{\mathrm{t}} \mathrm{T}+$ dadult $_{\mathrm{t}-1}$ & $0.007(-/-0.19)$ & $0.013(+/-0.23)$ & $0.128(-/-0.61)^{*}$ & $0.047(+/-0.59)$ & $0.020(+/-0.36)$ & $0.022(+/-0.46)$ & $0.121(-/-0.70)^{*}$ \\
\hline & $\mathrm{sp}_{\mathrm{t}} \mathrm{Q}+\mathrm{dadult}_{\mathrm{t}-1}$ & $0.011(+/-0.27)$ & $0.015(+/-0.26)$ & $0.008(+/-0.29)$ & $0.025(-/-0.53)$ & $0.010(+/-0.26)$ & $0.019(-/-0.43)$ & $0.020(-/-0.55)$ \\
\hline & $\mathrm{su}_{\mathrm{t}-1} \mathrm{~T}+$ dyoy $_{\mathrm{t}-1}$ & $0.006(+/-0.16)$ & & $0.006(-/-0.25)$ & & & & $0.001(+/-0.20)$ \\
\hline & $\mathrm{sp}_{\mathrm{t}} \mathrm{T}+$ dyoy $_{\mathrm{t}-1}$ & $0.004(+/-0.07)$ & & $0.009(-/-0.29)$ & & & $0.004(+/-0.22)$ & $0.002(-/-0.25)$ \\
\hline & $\mathrm{sp}_{\mathrm{t}} \mathrm{Q}+$ dyoy $_{\mathrm{t}-1}$ & $0.009(+/-0.23)$ & & $0.006(-/-0.25)$ & & & $0.002(-/-0.07)$ & $0.001(+/-0.18)$ \\
\hline & global & $0.000(0.87)$ & $0.000(0.38)$ & $0.000(0.73)$ & $0.000(0.64)$ & $0.000(0.37)$ & $0.000(0.62)$ & $0.000(0.82)$ \\
\hline ryoy & dadult $_{\mathrm{t}-1}$ & $0.093(+0.12)^{*}$ & $0.215(-0.07)^{*}$ & $0.005(+0.07)$ & & & & \\
\hline & dyoy $_{t-1}$ & $0.306(-0.32)^{*}$ & $0.409(-0.19) *$ & $0.800(-0.69) *$ & & & & \\
\hline & $\mathrm{su}_{\mathrm{t}-1} \mathrm{~T}$ & $0.212(+0.27)^{*}$ & & $0.007(+0.11)$ & & & & \\
\hline & $\mathrm{sp}_{\mathrm{t}} \mathrm{T}$ & $0.056(-0.01)^{*}$ & $0.159(-0.00)^{*}$ & $0.015(-0.26)$ & & & & \\
\hline & $\mathrm{sp}_{\mathrm{t}} \mathrm{Q}$ & $0.149(+0.21)^{*}$ & $0.168(+0.01)^{*}$ & $0.005(-0.01)$ & & & & \\
\hline & $\mathrm{sp}_{\mathrm{t}} \mathrm{T}+\mathrm{sp}_{\mathrm{t}} \mathrm{Q}$ & $0.006(-/+0.28)$ & $0.005(-/+0.02)$ & $0.000(-/+0.27)$ & & & & \\
\hline & $\mathrm{su}_{\mathrm{t}-1} \mathrm{~T}+$ dadult $_{\mathrm{t}-1}$ & $0.006(+/+0.27)$ & & $0.000(+/+0.14)$ & & & & \\
\hline & $\mathrm{sp}_{\mathrm{t}} \mathrm{T}+$ dadult $_{\mathrm{t}-1}$ & $0.003(-/+0.12)$ & $0.006(-/-0.07)$ & $0.000(-/+0.28)$ & & & & \\
\hline
\end{tabular}




$\begin{array}{llll}\mathrm{sp}_{\mathrm{t}} \mathrm{Q}+\text { dadult }_{\mathrm{t}-1} & 0.016(+/+0.42) & 0.007(+/-0.09) & 0.000(-/+0.08) \\ \text { su }_{\mathrm{t}-1} \mathrm{~T}+\text { dyoy }_{\mathrm{t}-1} & 0.102(+/-0.61)^{*} & & 0.100(+/-0.78)^{*} \\ \mathrm{sp}_{\mathrm{t}} \mathrm{T}+\text { dyoy }_{\mathrm{t}-1} & 0.008(+/-0.32) & 0.013(-/-0.22) & 0.025(-/-0.70) \\ \mathrm{sp}_{\mathrm{t}} \mathrm{Q}+\text { dyoy }_{\mathrm{t}-1} & 0.041(+/-0.52)^{*} & 0.018(-/-0.27) & 0.042(-/-0.73) \\ \text { global } & 0.000(0.93) & 0.000(0.29) & 0.000(0.88)\end{array}$

The first value represents the Akaike's weight $\left(w_{i}\right)$ given to each model in the candidate set followed by the direction of the relationship and $\mathrm{R}^{2}$ statistic. Bold values represent the best model in each candidate set. Both response and predictor variables follow the same notation as that in Table 2. Missing values represent predictor variables that were correlated with another predictor variable in the candidate set and therefore removed. No models were constructed for ryoy at mainstem sites because few YOY were found in those sites. Models with an * were considered interpretable models using criteria from Grossman et al. [14]. 
Appendix C: Seasonal parameter estimates from the best fitted model in forward-time mark recapture

analysis. "LCI" represent the lower 95\% confidence interval and "UCI" represents the upper 95\%

confidence interval, and "SE" represents the standard error.

\begin{tabular}{|c|c|c|c|c|c|c|c|c|c|c|c|c|c|}
\hline oup & eason & $\varphi_{j}^{r r}$ & SE & LCI & JCI & $\varphi_{A}^{r r}$ & SE & LCI & UCI & $\psi$ & SE & LCI & UCI \\
\hline MS & SP-SU & 0.385 & 0.066 & 0.266 & 0.519 & 0.676 & 0.060 & 0.550 & 0.781 & 0.018 & 0.007 & 0.008 & 0.040 \\
\hline MS & & 367 & & 158 & & 333 & & & & & & .008 & .040 \\
\hline MS & & 740 & & & & & & & & & & & \\
\hline & & & & & & 644 & & & & & & & .037 \\
\hline & & & & & & & & & & & & 007 & 0.037 \\
\hline LT & & 752 & 39 & & .820 & 685 & .066 & & & 0.830 & & 516 & 0.957 \\
\hline HW 1 & & 780 & 035 & & 0.841 & 898 & 0.026 & 35 & & 0.013 & .005 & 0.006 & 0.028 \\
\hline HW 1 & & & & & & & & & & & & & \\
\hline HW 1 & & 0.9 & & & 0.9 & & & & & & & & \\
\hline HW 2 & & & & & & & & & & & & & 0.022 \\
\hline HW 2 & & 0 & & & .703 & 631 & 68 & & 52 & 9 & 04 & .004 & 0.022 \\
\hline HW 2 & & 0.888 & 019 & & 0.921 & 396 & 0.028 & .827 & 939 & 0.490 & 088 & 325 & 0.658 \\
\hline HW 3 & & 722 & & & & & 0.037 & & & 0.010 & 004 & & 0.023 \\
\hline HW 3 & & 0.7 & & & 0.791 & & & & & & & & \\
\hline HW 3 & & & & & & & & & & & & & \\
\hline HW 4 & & & & & & & & & & 0.0 & & & 0.027 \\
\hline HW 4 & & 720 & 038 & 0. & 0.789 & 0.478 & 0.051 & 380 & 0.577 & 0.012 & .005 & .005 & 0.027 \\
\hline HW 4 & FA- & 0.926 & 0.014 & 0.895 & 0.949 & 0.822 & 0.029 & 0.757 & 0.872 & 0.609 & 076 & .455 & 0.744 \\
\hline HW 5 & & 0.718 & & & 0.788 & & 0.027 & & & 0.013 & & 06 & 0.030 \\
\hline HW 5 & SU-FA & 0.702 & & & 0.772 & 97 & 0.055 & 0.580 & 0.794 & 0.013 & 0.006 & 0.006 & 0.030 \\
\hline HW 5 & & 0.920 & & & & & & & & 0.696 & & & 0.818 \\
\hline & & & & & & & & & & & & & \\
\hline & & & & & & & 0.0 & & 73 & 0.0 & & 0 & 0.024 \\
\hline HW 6 & & 0.896 & 0.017 & 0.857 & 0.925 & 0.805 & 0.039 & 0.717 & 0.871 & 0.542 & .081 & .384 & 0.692 \\
\hline HW 7 & SP-SU & 0.716 & 0.097 & 0.498 & 0.865 & 0.864 & 0.077 & 0.637 & 0.958 & 0.011 & .006 & 0.004 & 0.033 \\
\hline HW 7 & SU-F & 0.701 & 0.099 & 0.482 & 0.855 & 0.602 & 0.154 & 0.300 & 0.842 & 0.011 & 0.006 & 0.004 & 0.033 \\
\hline & & & & & & & & & & & & & 0.896 \\
\hline & & & & & & & & & & & & 006 & 0.034 \\
\hline HW 8 & & 0.683 & & & 0.785 & & & & 0.231 & 0.015 & 0.006 & 0.006 & 0.034 \\
\hline HW 8 & FA-SP & 0.913 & 0.021 & 0.861 & 0.947 & 0.500 & 0.000 & 0.500 & 0.500 & 0.759 & 0.105 & 0.506 & 0.906 \\
\hline
\end{tabular}


Appendix D: Seasonal parameter estimates from the best fitted model in reverse-time mark recapture analysis. " $\gamma_{B A}$ " indicate transitions from large adults to small adults and " $\gamma_{A A}$ " represent the seniority parameter, "LCI" represent the lower 95\% confidence interval and "UCI" represents the upper 95\% confidence interval, and "SE" represents the standard error. Standard error (S.E.) estimates for immigration and local $\left(\gamma_{B A}+\gamma_{B B}\right)$ contributions to population growth are the same since Immigration $=1$ - Local.

\begin{tabular}{|c|c|c|c|c|c|c|c|c|c|c|c|}
\hline Group & Season & $\gamma_{B A}$ & S.E. & LCI & UCI & $\gamma_{A A}$ & S.E. & LCI & UCI & Immigration & S.E. \\
\hline MS & FA-SP & 0.074 & 0.018 & 0.046 & 0.118 & 0.278 & 0.050 & 0.191 & 0.387 & 0.650 & 0.059 \\
\hline MS & SU-FA & 0.140 & 0.049 & 0.068 & 0.266 & 0.526 & 0.100 & 0.336 & 0.708 & 0.338 & 0.118 \\
\hline MS & SP-SU & 0.084 & 0.023 & 0.048 & 0.142 & 0.316 & 0.064 & 0.206 & 0.451 & 0.599 & 0.075 \\
\hline LT & FA-SP & 0.092 & 0.028 & 0.050 & 0.162 & 0.346 & 0.073 & 0.220 & 0.498 & 0.563 & 0.085 \\
\hline LT & SU-FA & 0.155 & 0.064 & 0.066 & 0.325 & 0.585 & 0.117 & 0.354 & 0.784 & 0.264 & 0.141 \\
\hline $\mathrm{LT}$ & SP-SU & 0.102 & 0.034 & 0.052 & 0.192 & 0.386 & 0.087 & 0.235 & 0.562 & 0.516 & 0.104 \\
\hline HW 1 & FA-SP & 0.201 & 0.077 & 0.089 & 0.392 & 0.757 & 0.087 & 0.552 & 0.887 & 0.042 & 0.141 \\
\hline HW 1 & SU-FA & 0.207 & 0.105 & 0.070 & 0.476 & 0.781 & 0.108 & 0.510 & 0.924 & 0.012 & 0.194 \\
\hline HW 1 & SP-SU & 0.202 & 0.078 & 0.089 & 0.397 & 0.763 & 0.087 & 0.557 & 0.891 & 0.036 & 0.144 \\
\hline HW 2 & FA-SP & 0.201 & 0.110 & 0.062 & 0.489 & 0.759 & 0.124 & 0.456 & 0.922 & 0.043 & 0.210 \\
\hline HW 2 & SU-FA & 0.207 & 0.126 & 0.055 & 0.540 & 0.781 & 0.130 & 0.447 & 0.941 & 0.000 & 0.231 \\
\hline HW 2 & SP-SU & 0.203 & 0.110 & 0.063 & 0.490 & 0.765 & 0.121 & 0.465 & 0.924 & 0.028 & 0.211 \\
\hline HW 3 & FA-SP & 0.199 & 0.096 & 0.071 & 0.448 & 0.751 & 0.112 & 0.484 & 0.907 & 0.050 & 0.183 \\
\hline HW 3 & SU-FA & 0.207 & 0.116 & 0.061 & 0.509 & 0.779 & 0.120 & 0.473 & 0.933 & 0.010 & 0.214 \\
\hline HW 3 & SP-SU & 0.201 & 0.096 & 0.073 & 0.447 & 0.758 & 0.108 & 0.496 & 0.909 & 0.047 & 0.183 \\
\hline HW 4 & FA-SP & 0.208 & 0.281 & 0.009 & 0.882 & 0.784 & 0.289 & 0.113 & 0.990 & 0.013 & 0.491 \\
\hline HW 4 & SU-FA & 0.209 & 0.287 & 0.009 & 0.888 & 0.788 & 0.289 & 0.111 & 0.991 & 0.024 & 0.476 \\
\hline HW 4 & SP-SU & 0.208 & 0.279 & 0.009 & 0.879 & 0.785 & 0.285 & 0.117 & 0.990 & 0.023 & 0.479 \\
\hline HW 5 & FA-SP & 0.192 & 0.063 & 0.097 & 0.346 & 0.724 & 0.080 & 0.545 & 0.851 & 0.086 & 0.118 \\
\hline HW 5 & SU-FA & 0.205 & 0.091 & 0.079 & 0.436 & 0.771 & 0.098 & 0.532 & 0.909 & 0.015 & 0.169 \\
\hline HW 5 & SP-SU & 0.195 & 0.065 & 0.097 & 0.354 & 0.735 & 0.080 & 0.555 & 0.861 & 0.070 & 0.118 \\
\hline HW 6 & FA-SP & 0.184 & 0.060 & 0.093 & 0.329 & 0.692 & 0.083 & 0.511 & 0.828 & 0.113 & 0.118 \\
\hline HW 6 & SU-FA & 0.202 & 0.089 & 0.079 & 0.428 & 0.761 & 0.099 & 0.523 & 0.902 & 0.041 & 0.163 \\
\hline HW 6 & SP-SU & 0.188 & 0.061 & 0.096 & 0.336 & 0.708 & 0.081 & 0.530 & 0.839 & 0.104 & 0.114 \\
\hline HW 7 & FA-SP & 0.192 & 0.163 & 0.029 & 0.652 & 0.724 & 0.209 & 0.252 & 0.954 & 0.091 & 0.329 \\
\hline HW 7 & SU-FA & 0.205 & 0.185 & 0.027 & 0.705 & 0.771 & 0.200 & 0.268 & 0.969 & 0.033 & 0.371 \\
\hline HW 7 & SP-SU & 0.195 & 0.165 & 0.030 & 0.655 & 0.736 & 0.203 & 0.264 & 0.956 & 0.079 & 0.327 \\
\hline HW 8 & FA-SP & 0.200 & 0.118 & 0.056 & 0.514 & 0.755 & 0.135 & 0.424 & 0.928 & 0.046 & 0.229 \\
\hline HW 8 & SU-FA & 0.207 & 0.135 & 0.050 & 0.567 & 0.780 & 0.140 & 0.417 & 0.946 & 0.015 & 0.257 \\
\hline
\end{tabular}


\begin{tabular}{llllllllllll} 
HW 8 & SP-SU & 0.202 & 0.120 & 0.055 & 0.522 & 0.761 & 0.135 & 0.427 & 0.932 & 0.032 & 0.227 \\
\hline
\end{tabular} 
Appendix E: Parameters used for bioenergetic simulations. Proportion of brook trout diets contributed by weight for different seasons, site types, and fish size-class were taken from Petty et al. (2014). Prey items were grouped into 6 categories, fish (FIS), amphibian (AMP), crayfish (CRA), obligate aquatic invertebrates (OAI), non-obligate aquatic invertebrates (NOI), and obligate terrestrial invertebrates (OTI). Energy density of prey items were taken from Cummins and Wuycheck (1971)* and James et al. (2012)^.

\begin{tabular}{|c|c|c|c|c|c|c|c|c|c|c|c|c|c|}
\hline \multirow[b]{2}{*}{ SEASON } & \multirow[b]{2}{*}{ SITE } & \multicolumn{6}{|c|}{ SMALL ADULT } & \multicolumn{6}{|c|}{ LARGE ADULT } \\
\hline & & FIS & AMP & CRA & OAI & NOI & OTI & FIS & AMP & CRA & OAI & $\mathrm{NOI}$ & OTI \\
\hline SPRING & HW & 0.00 & 0.00 & 0.06 & 0.30 & 0.45 & 0.19 & 0.05 & 0.52 & 0.00 & 0.07 & 0.19 & 0.17 \\
\hline SPRING & $\mathrm{LT}$ & 0.00 & 0.02 & 0.00 & 0.26 & 0.42 & 0.30 & 0.00 & 0.00 & 0.00 & 0.35 & 0.41 & 0.24 \\
\hline SPRING & MS & 0.39 & 0.00 & 0.44 & 0.08 & 0.06 & 0.03 & 0.81 & 0.00 & 0.00 & 0.11 & 0.05 & 0.03 \\
\hline SUMMER & HW & 0.00 & 0.00 & 0.05 & 0.17 & 0.10 & 0.68 & 0.00 & 0.00 & 0.35 & 0.02 & 0.06 & 0.57 \\
\hline SUMMER & $\mathrm{LT}$ & 0.19 & 0.00 & 0.00 & 0.14 & 0.23 & 0.44 & 0.01 & 0.00 & 0.60 & 0.26 & 0.03 & 0.10 \\
\hline SUMMER & MS & 0.59 & 0.00 & 0.00 & 0.18 & 0.13 & 0.10 & 0.51 & 0.00 & 0.44 & 0.02 & 0.00 & 0.03 \\
\hline FALL & HW & 0.00 & 0.07 & 0.00 & 0.43 & 0.04 & 0.46 & 0.00 & 0.00 & 0.00 & 0.07 & 0.04 & 0.89 \\
\hline FALL & $\mathrm{LT}$ & 0.00 & 0.00 & 0.00 & 0.31 & 0.20 & 0.49 & 0.20 & 0.14 & 0.00 & 0.06 & 0.07 & 0.53 \\
\hline FALL & MS & 0.00 & 0.66 & 0.00 & 0.04 & 0.00 & 0.30 & 0.62 & 0.01 & 0.00 & 0.01 & 0.00 & 0.36 \\
\hline \multicolumn{14}{|c|}{$\begin{array}{l}\text { Energy Density } \\
\text { (J/g wet weight) }\end{array}$} \\
\hline
\end{tabular}


Appendix F: Results from bioenergetic simulations of growth across site types and consumption estimates for each temperature regime and associated forcasted temperatures. Growth estimates are in grams.

\begin{tabular}{|c|c|c|c|c|c|c|c|c|c|c|c|c|c|c|c|}
\hline \multirow[b]{2}{*}{ Site } & \multirow[b]{2}{*}{ Size } & \multirow[b]{2}{*}{ Season } & \multirow[b]{2}{*}{$\operatorname{PrC}_{\max }$} & \multicolumn{4}{|c|}{2001} & \multicolumn{4}{|c|}{2005} & \multicolumn{4}{|c|}{2010} \\
\hline & & & & Current & Plus 1 & Plus 2 & Plus 3 & Current & Plus 1 & Plus 2 & Plus 3 & Current & Plus 1 & Plus 2 & Plus 3 \\
\hline $\begin{array}{l}\text { Small Tributary } \\
\text { (min) }\end{array}$ & LA & FALL & 0.08 & -19.03 & -22.74 & -26.64 & -30.53 & -22.35 & -26.39 & -30.46 & -34.35 & -19.50 & -23.35 & -27.38 & -31.40 \\
\hline $\begin{array}{l}\text { Small Tributary } \\
\text { (avg) }\end{array}$ & LA & FALL & 0.27 & 1.48 & -2.16 & -6.60 & -11.59 & -1.36 & -6.07 & -11.40 & -17.00 & 1.62 & -2.34 & -7.15 & -12.51 \\
\hline $\begin{array}{l}\text { Small Tributary } \\
(\max )\end{array}$ & LA & FALL & 0.50 & 35.44 & 33.21 & 29.17 & 23.57 & 34.78 & 30.25 & 24.02 & 16.60 & 37.04 & 34.22 & 29.44 & 23.02 \\
\hline $\begin{array}{l}\text { Large Tributary } \\
1 \text { (min) }\end{array}$ & LA & FALL & 0.19 & -5.97 & -9.63 & -13.89 & -18.53 & -10.92 & -15.57 & -20.54 & -25.50 & -8.14 & -12.39 & -17.15 & -22.11 \\
\hline $\begin{array}{l}\text { Large Tributary } \\
1 \text { (avg) }\end{array}$ & LA & FALL & 0.29 & 6.97 & 3.63 & -0.72 & -5.84 & 2.50 & -2.48 & -8.15 & -14.11 & 5.39 & 1.11 & -4.09 & -9.87 \\
\hline $\begin{array}{l}\text { Large Tributary } \\
1 \text { (max) }\end{array}$ & LA & FALL & 0.38 & 20.43 & 17.64 & 13.45 & 8.06 & 16.80 & 11.71 & 5.51 & -1.31 & 19.66 & 15.60 & 10.17 & 3.75 \\
\hline $\begin{array}{l}\text { Large Tributary } \\
2 \text { (min) }\end{array}$ & LA & FALL & 0.19 & -8.16 & -12.24 & -16.79 & -21.57 & -15.95 & -20.86 & -25.72 & -30.23 & -11.21 & -15.73 & -20.54 & -25.33 \\
\hline $\begin{array}{l}\text { Large Tributary } \\
2 \text { (avg) }\end{array}$ & LA & FALL & 0.29 & 5.07 & 1.05 & -3.85 & -9.32 & -3.08 & -8.67 & -14.50 & -20.13 & 2.18 & -2.62 & -8.08 & -13.81 \\
\hline $\begin{array}{l}\text { Large Tributary } \\
2(\max )\end{array}$ & LA & FALL & 0.38 & 18.98 & 15.27 & 10.24 & 4.26 & 10.85 & 4.75 & -1.90 & -8.55 & 16.45 & 11.60 & 5.68 & -0.85 \\
\hline Mainstem 1 & LA & FALL & 0.39 & 19.56 & 15.06 & 9.41 & 3.06 & 11.53 & 5.60 & -0.75 & -6.97 & 15.06 & 9.88 & 4.00 & -3.63 \\
\hline
\end{tabular}




\begin{tabular}{|c|c|c|c|c|c|c|c|c|c|c|c|c|c|c|c|}
\hline Mainstem 2 & LA & FALL & 0.39 & 12.81 & 7.42 & 1.58 & -4.17 & -2.32 & -8.39 & -13.57 & -17.34 & 8.46 & 2.90 & -2.68 & -7.80 \\
\hline Mainstem 3 & LA & FALL & 0.39 & 8.23 & 3.51 & -1.17 & -5.47 & -4.19 & -9.89 & -14.51 & -17.68 & 9.69 & 4.59 & -0.65 & -5.55 \\
\hline Mainstem 4 & LA & FALL & 0.39 & 18.38 & 13.91 & 8.40 & 2.30 & 11.15 & 5.31 & -0.91 & -6.95 & 15.46 & 10.23 & 4.25 & -1.92 \\
\hline Mainstem 5 & LA & FALL & 0.39 & 17.54 & 13.67 & 8.80 & 3.31 & 9.85 & 4.60 & -0.93 & -6.22 & 14.69 & 10.58 & 5.84 & 0.87 \\
\hline Mainstem 6 & LA & FALL & 0.39 & 12.98 & 7.89 & 2.32 & -3.19 & -1.36 & -7.43 & -12.71 & -16.65 & 8.65 & 3.32 & -2.04 & -6.98 \\
\hline Mainstem 7 & LA & FALL & 0.39 & 17.81 & 13.04 & 7.30 & 1.06 & 5.71 & -0.55 & -6.69 & -12.13 & 12.54 & 7.55 & 2.11 & -3.25 \\
\hline Mainstem 8 & LA & FALL & 0.39 & 8.04 & 3.08 & -1.79 & -6.20 & -7.67 & -12.51 & -15.99 & -18.00 & 7.22 & 2.59 & -1.95 & -6.16 \\
\hline Mainstem 9 & LA & FALL & 0.39 & 14.12 & 9.37 & 4.02 & -1.40 & -3.12 & -8.82 & -13.57 & -16.85 & 9.63 & 5.01 & 0.25 & -4.28 \\
\hline Mainstem 10 & LA & FALL & 0.39 & 8.80 & 3.25 & -2.34 & -7.41 & -9.21 & -13.93 & -17.17 & -18.70 & 2.41 & -2.46 & -6.94 & -10.91 \\
\hline $\begin{array}{l}\text { Small Tributary } \\
(\mathrm{min})\end{array}$ & LA & SPRING & 0.21 & 3.28 & 1.29 & -2.35 & -7.03 & 0.69 & -1.39 & -4.87 & -9.10 & -1.83 & -5.77 & -10.51 & -15.79 \\
\hline $\begin{array}{l}\text { Small Tributary } \\
\text { (avg) }\end{array}$ & LA & SPRING & 0.25 & 9.99 & 8.74 & 5.45 & 0.87 & 6.77 & 5.34 & 2.20 & -1.90 & 5.29 & 1.59 & -3.13 & -8.63 \\
\hline $\begin{array}{l}\text { Small Tributary } \\
(\max )\end{array}$ & LA & SPRING & 0.33 & 19.06 & 25.64 & 23.45 & 19.40 & 20.20 & 20.53 & 18.38 & 14.87 & 21.45 & 18.58 & 14.21 & 8.53 \\
\hline Large Tributary & & & & & & & & & & & & & & & \\
\hline $1(\min )$ & LA & SPRING & 0.33 & 5.17 & 2.44 & -1.51 & -6.56 & 2.27 & -0.55 & -4.29 & -8.84 & -2.14 & -6.57 & -11.74 & -17.35 \\
\hline Large Tributary & & & & & & & & & & & & & & & \\
\hline $1(\operatorname{avg})$ & LA & SPRING & 0.35 & 7.49 & 4.93 & 1.08 & -3.97 & 4.40 & 1.73 & -1.92 & -6.46 & 0.24 & -4.15 & -9.36 & -15.09 \\
\hline Large Tributary & & & & & & & & & & & & & & & \\
\hline $1(\max )$ & LA & SPRING & 0.53 & 30.91 & 30.55 & 28.17 & 23.67 & 25.79 & 25.02 & 22.72 & 18.85 & 24.86 & 21.37 & 16.26 & 9.84 \\
\hline Large Tributary & & & & & & & & & & & & & & & \\
\hline $2(\min )$ & LA & SPRING & 0.33 & 1.85 & -2.35 & -7.64 & -13.71 & -0.97 & -4.72 & -9.24 & -14.33 & -7.38 & -12.61 & -18.20 & -23.75 \\
\hline
\end{tabular}




\begin{tabular}{|c|c|c|c|c|c|c|c|c|c|c|c|c|c|c|c|}
\hline \multicolumn{16}{|l|}{ Large Tributary } \\
\hline $2(\operatorname{avg})$ & LA & SPRING & 0.35 & 4.37 & 0.25 & -5.07 & -11.26 & 1.31 & -2.35 & -6.86 & -12.00 & -4.97 & -10.25 & -15.97 & -21.70 \\
\hline \multicolumn{16}{|l|}{ Large Tributary } \\
\hline $2(\max )$ & LA & SPRING & 0.53 & 30.36 & 27.53 & 22.53 & 15.65 & 24.66 & 22.36 & 18.52 & 13.31 & 20.50 & 15.22 & 8.73 & 1.57 \\
\hline Mainstem 1 & LA & SPRING & 0.41 & 26.06 & 18.04 & 8.82 & -0.66 & 27.44 & 23.28 & 17.66 & 11.07 & 13.04 & 5.33 & -2.27 & -8.96 \\
\hline Mainstem 2 & LA & SPRING & 0.41 & 26.54 & 20.05 & 12.21 & 3.78 & 18.15 & 13.82 & 9.09 & 4.45 & 11.74 & 5.46 & -0.59 & -8.96 \\
\hline Mainstem 3 & LA & SPRING & 0.41 & 22.15 & 16.44 & 9.85 & 3.04 & 6.79 & 6.95 & 3.45 & 0.13 & 8.52 & 2.90 & -6.49 & -9.92 \\
\hline Mainstem 4 & LA & SPRING & 0.41 & 24.46 & 18.16 & 9.30 & 0.14 & 26.94 & 22.67 & 16.99 & 10.39 & 12.22 & 4.40 & -3.22 & -6.49 \\
\hline Mainstem 5 & LA & SPRING & 0.41 & 20.39 & 14.55 & 6.53 & -1.55 & 18.96 & 15.06 & 9.70 & 4.22 & 8.00 & 0.74 & -5.97 & -11.61 \\
\hline Mainstem 6 & LA & SPRING & 0.41 & 24.99 & 18.35 & 10.51 & 2.26 & 16.56 & 12.46 & 8.14 & 4.02 & 8.55 & 2.61 & -2.75 & -7.12 \\
\hline Mainstem 7 & LA & SPRING & 0.41 & 26.13 & 18.90 & 10.41 & 1.49 & 21.42 & 17.06 & 11.88 & 6.41 & 10.48 & 3.37 & -3.35 & -9.02 \\
\hline Mainstem 8 & LA & SPRING & 0.41 & 19.53 & 12.83 & 5.54 & -1.59 & 9.66 & 6.68 & 3.99 & 0.83 & 4.70 & -0.21 & -4.35 & -8.37 \\
\hline Mainstem 9 & LA & SPRING & 0.41 & 22.42 & 15.33 & 7.36 & -0.68 & 14.30 & 10.00 & 5.73 & 1.71 & 6.10 & 0.11 & -5.07 & -9.37 \\
\hline Mainstem 10 & LA & SPRING & 0.41 & 20.40 & 14.12 & 6.32 & -1.44 & 12.21 & 8.52 & 5.01 & 1.46 & 4.18 & -0.96 & -5.23 & -9.17 \\
\hline $\begin{array}{l}\text { Small Tributary } \\
(\min )\end{array}$ & LA & SUMMER & 0.35 & -7.21 & -13.41 & -19.53 & -25.07 & -9.99 & -16.55 & -22.80 & -28.28 & -9.57 & -16.04 & -22.23 & -27.68 \\
\hline $\begin{array}{l}\text { Small Tributary } \\
\text { (avg) }\end{array}$ & LA & SUMMER & 0.43 & 2.82 & -4.05 & -11.02 & -14.49 & -0.10 & -7.52 & -14.78 & -21.27 & 0.33 & -6.96 & -14.13 & -22.47 \\
\hline $\begin{array}{l}\text { Small Tributary } \\
(\max )\end{array}$ & LA & SUMMER & 0.60 & 28.60 & 20.44 & 11.67 & 3.14 & 25.58 & 16.38 & 6.91 & -1.91 & 25.98 & 17.01 & 7.73 & -0.97 \\
\hline Large Tributary & & & & & & & & & & & & & & & \\
\hline $1(\min )$ & LA & SUMMER & 0.50 & -3.92 & -10.30 & -16.71 & -22.66 & -7.89 & -14.65 & -21.13 & -26.82 & -9.91 & -16.53 & -22.71 & -27.98 \\
\hline
\end{tabular}




\begin{tabular}{|c|c|c|c|c|c|c|c|c|c|c|c|c|c|c|c|}
\hline \multicolumn{16}{|l|}{ Large Tributary } \\
\hline $1(\operatorname{avg})$ & LA & SUMMER & 0.71 & 16.98 & 9.47 & 1.48 & -6.25 & 12.61 & 4.25 & -4.14 & -11.81 & 10.07 & 1.80 & -6.28 & -13.43 \\
\hline \multicolumn{16}{|l|}{ Large Tributary } \\
\hline $1(\max )$ & LA & SUMMER & 0.86 & 34.36 & 26.21 & 17.19 & 8.19 & 29.88 & 20.49 & 10.75 & 1.63 & 27.00 & 17.62 & 8.20 & -0.34 \\
\hline \multicolumn{16}{|l|}{ Large Tributary } \\
\hline $2(\min )$ & LA & SUMMER & 0.50 & -9.46 & -16.04 & -22.20 & -27.49 & -16.81 & -23.08 & -28.43 & -32.48 & -17.70 & -23.73 & -28.78 & -32.50 \\
\hline \multicolumn{16}{|l|}{ Large Tributary } \\
\hline $2(\operatorname{avg})$ & LA & SUMMER & 0.71 & 10.58 & 2.40 & -5.62 & -12.76 & 1.49 & -6.74 & -14.02 & -19.74 & 0.29 & -7.65 & -14.54 & -19.77 \\
\hline \multicolumn{16}{|l|}{ Large Tributary } \\
\hline $2(\max )$ & LA & SUMMER & 0.86 & 27.53 & 18.30 & 8.96 & 0.46 & 17.32 & 7.68 & -1.05 & -8.02 & 15.88 & 6.58 & -1.68 & -8.07 \\
\hline Mainstem 1 & LA & SUMMER & 0.56 & 5.27 & -3.24 & -10.58 & -16.07 & 0.46 & -7.61 & -14.13 & -18.47 & 0.47 & -12.80 & -17.42 & -19.72 \\
\hline Mainstem 2 & LA & SUMMER & 0.56 & -4.54 & -11.22 & -15.99 & -18.74 & -15.45 & -19.16 & -20.15 & -19.12 & -13.65 & -17.82 & -19.55 & -19.72 \\
\hline Mainstem 3 & LA & SUMMER & 0.56 & -10.06 & -14.37 & -17.21 & -17.47 & -19.19 & -19.78 & -19.24 & -18.89 & -14.77 & -18.04 & -19.23 & -19.28 \\
\hline Mainstem 4 & LA & SUMMER & 0.56 & 6.38 & -2.05 & -9.38 & -14.96 & 1.30 & -6.69 & -13.18 & -17.57 & -6.52 & -12.77 & -17.00 & -19.24 \\
\hline Mainstem 5 & LA & SUMMER & 0.56 & 7.10 & -0.99 & -8.05 & -13.41 & -0.15 & -7.78 & -13.78 & -17.59 & -5.59 & -11.67 & -15.82 & -17.98 \\
\hline Mainstem 6 & LA & SUMMER & 0.56 & -6.06 & -12.30 & -16.58 & -19.01 & -16.04 & -19.38 & -20.00 & -18.94 & -15.18 & -18.47 & -19.51 & -19.58 \\
\hline Mainstem 7 & LA & SUMMER & 0.56 & 1.73 & -6.29 & -12.84 & -17.34 & -7.57 & -14.06 & -18.38 & -20.05 & -10.64 & -15.94 & -18.96 & -19.97 \\
\hline Mainstem 8 & LA & SUMMER & 0.56 & -12.12 & -16.04 & -18.28 & -18.14 & -19.75 & -19.34 & -19.12 & -18.05 & -17.18 & -18.97 & -19.45 & -19.05 \\
\hline Mainstem 9 & LA & SUMMER & 0.56 & -6.32 & -12.42 & -16.61 & -19.07 & -17.51 & -19.86 & -19.62 & -18.91 & -15.78 & -18.74 & -19.54 & -19.73 \\
\hline Mainstem 10 & LA & SUMMER & 0.56 & -10.51 & -15.42 & -18.33 & -19.68 & -19.34 & -19.81 & -18.97 & -19.33 & -18.52 & -19.46 & -19.60 & -18.64 \\
\hline $\begin{array}{l}\text { Small Tributary } \\
(\min )\end{array}$ & SA & FALL & 0.12 & -4.66 & -5.60 & -6.55 & -7.44 & -5.50 & -6.49 & -7.42 & -8.24 & -4.77 & -5.74 & -6.72 & -7.62 \\
\hline
\end{tabular}




\begin{tabular}{|c|c|c|c|c|c|c|c|c|c|c|c|c|c|c|c|}
\hline $\begin{array}{l}\text { Small Tributary } \\
\text { (avg) }\end{array}$ & SA & FALL & 0.35 & 2.25 & 1.15 & -0.21 & -1.74 & 1.43 & -0.04 & -1.68 & -3.36 & 2.36 & 1.14 & -0.35 & -2.00 \\
\hline $\begin{array}{l}\text { Small Tributary } \\
(\max )\end{array}$ & SA & FALL & 0.52 & 9.85 & 8.95 & 7.50 & 5.61 & 9.44 & 7.82 & 5.73 & 3.36 & 10.31 & 9.22 & 7.53 & 5.38 \\
\hline Large Tributary & & & & & & & & & & & & & & & \\
\hline $1(\min )$ & SA & FALL & 0.28 & -0.09 & -1.15 & -2.40 & -3.75 & -1.52 & -2.89 & -4.32 & -5.68 & -0.68 & -1.93 & -3.33 & -4.75 \\
\hline Large Tributary & & & & & & & & & & & & & & & \\
\hline $1(\operatorname{avg})$ & SA & FALL & 0.39 & 3.93 & 2.91 & 1.55 & -0.07 & 2.58 & 0.99 & -0.80 & -2.62 & 3.51 & 2.16 & 0.50 & -1.31 \\
\hline Large Tributary & & & & & & & & & & & & & & & \\
\hline $1(\max )$ & SA & FALL & 0.49 & 8.35 & 7.48 & 6.09 & 4.29 & 7.23 & 5.50 & 3.42 & 1.17 & 8.20 & 6.86 & 5.02 & 2.86 \\
\hline Large Tributary & & & & & & & & & & & & & & & \\
\hline $2(\min )$ & SA & FALL & 0.28 & -0.72 & -1.91 & -3.24 & -4.60 & -3.02 & -4.42 & -5.76 & -6.91 & -1.60 & -2.93 & -4.31 & -5.63 \\
\hline Large Tributary & & & & & & & & & & & & & & & \\
\hline $2(\operatorname{avg})$ & SA & FALL & 0.39 & 3.37 & 2.11 & 0.56 & -1.14 & 0.77 & -0.98 & -2.75 & -4.38 & 2.48 & 0.96 & -0.76 & -2.51 \\
\hline Large Tributary & & & & & & & & & & & & & & & \\
\hline $2(\max )$ & SA & FALL & 0.49 & 7.92 & 6.71 & 5.03 & 3.03 & 5.19 & 3.15 & 0.97 & -1.13 & 7.11 & 5.49 & 3.50 & 1.35 \\
\hline Mainstem 1 & SA & FALL & 0.28 & 3.79 & 2.31 & 0.58 & -1.22 & 1.34 & -0.42 & -2.17 & -3.76 & 2.35 & 0.75 & -0.95 & -2.58 \\
\hline Mainstem 2 & SA & FALL & 0.28 & 1.67 & 0.04 & -1.61 & -3.12 & -2.59 & -4.11 & -5.33 & -6.15 & 0.36 & -1.24 & -2.73 & -4.01 \\
\hline Mainstem 3 & SA & FALL & 0.28 & 0.36 & -1.02 & -2.31 & -3.42 & -3.08 & -4.48 & -5.54 & -6.22 & 0.77 & -0.73 & -2.18 & -3.45 \\
\hline Mainstem 4 & SA & FALL & 0.28 & 3.44 & 1.98 & 0.31 & -1.42 & 1.21 & -0.51 & -2.22 & -3.77 & 2.47 & 0.85 & -1.66 & -2.55 \\
\hline Mainstem 5 & SA & FALL & 0.28 & 3.34 & 2.05 & 0.54 & -1.06 & 0.94 & -0.62 & -2.16 & -3.54 & 2.39 & 1.07 & -0.36 & -1.76 \\
\hline Mainstem 6 & SA & FALL & 0.28 & 1.75 & 0.20 & -1.39 & -2.86 & -2.32 & -3.87 & -5.12 & -6.00 & 0.44 & -1.10 & -2.56 & -3.81 \\
\hline Mainstem 7 & SA & FALL & 0.28 & 3.23 & 1.70 & -0.02 & -1.76 & -0.37 & -2.10 & -3.68 & -4.98 & 1.62 & 0.10 & -1.44 & -2.87 \\
\hline
\end{tabular}




\begin{tabular}{|c|c|c|c|c|c|c|c|c|c|c|c|c|c|c|c|}
\hline Mainstem 8 & SA & FALL & 0.28 & 0.27 & -1.16 & -2.49 & -3.61 & -3.92 & -5.07 & -5.85 & -6.26 & 0.07 & -1.27 & -2.51 & -3.58 \\
\hline Mainstem 9 & SA & FALL & 0.28 & 2.12 & 0.65 & -0.91 & -2.39 & -2.76 & -4.19 & -5.31 & -6.03 & 0.79 & -0.59 & -1.93 & -3.12 \\
\hline Mainstem 10 & SA & FALL & 0.28 & 0.47 & -1.13 & -2.64 & -3.92 & -4.29 & -5.39 & -6.10 & -6.41 & -1.34 & -2.65 & -3.78 & -4.70 \\
\hline $\begin{array}{l}\text { Small Tributary } \\
(\mathrm{min})\end{array}$ & SA & SPRING & 0.30 & 0.90 & 0.29 & -0.82 & -2.18 & 0.10 & -0.52 & -1.55 & -2.77 & -0.66 & -1.82 & -3.15 & -4.56 \\
\hline $\begin{array}{l}\text { Small Tributary } \\
\text { (avg) }\end{array}$ & SA & SPRING & 0.40 & 4.65 & 4.46 & 3.48 & 2.05 & 3.44 & 3.17 & 2.25 & 1.00 & 3.25 & 2.13 & 0.68 & -1.01 \\
\hline $\begin{array}{l}\text { Small Tributary } \\
(\max )\end{array}$ & SA & SPRING & 0.65 & 16.95 & 18.97 & 19.15 & 7.53 & 14.24 & 15.85 & 15.92 & 15.26 & 16.94 & 16.67 & 15.55 & 13.63 \\
\hline $\begin{array}{l}\text { Large Tributary } \\
1 \text { (min) }\end{array}$ & SA & SPRING & 0.28 & 1.21 & 0.33 & -0.88 & -2.35 & 0.34 & -0.55 & -1.67 & -2.97 & -1.04 & -2.34 & -3.76 & -5.21 \\
\hline $\begin{array}{l}\text { Large Tributary } \\
1 \text { (avg) }\end{array}$ & SA & SPRING & 0.33 & 3.35 & 2.59 & 1.40 & -0.16 & 2.27 & 1.47 & 0.37 & -1.00 & 1.05 & -0.29 & -1.85 & -3.50 \\
\hline $\begin{array}{l}\text { Large Tributary } \\
1(\max )\end{array}$ & SA & SPRING & 0.39 & 6.25 & 5.70 & 4.60 & 2.98 & 4.86 & 4.24 & 3.22 & 1.82 & 3.94 & 2.61 & 0.93 & -0.96 \\
\hline $\begin{array}{l}\text { Large Tributary } \\
2 \text { (min) }\end{array}$ & SA & SPRING & 0.28 & 0.14 & -1.13 & -2.66 & -4.29 & -0.68 & -1.80 & -3.09 & -4.45 & -2.57 & -3.99 & -5.42 & -6.70 \\
\hline $\begin{array}{l}\text { Large Tributary } \\
2 \text { (avg) }\end{array}$ & SA & SPRING & 0.33 & 2.42 & 1.15 & -0.49 & -2.35 & 1.34 & 0.24 & -1.12 & -2.62 & -0.54 & -2.11 & -3.75 & -5.29 \\
\hline $\begin{array}{l}\text { Large Tributary } \\
2(\max )\end{array}$ & SA & SPRING & 0.39 & 5.56 & 4.35 & 2.61 & 0.51 & 4.11 & 3.08 & 1.69 & 0.04 & 2.33 & 0.62 & -1.26 & -3.12 \\
\hline Mainstem 1 & SA & SPRING & 0.47 & 7.41 & 4.73 & 1.82 & -0.99 & 7.99 & 6.52 & 4.62 & 2.49 & 3.12 & 0.73 & -1.47 & -3.29 \\
\hline Mainstem 2 & SA & SPRING & 0.47 & 7.62 & 5.41 & 2.87 & 0.30 & 4.88 & 3.43 & 1.91 & 0.48 & 2.74 & 0.79 & -0.99 & -3.29 \\
\hline Mainstem 3 & SA & SPRING & 0.47 & 6.17 & 4.25 & 2.14 & 0.08 & 1.30 & 1.31 & 0.23 & -0.74 & 1.74 & 0.03 & -1.44 & -2.62 \\
\hline
\end{tabular}




\begin{tabular}{|c|c|c|c|c|c|c|c|c|c|c|c|c|c|c|c|}
\hline Mainstem 4 & SA & SPRING & 0.47 & 6.88 & 4.76 & 1.96 & -0.76 & 7.82 & 6.31 & 4.40 & 2.28 & 2.87 & 0.47 & -1.73 & -3.52 \\
\hline Mainstem 5 & SA & SPRING & 0.47 & 5.58 & 3.66 & 1.16 & -1.21 & 5.18 & 3.86 & 2.14 & 0.45 & 1.60 & -0.58 & -2.46 & -3.94 \\
\hline Mainstem 6 & SA & SPRING & 0.47 & 7.10 & 4.86 & 2.34 & -0.15 & 4.37 & 3.01 & 1.63 & 0.37 & 1.75 & -0.06 & -1.60 & -2.79 \\
\hline Mainstem 7 & SA & SPRING & 0.47 & 7.46 & 5.02 & 2.31 & -0.37 & 5.98 & 4.48 & 2.79 & 1.08 & 2.32 & 0.15 & -1.78 & -3.30 \\
\hline Mainstem 8 & SA & SPRING & 0.47 & 5.28 & 3.09 & 0.83 & -1.25 & 2.17 & 1.22 & 0.39 & -0.53 & 0.57 & -0.88 & -2.04 & -3.10 \\
\hline Mainstem 9 & SA & SPRING & 0.47 & 6.22 & 3.88 & 1.38 & -0.99 & 3.62 & 2.23 & 0.89 & -0.31 & 0.98 & -0.79 & -2.24 & -3.38 \\
\hline Mainstem 10 & SA & SPRING & 0.47 & 5.56 & 3.50 & 1.07 & -1.20 & 2.97 & 1.77 & 0.68 & -0.37 & 0.42 & -1.09 & -2.28 & -3.32 \\
\hline $\begin{array}{l}\text { Small Tributary } \\
(\min )\end{array}$ & SA & SUMMER & 0.34 & -0.99 & -2.85 & -4.58 & -6.05 & -1.81 & -3.73 & -5.45 & -6.82 & -1.68 & -3.59 & -5.30 & -6.68 \\
\hline $\begin{array}{l}\text { Small Tributary } \\
\text { (avg) }\end{array}$ & SA & SUMMER & 0.41 & 2.22 & 0.00 & -2.15 & -4.03 & 1.30 & -1.06 & -3.23 & -5.05 & 1.43 & -0.89 & -3.05 & -4.86 \\
\hline $\begin{array}{l}\text { Small Tributary } \\
(\max )\end{array}$ & SA & SUMMER & 0.56 & 11.38 & 8.40 & 5.28 & 2.37 & 10.32 & 6.98 & 3.68 & 0.74 & 10.46 & 7.20 & 3.95 & 1.04 \\
\hline Large Tributary & & & & & & & & & & & & & & & \\
\hline $1(\min )$ & SA & SUMMER & 0.39 & 1.82 & -0.34 & -2.46 & -4.32 & 0.51 & -1.76 & -3.83 & -5.53 & -0.19 & -2.38 & -4.32 & -5.87 \\
\hline Large Tributary & & & & & & & & & & & & & & & \\
\hline $1(\operatorname{avg})$ & SA & SUMMER & 0.47 & 6.27 & 3.69 & 1.07 & -1.33 & 4.78 & 1.98 & -0.67 & -2.94 & 3.91 & 1.19 & -1.32 & -3.40 \\
\hline Large Tributary & & & & & & & & & & & & & & & \\
\hline $1(\max )$ & SA & SUMMER & 0.51 & 8.84 & 6.07 & 3.18 & 0.49 & 7.27 & 4.21 & 1.24 & -1.34 & 6.32 & 3.32 & 0.51 & -1.87 \\
\hline Large Tributary & & & & & & & & & & & & & & & \\
\hline $2(\min )$ & SA & SUMMER & 0.39 & -0.05 & -2.23 & -4.17 & -5.74 & -2.46 & -4.43 & -5.99 & -7.09 & -2.75 & -4.63 & -6.09 & -7.10 \\
\hline Large Tributary & & & & & & & & & & & & & & & \\
\hline $2(\operatorname{avg})$ & SA & SUMMER & 0.47 & 4.07 & 1.37 & -1.13 & -3.22 & 1.10 & -1.46 & -3.57 & -5.10 & 0.71 & -1.73 & -3.71 & -5.12 \\
\hline
\end{tabular}




\begin{tabular}{|c|c|c|c|c|c|c|c|c|c|c|c|c|c|c|c|}
\hline \multicolumn{16}{|l|}{ Large Tributary } \\
\hline $2(\max )$ & SA & SUMMER & 0.51 & 6.49 & 3.52 & 0.72 & -1.66 & 3.22 & 0.36 & -2.05 & -3.84 & 2.79 & 0.04 & -2.22 & -3.86 \\
\hline Mainstem 1 & SA & SUMMER & 0.61 & 10.21 & 6.48 & 3.33 & 1.03 & 8.13 & 4.62 & 1.86 & 0.06 & 5.24 & 2.41 & 0.48 & -0.53 \\
\hline Mainstem 2 & SA & SUMMER & 0.61 & 5.89 & 3.04 & 1.04 & -0.18 & 1.30 & -0.23 & -0.69 & -0.63 & 2.04 & 0.30 & -0.47 & -0.53 \\
\hline Mainstem 3 & SA & SUMMER & 0.61 & 3.46 & 1.49 & -0.02 & -0.59 & -0.26 & -0.63 & -0.97 & -2.10 & 1.58 & 0.19 & -0.48 & -1.09 \\
\hline Mainstem 4 & SA & SUMMER & 0.61 & 10.68 & 6.99 & 3.84 & 1.49 & 8.48 & 5.01 & 2.25 & 0.43 & 5.07 & 2.41 & 0.62 & -0.43 \\
\hline Mainstem 5 & SA & SUMMER & 0.61 & 10.09 & 7.39 & 4.36 & 2.11 & 7.82 & 4.53 & 1.99 & 0.40 & 5.45 & 2.86 & 1.09 & 0.06 \\
\hline Mainstem 6 & SA & SUMMER & 0.61 & 5.23 & 2.59 & 0.78 & -0.37 & 1.06 & -0.32 & -0.65 & -0.67 & 1.40 & 0.03 & -0.55 & -1.15 \\
\hline Mainstem 7 & SA & SUMMER & 0.61 & 8.64 & 5.16 & 2.37 & 0.50 & 4.63 & 1.88 & 0.09 & -0.62 & 3.32 & 1.10 & -0.19 & -0.81 \\
\hline Mainstem 8 & SA & SUMMER & 0.61 & 2.60 & 0.79 & -0.48 & -0.95 & -0.51 & -0.62 & -1.46 & -2.60 & 0.56 & -0.30 & -0.96 & -1.77 \\
\hline Mainstem 9 & SA & SUMMER & 0.61 & 5.12 & 2.53 & 0.76 & -0.43 & 0.45 & -0.53 & -0.59 & -1.04 & 1.16 & -0.09 & -0.60 & -1.33 \\
\hline Mainstem 10 & SA & SUMMER & 0.61 & 1.27 & -0.01 & -0.88 & -0.31 & -0.60 & -0.78 & -2.23 & 0.00 & -0.54 & -1.21 & -1.99 & -1.99 \\
\hline
\end{tabular}

